Portland State University

PDXScholar

\title{
Examining the Effects of Climate Change and Urban Development on Water Demand: A Multi-Scale Analysis of Future Water Demand in Hillsboro, Oregon
}

Lily House-Peters

Portland State University

Follow this and additional works at: https://pdxscholar.library.pdx.edu/open_access_etds

Part of the Hydrology Commons, Nature and Society Relations Commons, and the Physical and Environmental Geography Commons

Let us know how access to this document benefits you.

\section{Recommended Citation}

House-Peters, Lily, "Examining the Effects of Climate Change and Urban Development on Water Demand: A Multi-Scale Analysis of Future Water Demand in Hillsboro, Oregon" (2010). Dissertations and Theses. Paper 2251.

https://doi.org/10.15760/etd.2248

This Thesis is brought to you for free and open access. It has been accepted for inclusion in Dissertations and Theses by an authorized administrator of PDXScholar. Please contact us if we can make this document more accessible: pdxscholar@pdx.edu. 


\begin{abstract}
An abstract of the thesis of Lily Arielle House-Peters for the Master of Science in Geography presented May 21, 2010.

Title: Examining the Effects of Climate Change and Urban Development on Water Demand: A Multi-scale Analysis of Future Water Demand in Hillsboro, Oregon
\end{abstract}

In the Portland, Oregon, metropolitan area, suburban cities such as Hillsboro are projected to grow as people seek affordable housing near a rapidly growing metropolis. This thesis examines the combined impact of climate change and urban development on both neighborhood and municipal scale residential water demand in Hillsboro, Oregon. I use two models, a surface energy balance model, Local-scale Urban Meteorological Parameterization Scheme (LUMPS), and a system dynamics model, CCDomestic, to investigate changes in residential water demand in the 2040s at two distinct spatial scales, the neighborhood and the municipality. I calibrate and validate each model to the reference period and then simulate the future (2030-2059) under three statistically downscaled global climate models and two urban development scenarios. The findings of this study indicate that climate change and urban development will not evenly affect water consumption in neighborhoods across a city. Instead, the current land cover and residential density of a 
neighborhood exert an important influence on the response. Heavily vegetated neighborhoods exhibit large increases in water demand under urban sprawl and warming scenarios, while neighborhoods dominated by impervious surfaces decrease water consumption under sprawl scenarios and show little change in water consumption under combined sprawl and warming scenarios. At the municipal scale findings suggest that water demand is highly sensitive to urban design and management and that the combination of urban densification and water conservation regulations could mitigate increases in water consumption from population growth and climate change. 
Examining the Effects of Climate Change and Urban Development on Water Demand! A Multi-scale Analysis of Future Water Demand in Hillsboro, Oregon

\section{Lily Arielle, House-Peters,}

A thesis submitted in partial fulfillment of the requirements for the degree of

Master of Science

in

Geography

Thesis Committee:

Heejun Chang, Chair

Teresa Bulman

Geoffrey Duh

Portland State University

(C) 2010 


\section{Acknowledgements}

There are many people who I would like to acknowledge for their support and advice throughout the thesis research and writing process. First and foremost I gratefully acknowledge my advisor and mentor, Dr. Heejun Chang, for his unwavering commitment and investment in my research and growth as a graduate student. I would also like to thank the members of my committee, Dr. Teresa Bulman and Dr. Geoffrey Duh, for the ongoing assistance, honest feedback, and thought-provoking questions they provided throughout the process. I am grateful to Kristel Fesler and Niki Iverson at the City of Hillsboro Water Department, who provided data and assistance on numerous occasions during the last two years. I thank Il-Won Jung, Ariane Middel, and Tony Brazel for patiently assisting me with software and model questions and data analysis and interpretation. A number of organizations provided financial assistance to support my research and travel, including John Rockie, the James F. and Marion L: Miller Foundation, the Association of Pacific Coast Geographers (APCG), the Columbia River Region of the American Society of Photogrammetry and Remote Sensing (ASPRS), the International Network of Research on Coupled Human and Natural Systems, and the National Oceanic and Atmospheric Association (NOAA). Lastly, I thank my friends, colleagues, and partner, Carl, who provided love, emotional support, laughs, and opportunities to commiserate. 


\section{Table of Contents}

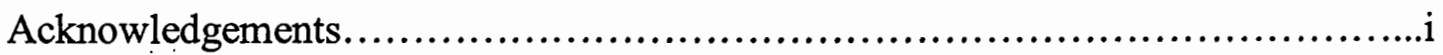

List of Tables.....................................................................

List of Figures.................................................................

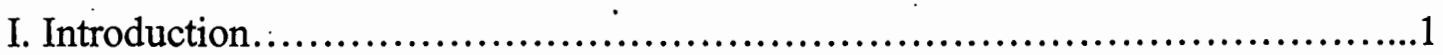

1. Background ..........................................................

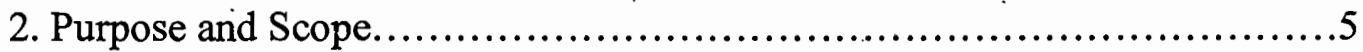

3. Hypotheses.......................................................

4. Implications..........................................................

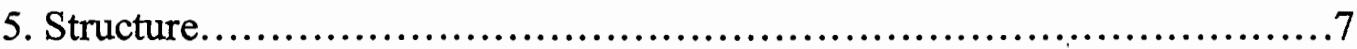

II. Tracing the Methodological and Epistemological Progression of Urban Water Demand Modeling Through a Coupled Human and Natural Systems Lens: A 30Year Review................................................................

1. Introduction..................................................................

2. Theoretical Background..............................................14

A. Coupled Human and Natural Systems Theory......................14

B. Urban Water Demand as a Coupled Human and Natural System....19

3. Methodological and Epistemological Review.............................21

A. Scale ..........................................................22

i. Temporal Scale ..............................................24

ii. Spatial Scale.................................................26

B. Uncertainty ................................................... 30 
C. Non-linearity..................................................34

D. Complexity.....................................................37

E. Dynamic modeling approaches..................................41

4. Conclusions...........................................................43

III. Modeling the Impact of Land Use and Climate Change on Neighborhood-Scale Evaporation and Nighttime Cooling: A Surface Energy Balance Approach.......................................................................

1. Introduction............................................................. 46

2. Background ........................................................ 51

3. Local Scale Urban Meteorological Parameterization Model..................54

4. Methods and Data.......................................................56

A. Study Area ..................................................56

B. Meteorological Data............................................61

C. Land Cover Analysis.............................................61

D. Climate Change Scenarios......................................65

E. Land Cover Change Scenarios.....................................67

F. LUMPS Model Calibration and Validation.........................70

G. Data Analysis.............................................. 75

5. Results and Discussion............................................76

A. Nine Neighborhood Average Response ..................................76

B. Land Cover Category Response to Scenarios........................79

C. Water Use Group Response to Scenarios.............................82 
6. Conclusions.

IV. Utilizing System Dynamics Modeling to Examine the Impacts of Climate Change and Land Use Change on Municipal-Scale Residential Water

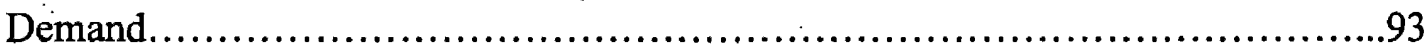

1. Introduction......................................................... 93

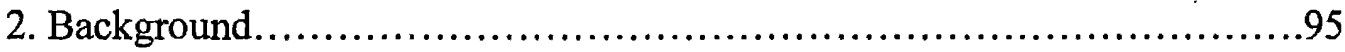

A. Influence of Natural System Variables.............................96

B. Influence of Human System Variables............................99

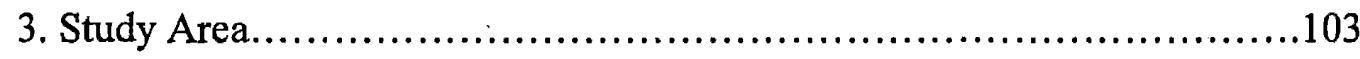

4. Data and Methods.................................................... 104

A. Data......................................................... 104

B. Survey Methods................................................107

C. Scenario Development .........................................111

D. CCDomestic Model...........................................113

5. Results and Discussion............................................117

A. Model Calibration and Validation................................117

B. Indoor Water Use ............................................. 121

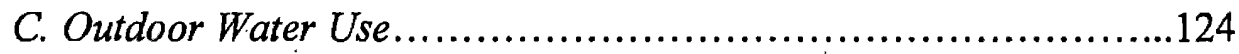

D. Total Water Use.............................................127

6. Conclusions.........................................................130

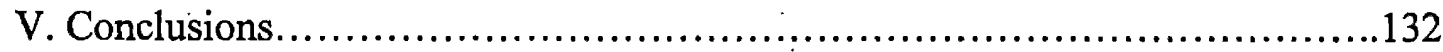




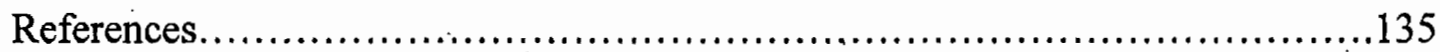

Appendix A: Household Water Use Survey.................................152

Appendix B: Human Subjects Review Waiver................................156 


\section{List of Tables}

Table 2.1 Common variables found primarily in temporal or spatial water demand analyses.

Table 3.1: Descriptive statistics for the nine study area neighborhoods, including external water use, socio-economic, and land-use variables

Table 3.2: Baseline land cover characteristics in the nine neighborhoods...........64

Table 3.3: Ensemble mean temperature data for input in the LUMPS model. .67

Table 3.4: Land cover fractions for each neighborhood under the two land cover change scenarios, sprawl and densification................................... 72

Table 3.5: Irrigated land cover fraction parameters calibrated for each neighborhood

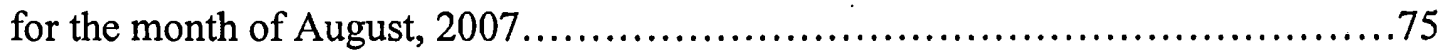

Table 4.1: Significant Variables in Determining Residential Water Demand........95

Table 4.2: CCDomestic model data requirements and data sources...............106

Table 4.3: Change in the micro-components of demand between the current period

and each future urban development scenario .115 
Table 4.4: Results of a paired t-test of the indoor demand modeling results under the combined climate change and urban development scenarios. Values shown in the table are $p$-values. If $p<0.05$, then the demand results of the two scenarios are significantly different (these cells are shaded)....

Table 4.5: Results of a paired t-test of the outdoor demand modeling results under the combined climate change and urban development scenarios. Values shown in the table are $p$-values. If $p<0.05$, then the demand results of the two scenarios are significantly different (these cells are shaded)....

Table 4.6: Results of a paired t-test of the total demand modeling results under the combined climate change and urban development scenarios. Values shown in the table are $p$-values. If $p<0.05$, then the demand results of the two scenarios are significantly different (these cells are shaded). 


\section{List of Figures}

Figure 2.1: Yearly count of academic papers published on the topics of urban water demand $(n=721)$ and urban water supply ( $n=1098), 1977-2009$. Count is based on publications from a search of ISI Web of Knowledge.

Figure 2.2: The graphic represents the complex multi-scale. interactions inherent in the coupled human and natural systems framing of urban water demand...........21

Figure 3.1: Map of the Portland metropolitan area, shows the unique urban growth boundary (UGB) and highlights the study area, City of Hillsboro, located on the western edge of the metropolitan area..........................................5

Figure 3.2: Map of previous empirical research of the surface energy balance and urban heat island in cities throughout the world.................................51

Figure 3.3: Ensemble mean for each month of the year 2040 based on 3 downscaled GCMs (low = PCM, medium = IPSL, high $=$ HadCM) for the period 2030-2059, the historical record (1981-2009) is included for comparison, for a) temperature (C) and

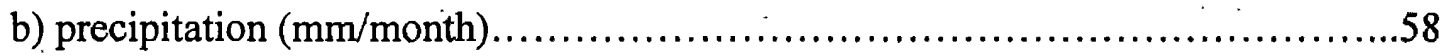

Figure 3.4: Map of the City of Hillsboro water service provider area, depicting the household-level summertime external water consumption for August 2007 and the location of the nine study area neighborhoods, as rectangular boxes

Figure 3.5: Object-based classification results for the nine Hillsboro neighborhoods

Figure 3.6: Land-use change scenarios for the 2040s for the City of Hillsboro (adapted from Hulse et al. 2004).

Figure 3.7: Calibration of the LUMPS model based on August 2007 data and validation based on September 2007 performance using the calibrated parameters..73

Figure 3.8: Nine neighborhood average response to scenarios; a) Average absolute change in evaporation $(1,000 \mathrm{~L} /$ household $)$ from the baseline across all nine neighborhoods in response to each of the future scenarios; b) Average absolute 
change in nighttime cooling rate $\left({ }^{\circ} \mathrm{C} /\right.$ hour) from the baseline across all nine neighborhoods in response to each of the future scenarios........................78

Figure 3.9: Response to scenarios by land cover category (mesic and xeric); a) Average absolute change in evaporation $(1,000 \mathrm{~L} /$ household $)$ from the baseline in mesic and xeric neighborhoods in response to each of the future scenarios; $b$ ) Average absolute change in nighttime cooling rate $\left({ }^{\circ} \mathrm{C} /\right.$ hour $)$ from the baseline in mesic and xeric neighborhoods in response to each of the future scenarios.

Figure 3.10: Response to scenarios by water consumption group (low, average, and high external water use); a) Average absolute change in evaporation $(1,000 \mathrm{~L} / \mathrm{HH})$ from the baseline in low, average and high external water consumption neighborhoods in response to each of the future scenarios; $b$ ) Average absolute change in nighttime cooling rate $\left({ }^{\circ} \mathrm{C} / \mathrm{hr}\right)$ from the baseline in low, average, and high external water consumption neighborhoods in response to each of the future

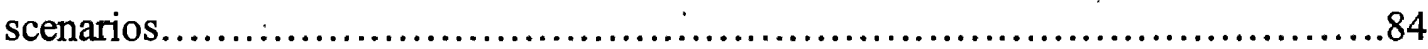

Figure 3.11: Relationship between external water consumption $(1,000 \mathrm{~L} / \mathrm{HH})$ and cooling rate $\left({ }^{\circ} \mathrm{C} / \mathrm{Hour}\right)$ under each alternative future scenario.

Figure 3.12: Relationship between vegetation cover (fraction grass and fraction trees) and external water use and cooling rate in the baseline scenario.

Figure 3.13: Relationship between vegetation cover (fraction grass and fraction trees) and external water use and cooling rate in the sprawl scenario

Figure 3.14: Relationship between vegetation cover (fraction grass and fraction trees) and external water use and cooling rate in the densification scenario.

Figure 4.1: The Water Balance component of the CCDomestic model, conceptualized as a flow diagram, where rectangular boxes indicate stocks, lines represent material flows, and circles represent converters. (Visualized with STELLA software) 105

Figure 4.2: Comparison of socio-economic indicators of the sample population $(n=103)$ to the entire Hillsboro population....................................108

Figure 4.3: Calibration of the CCDOM model for the period 1995-2001 .119 
Figure 4.4: Validation of the CCDOM model for the period 2002-2008...........119

Figure 4.5 CCDOM model performance for the reference period 1995-2008 .....120

Figure 4.6: Indoor residential water demand under a) individual GCM and land use

scenarios and b) combined GCM and land use scenarios........................122

Figure 4.7: Outdoor residential water demand under a) individual GCM and land use scenarios and b) combined GCM and land use scenarios...

Figure 4.8: Total residential water demand under a) individual GCM and land use scenarios and b) combined GCM and land use scenarios 


\section{Introduction}

\section{Background}

The process of urbanization, characterized by large-scale human engineering of natural systems and land conversion from pervious to impervious surfaces, fundamentally alters the natural hydrological cycle (Lee and Heaney 2003; Walsh 2005; Grimm et al. 2008). To meet the land, water, and energy needs demanded by the growing urban population, cities are forced to subsidize and redistribute resources, leading to the manipulation of the natural ecosystem. The urban hydrological cycle represents a key example of the complex interactions and feedbacks between human and natural systems in the urban environment. In cities, the once natural processes of water supply, transport, drainage, and wastewater treatment have become highly managed through the creation of artificial reservoirs, canals, sewer systems, and treatment plants. Human systems have also affected urban hydrology less deliberately yet still directly, through increased impervious surfaces, soil disturbance, reduced vegetation, warmer temperatures, altered biogeochemical and nutrient cycling, and decreased native flora and fauna species richness (Grimm et al. 2008; Pickett et al. 2008).

The growing realization that human and natural system dynamics are coupled in the urban environment, and that human behaviors and resource demands can act as both drivers and constraints of natural ecosystem processes requires that humans be 
explicitly included in urban resource management theory and modeling (Grimm et al. 2000; Martin et al. 2004; Pickett et al. 2008). The multiple human stresses of population growth, rapid urbanization, decreasing household sizes, and increasing standard of living, combined with the natural stresses of climate variability, such as drought, earlier snowmelt, and climate change projections are causing an increase in peak water demand while creating the potential for a reduced and overall more vulnerable supply. These couplings between the human and natural systems take place across nested spatial scales and are influenced by both broad-scale processes, such as climate change, and synergistic and cumulative effects of local processes, such as household garden watering decisions. These challenges are accelerating the need to develop a comprehensive understanding of water sensitive urban design (Wong 2006), in an attempt to increase the resiliency of cities to future climate and water supply uncertainties by ensuring the sustainable management of urban water resources (Brown et al. 2009; Wong and Brown 2009).

Research focusing on urban residential water consumption has grown substantially over the last decade. Much of this research examines either the ecological interactions among climate, vegetation, and water use (Martinez-Espineira 2002; Balling and Gober 2005; Gutzler and Nims 2005; Zhang and Brown 2005; Domene and Saurí 2006; Wentz and Gober 2007; Balling et al. 2008; Kenney et al. 2008; Praskievicz and Chang 2009; House-Peters et al. 2010; Chang et al. 2010) or the human dimension of water consumption behavior (Head and Muir 2006; Inman and 
Jeffrey 2006; Head and Muir 2007; Endter-Wada et al. 2008; Miller and Buys 2008; Harlan et al. 2009). Research investigating the coupled nature of this social-ecological system is limited. The task of predicting future water demand is greatly complicated due to the variability of climatic, socio-economic and vegetation characteristics exhibited by different geographic locations and the complex interactions and feedbacks inherent to a coupled human and natural system. These complexities are also compounded by the uncertainties introduced through climate change projections, population growth predictions, and urban development scenarios.

Historically, water managers concerned with resource conservation focused on supply-side management, such as altering hydrologic budgets through dams and reservoirs. However, a new paradigm shift points to managing the demand side of human water consumption as recognition of environmental damage and prohibitive expense have made large hydrologic projects, such as dam construction, less feasible (Cooley and Gleick 2009). Furthermore, increased uncertainty in future climate projections has caused local water planners to shift away from short-term fixes designed to deal with drought conditions. Instead the current emphasis is on longterm adaptation strategies that respond to a range of uncertain conditions, including climate change, environmental regulations, water quality concerns, and increasing competition for supplies (Balling et al. 2008). These concerns echo a warning from the Intergovernmental Panel on Climate Change (IPCC) which states that, "reduced 
water supplies coupled with increases in demand are likely to exacerbate competition for over-allocated water resources" (Bates et al. 2008, 130).

Overall streamflow in the Pacific Northwest has been found to be decreasing due to a change in climate since the mid twentieth century (Barnett et al. 2008). Because the climate of the Pacific Northwest is dominated by high winter precipitation, a decreasing trend in Oregon levels of April 1 Snow Water Equivalent will likely change summer stream flow patterns (Mote 2003; Kalra et al. 2008). Within the Clackamas River Basin, a significant river in the Portland area, water supply projections based on $21^{\text {st }}$ century climate change scenarios forecast moderate reductions in spring and summer flows by the 2020 s and significant reductions by the 2080s (Graves and Chang 2007). Simulated climate change studies project that there will be increased stress on water management systems as difficult tradeoffs are made between maintaining ecologically sufficient in-stream flows and serving the water needs of the growing residential population.

This thesis research focuses on answering the following questions: 1) How much water may the residential population of Hillsboro, Oregon demand in the 2040s under multiple urban development and climate change scenarios? 2) Do neighborhoods that experience a pronounced urban heat island (UHI) effect exhibit significantly higher rates of external water consumption? 3) To what extent will increasing urban sprawl or urban density affect residential water demand at the neighborhood and city scales? (4) Do variables exhibit thresholds, beyond which 
water demand increases at a more rapid and less predictable rate? (5) Can conservation efforts mitigate the impacts of population growth and climate change on water consumption, thus increasing the resiliency of the system? If so, to what extent?

\section{Purpose and Scope}

The purpose of this thesis is to examine the sensitivity of urban residential water demand to the coupled human and natural stresses of population growth, land use and land cover change, climate variability and projected climate change. Accurately determining residential water demand is complex, as water consumption patterns are affected by both natural-variability, such as climate, and human behavior, including garden vegetation and irrigation choices. Human modifications to the urban landscape also affect local-scale climate, which is highly integrated with water use at the neighborhood scale. This thesis uses the suburban city of Hillsboro, Oregon, as a case study and presents a methodology for modeling future urban residential water demand at multiple spatial scales.

\section{Hypotheses}

At the neighborhood-scale, I hypothesize that external water consumption in all neighborhoods will increase due to climate change, which is expected to raise summertime temperatures, regardless of the current land cover present in the neighborhood. Under the future land cover scenarios, I expect that highly vegetated 
neighborhoods that experience increased sprawl in the future will experience the highest rates of increase in external water consumption in order to meet the needs of increased amounts of vegetation. In contrast, highly developed neighborhoods that experience continued increases in density and reductions in vegetation in the future will exhibit the lowest levels of water consumption. I hypothesize that there will be a significant tradeoff between external water consumption and nighttime cooling at the local, neighborhood-scale. I expect the absolute highest levels of water consumption will be achieved under the combined high climate change and sprawl scenario, as there will be the highest levels of potential evapotranspiration under this scenario.

Coupled human and natural systems research has established that complex systems often exhibit nonlinear responses to increased stress due to interactions and feedbacks between variables that cannot always be fully anticipated. At the municipal-scale, the system dynamics model, STELLA, models indoor and outdoor water consumption and allows for the integration of multiple human and natural variables while elucidating the linkages and feedbacks between variables through stock and flow diagrams. The urban water cycle represents a coupled human and natural system and thus, I hypothesize that water demand will not exhibit a linear response to the introduced stresses of population growth, climate change, and land cover change to meet the housing needs of the growing urban population. Instead, the system will exhibit thresholds, beyond which water demand will increase at a significantly faster rate. Importantly, I hypothesize that it will not be possible for 
conservation measures and regulations to reduce future residential water consumption below current levels, under climate change, population growth, and urban development.

\section{Implications}

This research is significant because few water demand analyses examine water demand at multiple spatial scales and combine the following social and ecological variables: climate, vegetation, structural design, and demographics. Thus, this research represents an attempt to comprehensively model water demand accounting for the coupling of human and natural systems in the urban environment. The findings of this study will 1) improve the capability to improve long-term water demand predictions that account for a wide range of variables, including climate, vegetation, socio-economic characteristics, conservation programs and modifications to urban design, 2) inform readers of magnitude of the change to water demand as a result of population growth, climate change and conservation, and 3) advance understanding of the complex interactions and feedbacks between human and natural systems by revealing thresholds in social and ecological systems which directly impact urban water demand.

\section{Structure}

The body of this thesis is organized as three chapters, each representing a discrete academic paper. As such, each chapter is structured so that it can be read 
independently of the rest of the thesis. Chapter 2, directly following the Introduction chapter, is an extensive literature review detailing the methodological and epistemological advances of field of water resources research during the previous 30 years. Chapter 3 focuses on modeling neighborhood-level external water consumption and cooling patterns under combined land-use and climate change scenarios using a surface energy balance model. Chapter 4 introduces municipal-scale water consumption modeling utilizing a system dynamics model which is able to represent changes in both human and natural system variables over time to model future indoor and outdoor water consumption. Lastly, in chapter 5, I present conclusions, policy recommendations, and limitations that arose as a result of this effort to model future water consumption at multiple spatial scales. 


\section{Tracing the Methodological and Epistemological Progression of Urban Water Demand Modeling Through a Coupled Human and Naturai Systems Lens: A 30- Year Review}

\section{Introduction}

The twenty-first century marks the first time in history that half of the global human population resides in urban areas (UNPF 2007). Urban population and landscape dynamics are significant drivers of urban water demand, which represents a rapidly increasing portion of total water withdrawals worldwide. The multiple human stresses of population growth, rapid urbanization, decreasing household sizes, and increasing standard of living, combined with the natural stresses of climate variability, such as drought, earlier snowmelt, and climate change projections are causing an increase in peak water demand while creating the potential for a reduced and overall more vulnerable supply (Barnett et al. 2008; Bates et al. 2008). Predicting and managing urban water demand is complicated by the tightly coupled relationship that exists between human and natural systems in urban areas, which results from multiple interactions between micro-scale (individual, household, or parcel level) and macroscale (municipal or regional) processes and patterns. For example, in complex systems, local interactions among individuals cumulate over space and time generating meso- and macro-scale variables that in turn feedback to influence or constrain individual choices (Liu et al. 2007; Irwin et al. 2009). This embedded nature of social 
and ecological systems in natural resource management poses a significant challenge to water managers, as it is not feasible to separate these systems, yet remains extremely difficult to account for the complex and potentially unpredictable responses of the coupled system when exposed to external shocks and new policy decisions (Berkes and Folke 2001; Irwin et al. 2009).

Analyzing and forecasting urban water demand is a complex yet imperative task, as it is essential that cities meet the water demands of their residents. A product of the early twentieth century dam and canal building culture, the historical paradigm of urban water management encouraged water managers to expand water supply options to meet growing demand. The environmental movement beginning in the 1960 s and the increasing economic cost of building large-scale water detention and diversion projects forced a paradigm shift resulting in the growth of demand-side . water management research and literature (Gleick 2003; Cooley and Gleick 2009). The looming threat of anthropogenic climate change, which has the potential to affect both water demand and supply through increased summer and winter temperatures, increased evapotranspiration losses, decreased snowpack, and shifted timing of snowmelt, may soon force another important paradigm shift. Currently, water managers produce demand estimates based on the principle of stationarity (the idea that natural systems fluctuate within an unchanging envelope of variability) which depends on long-term historical climate trends (Milly et al. 2008). Historically, natural resource planners considered natural change and variability to be sufficiently 
small, allowing for confidence in stationarity-based policies (Milly et al. 2008). Today, however, facing deep uncertainty in terms of climate change, this method may prove untenable, as historical trends will no longer be reliable for predicting future climate-sensitive water demand (Milly et al. 2008; Gober et al. 2010). Moreover, in coupled human and natural systems, new dynamics can emerge in response to stochastic shocks, suggesting that the system dynamics that evolve in the future in response to policy interventions may be fundamentally different than those of the past (Irwin et al. 2009). It is in this context, at the verge of a paradigm shift in water management (Gober et al. 2010) and at a point when the knowledge base is changing rapidly (Milly et al. 2008), a review of the epistemological and methodological development of demand-side water management literature represents an important contribution. For a transition in water demand modeling, forecasting, and management to take place, it is first necessary to understand the current and historical methods of acquiring and producing knowledge in the discipline and the origin, structure, and limits of this knowledge.

During the previous 30 years, mounting environmental and social concerns coupled with advances in data collection, computer modeling capacity, and the growing threat of anthropogenic climate change have produced a rich body of literature focused on issues of urban water management (Figure 2.1). There are comprehensive literature reviews that assess and synthesize recent research findings in the urban water demand literature. However, many of these papers either focus solely 
on one aspect of urban water demand (i.e. economics or climate), or summarize the results of numerous studies without assessing the epistemological and methodological advances in the discipline. Brookshire et al. (2002) offer a review of water demand literature focused primarily on determining efficient residential water pricing, concluding with a recommendation for the addition of "scarcity value" for regions where demand outpaces supply. Gleick (2003) reviews multiple global-scale water forecasts developed during the period 1967-1998 and presents techniques for meeting levels of sustainable water withdrawals by improving large-scale water-use efficiency. Reviews of empirical economic analyses of water demand examine estimated price elasticities in relation to variations in the price structures and microeconomic choice models used (Dalhuisen et al. 2003) and the effects of different policy implementations on market-based industrial demand and residential demand (de Gispert 2004). Inman and Jeffrey (2006) and Hurlimann et al. (2009) synthesize the social science perspective, focusing on the impact of personal characteristics and behavior on the effectiveness of demand-side water management and conservation tools in the developed world. Most recently, Corbella and Pujol (2009) present. a broad review of the significant physical and social determinants of domestic water use, categorizing recent findings as four major categories of drivers of demand: economic, demographic, urban design, and climatic. One example of an epistemological review of water resources and hydrology knowledge is presented by Abbott (1993), who argues that water resources knowledge is becoming increasingly hidden and 
encapsulated in electronic media due to the strengthening dominance of computer modeling.

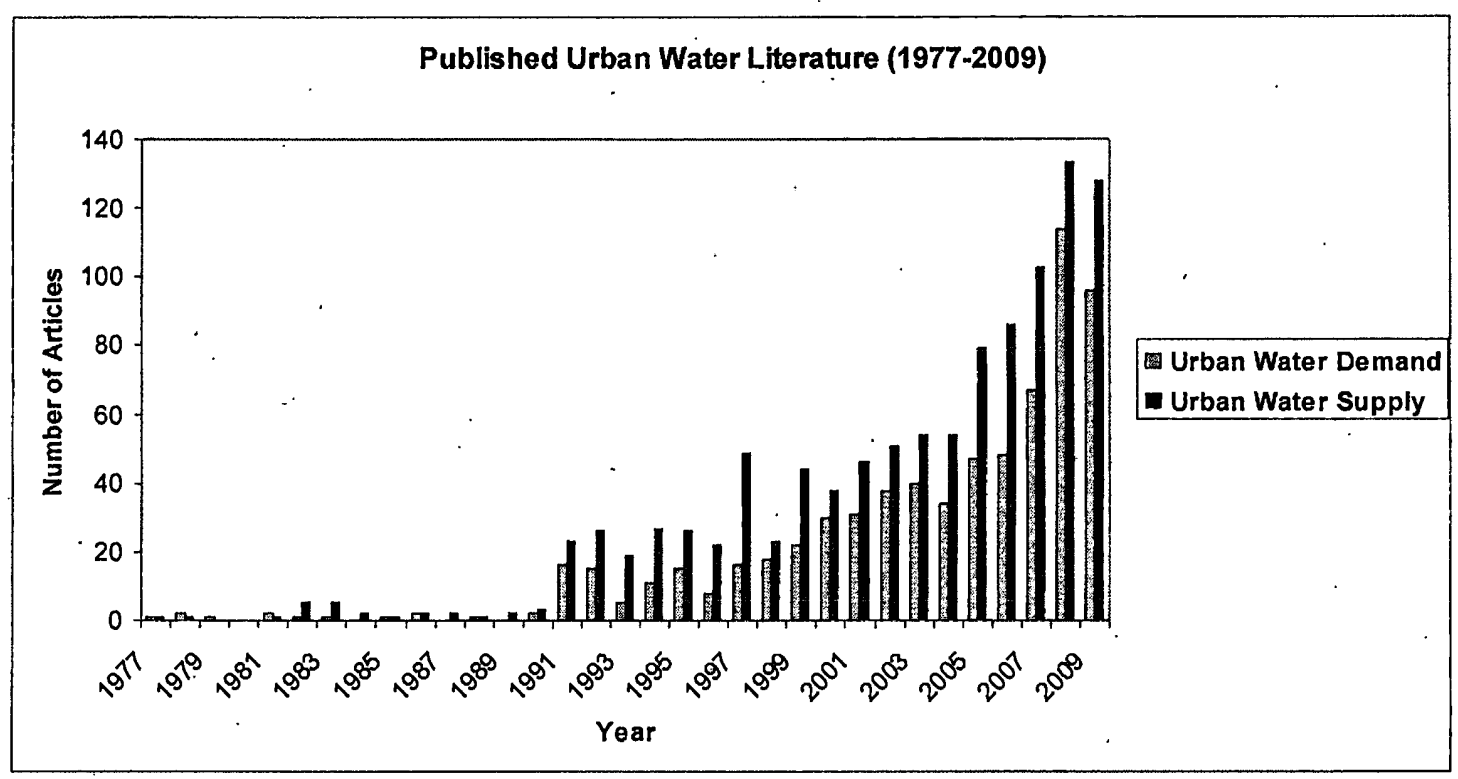

Figure 2.1: Yearly count of academic papers published on the topics of urban water demand $(n=721)$ and urban water supply $(\mathrm{n}=1098), 1977-2009$. Count is based on publications from a search of ISI Web of Knowledge.

To the authors' knowledge, no comprehensive, up-to-date review exists that traces the epistemological and methodological progression of urban water demand modeling and analysis. This paper seeks to fill that gap and represents a unique contribution to the literature, as it utilizes the theoretical framework of coupled human and natural (also known as, social-ecological) systems (Gunderson and Holling 2001; Holling 2001; Turner et al. 2003; Walker et al. 2004; Anderies et al. 2006; Cumming 
et al. 2006; Gunderson et al. 2006; Liu et al. 2007; Turner et al. 2007; Werner and McNamara 2007) to examine and synthesize the theoretical and technical advances that have transpired in urban water demand modeling.

This review begins by introducing the reader to the theoretical underpinnings of coupled human and natural systems. The following section presents a synthesis of the progress in urban water demand knowledge and methodology in terms of five themes that are central to coupled human and natural systems theory: 1) interactions within and across multiple spatial and temporal scales, 2) acknowledgement and quantification of uncertainty, 3) identification of thresholds and non-linear system responses and the consequences for resilience, 4) increased complexity, due to expansion of production and integration of knowledge from multiple disciplines, and 5) the transition from simple statistical modeling to fully-integrated dynamic modeling. Finally, the last section concludes the review by highlighting significant areas of theoretical and methodological progress as well as remaining limitations.

\section{Theoretical Background}

\section{A. Coupled Human and Natural Systems Theory}

The ability of humans to manipulate and transform the natural landscape has increased in both scope and intensity over the last one-hundred years due to a rapidly increasing global population, technological advances in agriculture, industry, and resource management, and the world-wide migration of people from rural to urban 
environments. As a result, what were once primarily local-scale interactions between humans and the biophysical environment have been transformed into complex, multiscale interactions. In response, researchers have increasingly turned their attention to empirical analysis of the outcomes of these interactions and to the development of a theoretical framework and process for understanding complex human and natural systems (Gunderson and Holling 2001; Holling 2001). Empirical research utilizing water management case studies to analyze coupled human and natural system dynamics has experienced an uptick in recent years. Examinations of reciprocal effects, complex feedback loops between human behavior and ecological response, and the maintenance and erosion of resilience have been carried out on multiple continents focusing on lake ecosystems (Gunderson et al. 2006; Liu et al. 2007; Asah 2008; Chen et al. 2009), wetlands (Gunderson et al. 2006; Liu et al. 2007), and rivers (Langridge et al. 2006; Schluter and Pahl-Wostl 2007).

Previously linear, one-way interactions between human and natural systems have been replaced due to the phenomenon of induced coupling. Induced coupling states that short-term, small-scale human activities become linked to and influence long-term, large-scale behaviors of natural systems, fundamentally altering the dynamics of the whole system by creating new and manipulating already existing feedbacks, which result in non-linear system behavior (Magliocca 2008). Simply put, human behavior not only influences; but is also influenced by, the behavior of natural systems (Walker et al. 2004; Liu 2007; Magliocca 2008). Scheffer et al. (2001) note 
that human societies respond not only to actual changes that occur in the biophysical environment, but also to perceived and anticipated changes, further complicating the interactions and feedbacks between the coupled systems. Ultimately, "the increasing strength of these interactions gives rise to the possibility that human agency and landscape processes can no longer meaningfully be treated separately, but rather only as an inter-weaved, coupled system" (Werner and McNamara 2007, 394).

Coupled human and natural systems are constantly changing through coevolution and adaptation (Folke et al. 2002) in order to remain resilient to internal and external disturbances. Ecological resilience is defined by the magnitude of shock (or amount of disturbance) that the system can absorb while maintaining its current structure and composition, hence not experiencing a collapse (Gunderson and Holling 2001; Folke et al. 2002; Walker et al. 2004; Gunderson et al. 2006; Liu et al. 2007). Constant change and variability in a natural resource, such as water supply, however, is not well-suited to large-scale human development. Thus, there is a long record of humans attempting to control natural change in aquatic ecosystems (especially riverine systems) through rigid management regimes designed to artificially institute stability. However, instead of building resilience, human interventions and management regimes that act to stabilize ecosystem processes, either by suppressing natural disturbances or altering slowly-changing ecological variables, may cause the erosion of resilience, leading to a higher probability of collapse (Folke et al. 2002; Gunderson et al. 2006). This threat of decreased resilience is important because continued 
production of ecosystem services is compromised by the loss of ecological resilience (Gunderson et al. 2006). Adaptability is the term used to describe the capacity of human systems to manage resilience (Walker et al. 2004). Therefore, the adaptability of natural resource management systems, such as implementing flexible and innovative systems and policies that promote resilience and prepare the socialecological system to sustain unpredictable shocks, will be crucial for successfully managing water resources under climate change uncertainty.

We have identified four themes found in coupled human and natural systems theory that are also echoed in the epistemological and methodological advancements in the urban water demand literature: 1) scale (Gunderson and Holling 2001; Holling 2001; Anderies et al. 2006; Cash 2006; Cumming 2006; Walker et al. 2006), 2) uncertainty (Liu et al. 2007), 3) non-linearity (Gunderson and Holling 2001; Liu et al. 2007; Werner and McNamara 2007), and 4) complexity (Anderies et al. 2006; Walker et al. 2006; Schluter and Pahl-Wostl 2007). Social and ecological phenomena occur over a continuous range of levels (Cash et al. 2006) and are characterized by a complex web of interactions that occur within and between spatial and temporal scales. Scale interactions are so important that the dynamics of a system at a particular scale of interest cannot be understood without taking into account the dynamics and cross-scale influences of the processes occurring at scales above and below (Walker et al. 2006). Mismanagement of natural resources can lead to scale mismatches, in which the scale of management and the scale of the process being 
managed do not match (Anderies et al. 2006; Cumming et al. 2006). Ultimately, lack of understanding regarding the processes and structures that interact across scales can lead to surprising outcomes, non-linear system responses, loss of diversity, and erosion of resilience (Walker et al. 2006).

Subtle losses of resilience can result in sudden and surprising changes in ecosystems (Liu et al. 2007). In coupled systems, bimodal interactions between social and ecological systems initiate positive and negative feedback loops, which can lead to acceleration or deceleration in the rates of change of both human and natural components (Liu et al:2007). The introduction of climate change, technological advances, and new government policies can lead to surprises, unintended consequences, and increased uncertainty. Non-linear responses are characteristic of systems with strong two-way coupling (Werner and McNamara 2007) and are often instigated when thresholds, or transition points, between alternate states are surpassed in either system (Gunderson and Holling 2001; Holling 2001). Furthermore, due to the phenomenon of nested spatial scales in coupled human and natural systems, local processes can have cumulative and synergistic effects that result in non-linear responses at higher scales (Liu et al. 2007). Maintenance of diversity builds resilience (Schluter and Pahl-Wostl 2007) because it enhances system performance by increasing the number of overall functions being performed in the system and provides redundancy of functions within and across scales (Walker et al. 2006). Diversity thus increases the capacity of the system to withstand disturbance because species and 
actors with similar functional capabilities are available to quickly fill in for components lost during the disturbance.

\section{B. Urban Water Demand as a Coupled Human and Natural System}

Urban water demand represents a coupled human and natural system (Figure 2.2), typified by complex interactions between human agency and landscape processes at multiple spatial and temporal scales, with the potential for scale mismatches between management and biophysical processes, non-linear system responses, and disturbance (Liu et al. 2007; Irwin et al. 2009). In urban landscapes, scale mismatches can be particularly pronounced because the scales of social organization and governance structures responsible for management are not correctly aligned with the scales of ecological dynamics (Borgstrom et al. 2006). Local-scale processes in both human and natural systems are significant drivers of change, contributing to the largescale patterns of water demand that occur. The amount of water used at the household-scale, for example, is influenced by the norms and values of the individual users as well as ownership of water-consuming appliances, lawn and garden preferences, and investment in conservation. Natural processes interact with human preferences by controlling ecological demand for water required to maintain vegetation health, which is based on local rates of potential evapotranspiration, soils, and the type of vegetation present. Larger-scale climate patterns also directly affect water use, as research has shown that water consumption increases during periods of 
hot, dry weather and decreases after precipitation events (Adamowski 2008;

Praskievicz and Chang 2009). Governance structures at multiple scales, from the neighborhood to the city to the region, can also influence water consumption decisions, though the direction of change depends on the policy and institutional systems (van de Meene and Brown 2009). For example, at the neighborhood-scale, the presence of a homeowner association (HOA) has been positively correlated to an increase in water consumption, due to mandatory lawn maintenance policies (Harlan et al. 2009). However, municipal-scale incentives that assist in replacing outdated appliances and installing low-flow faucets and showerheads and efficient lawn irrigation technologies can be successful in reducing residential and business sector water consumption (Hilaire et al. 2008). Thus, small shifts in individual household behavior can cumulate into large changes, either increases or decreases, in city-scale water demand. However, such multi-scale analysis in water consumption using a framework of coupled social and ecological systems has not yet been studied. 


\begin{tabular}{|c|c|c|c|c|c|c|}
\hline $\begin{array}{l}\text { - Norms } \\
\text { - Values } \\
\text { - Culture } \\
\text { - Owner } \\
\text { - Behavior }\end{array}$ & $\begin{array}{l}\text { - Grass. } \\
\text { roots } \\
\text { mgt } \\
\text { - HoA } \\
\text { - Social } \\
\text { capital }\end{array}$ & $\begin{array}{l}\text { - Top-down } \\
\text { mgt } \\
\text { - Zoning } \\
\text { - Pricing } \\
\text { - Mandates } \\
\text { - Incentives }\end{array}$ & $\begin{array}{l}\text { - Land- } \\
\text { use } \\
\text { planning } \\
\text { - Infra- } \\
\text { structure }\end{array}$ & $\begin{array}{l}\text { Surface } \\
\text { energy } \\
\text { balance } \\
\text { - UHI } \\
\text { - Solls } \\
\text { - Vegetation }\end{array}$ & $\begin{array}{l}\text { Drought } \\
\text { Snow - } \\
\text { molt } \\
\text { Geology }\end{array}$ & $\begin{array}{l}\text { - Climate } \\
\text { Chango } \\
\text { - PDO } \\
\text { - ENSO }\end{array}$ \\
\hline
\end{tabular}

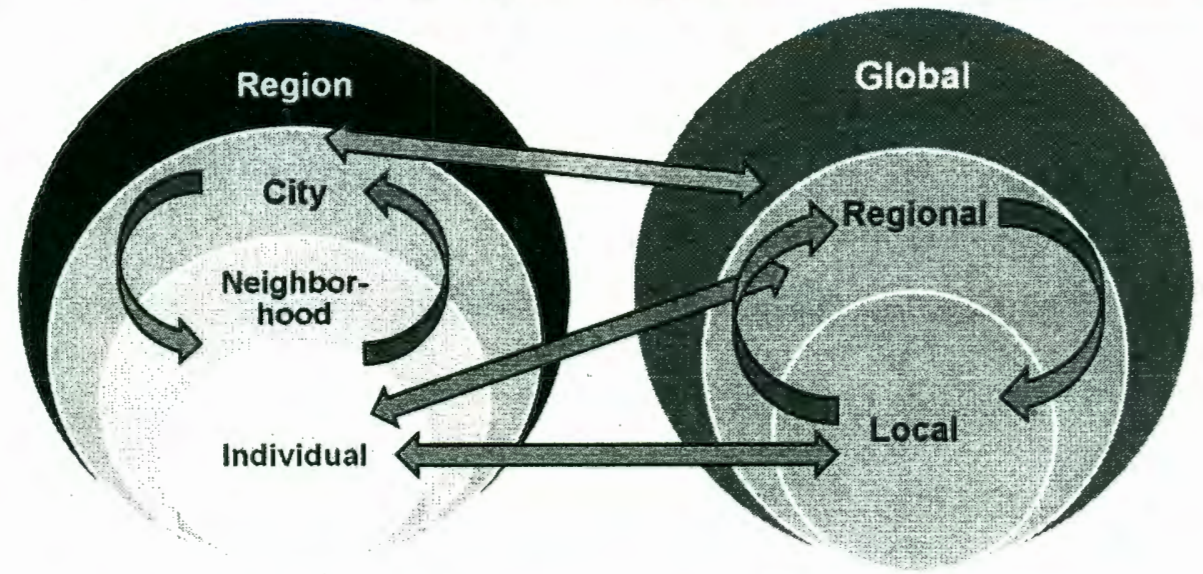

Human Systems , Natural Systems

Figure 2.2: The graphic represents the complex multi-scale interactions inherent in the coupled human and natural systems framing of urban water demand

\section{Methodological and Epistemological Review}

In the context of urban water consumption and demand, neither the complexity of the multi-scale interactions between and within the human and natural systems nor the strength of the feedbacks and implications for non-linear responses has been fully elucidated. Over the last 30 years there have been significant advances in technology and data processing ability, including the proliferation of geographic information systems (GIS) and the development of integrated dynamic models, such as agentbased models (ABMs). These developments have influenced the production of urban 
water demand knowledge by shifting the types of questions researchers, policy makers, and managers ask. What were once analyses confined to determining largescale water demand based on limited climate, water price, and household income variables, have been transformed into multi-scale analyses accounting for numerous social and natural system variables. Furthermore, new modeling and analysis methods have the ability to integrate policy interventions, individual choices, and climate change uncertainty to explore shifts in water demand under multiple alternative futures. This section presents a review of the developments in urban water demand methodology over a 30-year period (1980-2009) towards enhancing knowledge and understanding of the coupled human and natural system in five central areas: 1) scale, 2) uncertainty, 3) non-linearity, 4) complexity, and 5) dynamic modeling. I do not intend this review to be a synthesis of the determinants of urban water demand as such a review has already been comprehensively prepared by Corbella and Pujol (2009).

\section{A. Scale}

Understanding the spatial and temporal patterns of water usage concerns planners, scientists, and politicians due to natural variability of water supply and the complex interplay of social and ecological dynamics in the urban environment (Lee and Wentz 2008). In the 1980s, the primary focus of academic research on urban water demand was the development and utilization of statistical methods, principally 
multiple regression and time series analysis (Maidment and Parzen 1984) to improve the precision of daily (Maidment et al. 1985; Maidment and Miaou 1986) and monthly (Agathe and Billings 1980; Maidment and Parzen 1984; Al-Qunaibet and Johnston 1985; Maidment et al. 1985; Miaou 1990) demand forecasts. The main motive of such studies is to produce an accurate amount of water from the supply infrastructure each day to meet the city's needs. These early statistical analyses were fundamentally aspatial because the data obtained for analysis was either city-scale production data (the amount of water produced to meet all municipal needs) (Maidment and Parzen 1984; Maidment et al. 1985; Al-Qunaibet and Johnston 1985; Maidment and.Miaou 1986) or household-level data lacking spatial coordinates (Agthe and Billings 1980). Household-level data allowed for increased understanding of how household characteristics, such as income and water price, influence overall water consumption, given that the data are randomly selected across the study area. However, such an approach fails to account for the influence of neighborhood characteristics and spatial autocorrelation on water consumption. The use of aggregate city-scale data in statistical models inherently assumes a lack of a variation in spatial patterns and processes, such as clustering or dispersion of high water users at the neighborhood or census block scale. In recent years, these variations have been recognized as important determinants of future water consumption (Wentz and Gober 2007; Chang et al. 2010), especially related to efforts focused on consciously utilizing urban 
planning as a method for reducing water demand, coined "design-oriented approaches to water conservation" by Shandas and Parandvash (2010).

\section{i. Temporal Scale}

Although lacking spatial information, large-scale water production data can be obtained at fine temporal scales, often at the daily scale. When subjected to time series analysis methods this data reveals significant temporal trends in water consumption that correlates with weather and climate. Early research achieved significant gains in determining the relationship among climatic factors, including temperature, precipitation, evapotranspiration, and seasonality, and urban water demand. Agthe and Billings (1990) designed a dynamic multiple regression model that is capable of explicitly accounting for the strong influence of past water use on current water use, by including a time-lagged value of the dependent variable, monthly water consumption, as an independent variable. Maidment and Parzen (1984) recognized that the variation in water use over time results from responses to socio-economic and climatic factors at multiple time-scales and introduce a time-series cascade model that specifically targets these processes. Furthermore, while long-term changes in population and income affect water demand slowly over a period of years, climatic factors produce a seasonal influence on demand, and rainfall and stochastic events (such as a heat wave) produce immediate fluctuations in demand (Maidment et al. 1985; Miaou 1990; Zhou et al. 2000). 
Urban water consumption is especially sensitive to seasonal time scales, demonstrating peak demand during periods of hot, dry weather due to increases in external water application for irrigation of lawn and gardens and replacing water lost to evaporation in pools and other water features. Seasonal peak water demand is party physical and partly psychological (Zhou et al. 2000), as human behavior responds to both actual and perceived changes in the environment, such as determining how much water vegetation needs to survive a dry spell. One simple methodology that has been used extensively and explicitly accounts for sinusoidal seasonal variability of water demand is separating water use into two components: 1) weather-insensitive, nonseasonal base (winter) use and 2) weather-sensitive, seasonal (summer) use (Maidment et al. 1985; Maidment and Miaou 1986; Miauo 1990; Rufenacht and Guibentif 1997; Syme et al. 2004; Gutzler and Nims 2005; Gato et al. 2007; Praskievicz and Chang 2009; House-Peters et al. 2010; Polebitski and Palmer 2010; Wong et al. 2010). A more sophisticated method, developed by Zhou et al. (2000), recognizes that seasonal variations in water consumption are not completely the result of sinusoidal patterns of air temperature and evaporation, which produce smooth increases and decreases in consumption over a year and can be modeled relatively easily using a Fourier series. Seasonal variation is also dependent on more stochastic events, such as bursts of precipitation, which garner quick behavioral responses, such as immediate reduction in consumption. Thus, additional components must be included in comprehensive models, including the number of days since the last precipitation event (Antecedent 
Precipitation Index) and an autoregressive function to account for the short-term memory of the system, because water use is dependent on its own past values (Agthe and Billings 1980; Zhou et al. 2000). Praskievicz and Chang (2009) offer a different methodology for modeling temporal autocorrelation in seasonal water consumption, utilizing an autoregressive integrated moving average (ARIMA) model, which includes water use during the previous time period as an independent variable. In addition to modeling base and seasonal water demand, Wong et al. (2010) address calendrical use, which accounts for the effect of the day-of-the-week, pre-, during-, and post-holiday effects, and persistence (the dependence of water use on its own values) in the temporal data series.

\section{ii. Spatial Scale}

Increasing understanding of the complexity of coupled human and natural systems has led to the realization that urban water demand analyses must utilize spatially explicit methodologies to develop knowledge about the interactions of social and ecological variables within and between multiple spatial scales. Furthermore, these methodologies must be able to model the influence of significant variables at multiple resolutions to determine the scales at which certain processes are most influential and the effect of these processes on the patterns of demand that emerge at larger-scales. Geographic information systems (GIS) and spatial quantitative analysis techniques have become increasingly important and pervasive components of water 
demand analysis (Guhathakurta and Gober 2007; Wentz and Gober 2007; Balling et al., 2008; Lee and Wentz 2008; Franczyk and Chang 2009; Praskievicz and Chang 2009; House-Peters et al. 2010; Lee et al. 2010; Polebitski and Palmer 2010; Shandas and Parandvash 2010; Chang et al. 2010). Reliability and availability of spatial data has been steadily increasing. Water providers across the United States have increased public access to water consumption data containing spatial information, such as household address or census block ID, and the accuracy of satellite image classification in urban areas has improved due to the proliferation of high-resolution aerial and satellite imagery. GIS databases, capable of storing and joining myriad types of qualitative and quantitative data based on spatial location, have facilitated the ability of researchers and managers to compile rich datasets at fine spatial scales making possible visualization and quantification of water use patterns across geographic areas (Lee and Wentz 2008).

A recent shift in urban water demand analysis away from dominance of aggregate scale forecasting and econometric research towards an emphasis on exploring patterns of water demand at multiple geographic scales is concomitant with a noticeable shift in the variables of interest to researchers. To understand how localscale human and natural processes interact to influence water demand, variables •beyond water price, household income, and city-scale climate factors must be examined. Investigations of local-scale ecological processes such as the influence of the presence of a garden and household-level vegetation composition on external 
water use have utilized computer simulation modeling (McPherson 1990), installation of meters on a sample of household ịrigation śystems (Sovocool et al. 2006), landcover classification to determine irrigated area (Wentz and Gober 2007), and resident surveys (Syme et al. 2004; Zhang and Brown 2005). Questions regarding the role of urban design and the effect of property characteristics on water consumption have become increasingly popular as city planners and policy makers attempt to integrate land and water planning to accommodate future population growth while halting urban sprawl and reducing per capita water demand. Fox et al. (2009) develop a methodology for statistically forecasting the amount of water demand that a new residential development would require based on three property characteristics: number of bedrooms, architectural type (i.e. detached or semi-detached), and presence of a garden. Alternately, Shandas and Parandvash (2010) utilize ordinary least squares multiple regression models to determine the influence of urban zoning (ie. single family residential or commercial), total building area, and the density of single family residential developments on water consumption during the period (1999-2005). The authors use the results to suggest recommendations regarding the possible role of landuse planning regulations (zoning and density) as a tool for reducing water consumption.

Intra-urban analyses of water consumption at the census block group scale (Chang et al. 2010; House-Peters et al. 2010) and at the census tract scale (Guhathakurta and Gober 2007; Wentz and Gober 2007; Balling et al. 2008; Lee and 
Wentz 2008; Lee et al. 2010) utilize spatial statistics to elucidate spatial patterns of clustering and dispersion of high and low water users across a municipal area. Identification of neighborhoods that exhibit more or less sensitivity to variations in climate than average (Guhathakurta and Gober 2007; Balling et al. 2008; House-Peters et al. 2010) represents an important step towards pinpointing combinations of social and ecological variables that either lead to increased resilience or vulnerability in the context of future climate uncertainties. Simply, spatial autocorrelation refers to whether adjacent regions exhibit similar or dissimilar patterns. Statistical methods, such as spatial regression and geographically weighted regression (GWR), which account for spatial autocorrelation, tend to be an improvement over ordinary least squares (OLS) methods in complex environments where spatial dependence between variables is common (Wentz and Gober 2007; Chang et al. 2010). In many cities the urban heat island (UHI) phenomenon compounds summertime heat, creating variable temperatures across the urban area based on local-scale land cover characteristics, such as the fraction land cover of water, trees, grass, impervious surfaces, and buildings (Guhathakurta and Gober 2007; Hart and Sailor 2009; Gober et al. 2010). Guhathakurta and Gober (2007) include the spatially variable pattern of heating produced by the UHI in their analysis of residential water demand in 287 census tracts throughout Phoenix, Arizona. The authors found that an increase in daily low temperature by one degree Fahrenheit results in a monthly increase of 290 gallons of water use per household. One challenge of using high resolution spatial data is that 
the water service provider area is not necessarily the same as the administrative boundary (ie., census block group or census tract). Often different water providers collect water consumption data at different temporal frequencies, which results in uncertainty for cross-comparison over different geographical areas.

A significant future research direction is the development of methods that are able to fully integrate analysis of both spatial and temporal data. Traditional statistical methods are designed to either examine time-series data or spatially explicit data, but are not suitable to model both types of data. To fully understand patterns and processes of urban water demand, it is necessary that demographic, climatic, and physical processes variables can be modeled for spatially-explicit aerial units over multiple time periods. Rey and Janikas (2010) developed the Space-time analysis of

regional systems (STARS) statistical package to overcome the limitation of traditional methods in order to integrate temporal and spatial data to examine regional income dynamics. STARS is an open-source software that supports dynamic spatial data analysis, which incorporates time into the exploratory analysis of space-time data and enables visualization and exploration of patterns through time.

\section{B. Uncertainty}

Uncertainty is inherent in analyses of water demand due to the spatial and temporal distribution of measured data that contains random fluctuations based on variability across space and time. Visualizing and quantifying spatial and temporal 
variability is one goal of water demand analysis because once this variation is recognized, investigation of the drivers behind the varied responses to stresses through space and time can begin. Like most water resource data, water demand data represent a significant source of uncertainty associated with scale mismatch (Bloschl and Sivapalan 1995). Data availability across a study area may be limited by legal constraints or non-public status. No industry standard exists across water management departments regarding the spatial and temporal scales to which water consumption data are aggregated before becoming available for research. Thus, comparisons of water consumption between geographical areas (ex. neighboring cities) are limited by data aggregated at conflicting spatial scales (census block vs. census tract vs. county), or temporal scales (monthly vs. quarterly) (Clarke et al. 1997; Lee and Wentz 2008). Furthermore, the spatial and temporal scale of water use data may not match the scale of explanatory data, such as census estimates and property tax lot data. To overcome these challenges, researchers commonly rely on the methods of interpolation, estimating values for locations within the study area which do not have recorded values, and extrapolation, extending the spatial area of temporal sequence beyond the scope of the observed data, which build additional uncertainty into space-time analysis (Lee et al. 2010). Clarke et al. (1997) present microsimulation as one method to disaggregate larger-scale water consumption data to effectively estimate micro-level data using chain conditional probabilities, which allow for the incorporation of a wide range of available known data to reconstruct detailed micro-level populations. A more 
recent method developed to improve data extrapolation for water demand research is the space-time extrapolation technique. Lee et al. (2010) derive statistical moments from the relationship between their dependent variable (water usage) and their independent variable (population density) in the present and apply the statistical moments to projections of the independent variable to generate soft data of future water use.

Modern water management tools for coping with uncertainty developed in line with the principle of stationarity, which assumes that the envelope of variability in natural systems is unchanging and can be estimated from the historical record (Milly et al. 2008; Gober et al. 2010). For example, climate variables, such as precipitation, exhibit uncertainty due to stochastic events, such as floods or droughts, and the multiyear cycling of the Pacific Decadal Oscillation.(PDO) and El Niño Southern Oscillation (ENSO) that affect the timing and quantity of seasonal precipitation. Examined over a sufficiently long historical period, these uncertainties can be quantified with frequencies and probabilities of occurrence, which water managers integrate into their supply and demand calculations in order to hedge the risk of experiencing this type of natural variability each year (Lowrey et al. 2009).

Climate change projections, however, do not fit within the historical envelope of variability and are filled with deep uncertainties (Gober et al. 2010), regarding the magnitude, timing, and even the direction of the changes that will be experienced (Frederick 1997). Thus, researchers and decision-makers are challenged to develop 
methodologies to recognize, isolate, examine, and ultimately quantify sources and magnitudes of uncertainty in water demand analyses. The fields of study of climate change science, remote sensing and land use change science, and hydrology have been leaders in developing and utilizing methodologies to assess uncertainty and incorporate it into modeling predictions (Beven 2009). Bayesian methods of determining levels of uncertainty are used extensively in remote sensing for quantifying the amount of uncertainty associated with the land cover class assigned to each pixel of an image. The geostatistical methodology of Bayesian Maximum Entropy (BME) has recently been used to successfully assimilate data uncertainty into the process of visualizing water consumption data through the mapping of extrapolated soft data (Lee and Wentz 2008). Importantly, geostatistical methods can cope with non-stationarity properties inherent in environmental data while accounting for spatial autocorrelation (Lee et al. 2010). An increasingly popular method of analyzing future uncertainty is to conduct a sensitivity analysis, based on multiple scenarios designed according to possible variations and constraints that could be placed on key variables, such as an increase or decrease in industrial growth, and to then compare the modeled scenario results to the original base case results (Wei et al. 2010). 


\section{Non-linearity}

A fundamental property of coupled human and natural systems is the existence of thresholds, or tipping points, which represent transitions between alternate system states or regimes, which once crossed, can initiate system collapse (Gunderson and Holling 2001; Holling 2001; Liu et al. 2007). Induced coupling, due to fast, shortterm responses by human systems to slow, long-term processes in natural systems (Magliocca 2008), and complex multi-scale interactions between social and ecological systems result in nonlinear responses when systems are exposed to stress, such as drought or population growth. Twenty years ago, in response to a literature dominated by linear modeling of water demand, Miaou $(1990,169)$ posed the following two questions, "Is it a good assumption that monthly water use is affected by temperature and rainfall 'linearly,' as the linear regression model assumes? Are the climatic effects adequately accounted for in the traditional linear monthly demand models?" In the following two decades, several methods to identify thresholds and to explicitly model non-linearity have emerged in the water demand literature (Maidment and Miaou 1986; Martinez-Espiñeira 2002; Gato et al. 2007; Chang et al. 2010; Polebitski and Palmer 2010; Zhou et al. 2000), yet explicit acknowledgement of nonlinear water use behavior in methodologies analyzing water demand remains limited (Ghiassi et al. 2008; Ghiassi and Nangoy 2009). 
Water demand exhibits sensitivity to both human and natural system stresses, reacting with a non-linear response once a tipping point value in an independent variable is met. To model the effect of climate thresholds on water use behavior, Miaou (1990) devised two functions, $H \tau\left(T_{m}\right)$ and $G \gamma\left(R_{m}\right)$, where $H \tau\left(T_{m}\right)$ represents effective heating based on a threshold temperature and $G \gamma\left(R_{m}\right)$ represents effective rainfall based on a threshold level of precipitation. Piecewise linear regression models are designed to treat structural or temporal regime shift in a regression model (Chen and Chen 2009). They create discrete linear segments connected at the empirically or theoretically derived threshold, which is represented by the point of change, and can model the changes in slope that occur once a threshold is passed. Piecewise linear regression models have been used to analyze the effect of temporal variables such as crossing temperature thresholds (Maidment and Miaou 1986) and spatial variables such as urban building density, building size, and household income thresholds (Chang et al. 2010). Gato et al. (2007) empirically identify temperature and rainfall thresholds for an urban area in Victoria, Australia. The authors fit polynomial functions of daily maximum temperature and daily rainfall against the reciprocal of the corresponding daily water use and then use the derivative of the function to solve for the threshold when the derivative is equal to zero. In terms of social system variables, Polebitski and Palmer (2010) modeled the non-linear relationship between affluence, defined as income and property lot value, and seasonal peaking, defined as the ratio of seasonal water use to base use, in Washington state, USA and concluded 
that a certain threshold of affluence exists above which water consumption increases at a significantly higher rate during the summer season.

Artificial neural networks (ANNs) have proven useful for modeling complex nonlinear functions associated with water demand (Adya and Collopy 1998;

Adamowski 2008; Ghiassi et al. 2008; Firat et al. 2009). ANNs are statistical models built through an iterative training process that accumulates knowledge at each model layer until a model is created that accurately captures the behavior of the process being modeled and can be used to forecast future values (Ghiassi and Nangoy 2009). ANNs have been offered as effective alternatives to traditional linear modeling approaches, due to its ability to explicitly analyze nonlinear time series events. One ANN, the dynamic architecture for artificial neural networks (DAN2), models nonlinearity through a transfer function of a weighted and normalized sum of the input variables (Ghiassi and Nangoy 2009). DAN2 performance was compared to ARIMA for modeling future water demand at multiple temporal scales, 2-year future demand, 2week future demand, and 48-hour future demand, and was found to perform significantly better than the ARIMA method (Ghiassi and Nangoy 2009). A significant limitation to ANNs is the lack of explanatory power of the results, which makes this methodology unsuitable for use in many management and planning contexts (Galán et al. 2009). 


\section{Complexity}

Coupled human and natural systems are by nature highly complex. During the last three decades, scientists have increasingly relied on interdisciplinary, mixedmethods research and expansions in data sources, variable types, and methodological approaches to more comprehensively examine the complex patterns, processes, and structures that determine urban water consumption. What was once a research field dominated by economists, civil engineers, water managers, and statisticians is now a diverse field employing geographers, natural scientists, sociologists, urban planners, and policy analysts. The integration of multiple disciplines within water resources research teams has affected the types of research questions being asked and the methods of producing and disseminating knowledge.

Early methodologies for analyzing urban water demand utilized relatively simple econometric time series models based on linear multivariate regression that required a limited number of datasets and could be performed with modest computing power. These early methods were focused narrowly on increasing the accuracy of forecasting methods in order to optimize water supply infrastructure and reduce the cost and risk borne by water suppliers. As discussed in section A, these analyses were aspatial, ignoring variations in water consumption across the geographic focus area, due to the lack of available software to process and store large amounts of spatial information for effective analysis. Today, the robustness of mathematical analyses is 
augmented by fine-scale land use and land cover data, These spatially-explicit data include measures of irrigated vegetation and greenness (Guhathakurta and Gober 2007; Wentz and Gober 2007), and social-science data focused on obtaining data to measure human agency, household decision-making, and water use attitudes, norms and behaviors through surveying methods (Syme et al. 2004; Miller and Buys 2008; Randolph and Troy 2008; Harlan et al. 2009), which can be linked to household scale water consumption data with GIS. Increased data richness has led to significant progress in identifying and quantifying relationships among numerous social, climate and water consumption variables, but it has also led to the development of increasingly complex methodologies. Although these new models have the capability to significantly improve our understanding of complex systems by integrating natural and social system variables and modeling non-linear processes; there is a tradeoff between the parsimony of traditional methodologies and the data-hungry, computationally-intensive methods currently being developed.

The availability of both long-term temporal data and fine spatial data allow for a mix of time-series analyses and spatially explicit point analyses to be carried out. The data that can be utilized in time-series analyses of demand is limited because explanatory variables must have sufficiently long records to be utilized as independent variables for developing forecasting models. The advent of geo-coding, which allows for water consumption data, survey data, and property data to be linked to specific addresses and later aggregated and visualized at multiple spatial scales, made possible 
a new generation of water demand analysis, focused on elucidating patterns across space rather than patterns across time. Analysis of water demand across a city, or a number of cities, at one point in time does not require explanatory variables to have long temporal records as long the variables have spatial information. Thus, the types of variables recently included in spatial analyses of water consumption are far more diverse than those found in time-series analyses (Table 2.1). Nonetheless, integrating diverse socioeconomic and ecological variables in a single conventional model remains difficult (Galán et al. 2009): 
Table 2.1 Common variables found primarily in temporal or spatial water demand analyses

\begin{tabular}{|c|c|}
\hline Explanatory Variable & Examples from the Literature \\
\hline \multicolumn{2}{|l|}{ Temporal Analysis } \\
\hline Temperature & $\begin{array}{l}\text { Maidment and Parzen 1984; Al-Qunaibet and Johnston 1985; } \\
\text { Maidment et al. 1985; Miaou 1990; Zhou et al. 2000; Gutzler } \\
\text { and Nims 2005; Balling and Gober } 2007\end{array}$ \\
\hline Precipitation & $\begin{array}{l}\text { Maidment and Parzen 1984; Maidment et al. 1985; Miaou 1990; } \\
\text { Zhou et al. 2000; Gutzler and Nims 2005; Balling and Gober } \\
2007\end{array}$ \\
\hline Wind speed & $\begin{array}{l}\text { Al-Qunaibet and Johnston 1985; Ruth et al. 2007; Praskievicz } \\
\text { and Chang 2009. }\end{array}$ \\
\hline Evapotranspiration & $\begin{array}{l}\text { Agthe and Billings 1980; Maidment and Parzen 1984; Zhou et } \\
\text { al. } 2000\end{array}$ \\
\hline Water price & Agthe and Billings 1980; Al-Qunaibet and Johnston 1985 \\
\hline Population growth & Morehouse et al. 2002, Ruth et al. 2007 \\
\hline Income & Agthe and Billings 1980; Al-Qunaibet and Johnston 1985 \\
\hline \multicolumn{2}{|l|}{ Spatial Analysis } \\
\hline Age & Kenney et al. 2008; Schleich and Hillenbrand 2009 \\
\hline Family size & $\begin{array}{l}\text { Domene and Sauri 2006; Wentz and Gober 2007; Schleich and } \\
\text { Hillenbrand 2009; House-Peters et al. } 2010\end{array}$ \\
\hline Education & House-Peters et al. 2010; Shandas and Parandvash 2010 \\
\hline Percent Hispanic & Balling et al. 2008 \\
\hline House square footage & $\begin{array}{l}\text { Tinker et al. 2005; Domene and Sauri, 2006; Wentz and Gober } \\
\text { 2007; Balling et al. 2008; Harlan et al. 2009; Chang et al. } 2010\end{array}$ \\
\hline Number of bedrooms & Fox et al. $2005 ;$ Kenney et al. 2008 \\
\hline Size of outdoor space & Tinker et al. $2005 ;$ Harlan et al. $2009 ;$ House-Peters et al. 2010 \\
\hline Pool & $\begin{array}{l}\text { Tinker et al. 2005; Domene and Saur 2006; Wentz and Gober } \\
2007 \text {; Balling et al. } 2008\end{array}$ \\
\hline Garden & Fox et al. 2005; Domene and Sauri 2006 \\
\hline $\begin{array}{l}\text { Proportion of single family } \\
\text { households }\end{array}$ & Schleich and Hillenbrand 2009; Shandas and Parandvash 2010 \\
\hline Housing typology & $\begin{array}{l}\text { Zhang and Brown 2005; Domene and Sauri 2006; Fox et al. } \\
2009\end{array}$ \\
\hline $\begin{array}{l}\text { Normalized Difference of } \\
\text { Vegetation Index (NDVI) }\end{array}$ & $\begin{array}{l}\text { Guhathakurta and Gober 2007; Wentz and Gober 2007; Balling } \\
\text { et al. } 2008\end{array}$ \\
\hline Urban Heat Island (UHI) & Guhathakurta and Gober 2007 \\
\hline $\begin{array}{l}\text { Conservation policy } \\
\text { implementation }\end{array}$ & Campbell et al. 2004; Kenney et al. 2008 \\
\hline
\end{tabular}




\section{E. Dynamic modeling approaches}

Recognition that water demand is generated through dynamic and continually evolving processes based on multi-scale interactions between human agents and the natural world has led to a recent increase in the development and implementation of dynamic models. In contrast to conventional static times-series and econometric models, dynamic models are developed with the intent to capture how influential socioeconomic and ecological aspects of water demand, such as urban form and housing typology (Galán et al. 2009), changes in price (Athanasiadis et al. 2005; Chu et al. 2009), conservation policies (Chu et al. 2009), and climate change (Downing et al. 2003), affect water consumption decisions and behaviors, under plausible future scenarios. The growing trend toward dynamic models represents a shift away from deterministic modeling approaches intended to deliver sharp predictions, such as forecasting. Instead, the new focus is on rigorous scenario analysis and improving the explanatory abilities of methodologies to progress understanding of the highly adaptive components that compose coupled human and natural systems (Galán et al. 2009). Two dynamic modeling methods being used to examine urban water demand are agent-based models (ABMs) and system dynamics models (SDMs).

ABMs have been used widely in land-change science (Parker et al. 2003; Janssen and Ostrom 2006; Manson and Evans 2007; Parker et al. 2008) to examine the drivers and impacts of land use change on sustainability in coupled human and natural 
systems. ABMs have rapidly gained popularity in complex system analysis due to their ability to: 1) incorporate both spatially- and temporally-explicit data, 2) model bidirectional relations between individual human agents and the macro-behavior of the social or environmental system being modeled, 3) capture emerging patterns at higher scales of the system that result from interactions at lower levels, and 4) blend qualitative and quantitative approaches (Janssen and Ostrom 2006; Manson and Evans 2007; Galán et al. 2009). Human action is the primary focus of ABMs (Parker et al. 2003). In water demand models, water consumers are represented as autonomous agents who make decisions based on set model parameters, for example, societal attitudes toward water conservation and the availability of information regarding water scarcity (Chu et al. 2009; Galán et al. 2009) or social networks and the speed of diffusion of information about new technology and conservation methods (Athanasiadis et al. 2005). ABMs allow for positive reinforcement and feedbacks to be integrated into the system, because changes in agent (water user) behavior happens over a period of time as agents are influenced by the behaviors of their neighbors and social groups as well as by emerging large-scale patterns that result from the changes in water consumption made by the agents who are initially most receptive to the scenario signals and thus are the first to change their behaviors.

SDMs are an alternative method that can be used to address dynamically complex problems in water resource management. Dynamic models allow for the examination of how the behavior of a modeled system and its response to 
interventions changes over time (Ford 1999). The foundation of system dynamics is that the behavior exhibited by a system is based on the system structure and the relationships, interactions, and feedbacks among key variables within the system. SDMs also have the ability to link external systems, such as climate change, to examine the impact on water demand over long periods of time. SDMs improve on traditional statistical models because there is a deeper understanding of the system structure and the relationships and interactions among the variables. However, unlike ABMs, the behavior of neighbors and the influence of this behavior on system components over time cannot be simulated. SDMs are often conceptualized using stock-and-flow models, which allow for visualization of the effects of different intervention strategies over time. Importantly, in both SDMs and ABMs, modeling and simulation are aimed at providing valuable insights into the behavior of the system over time; not point prediction. Advantages of the SDM methodology are its ability to: 1) use qualitative and quantitative variables, 2) develop nested models to address a problem at multiple scales, and 3) continuously test assumptions and system sensitivity under multiple alternative futures (Winz et al. 2009).

\section{Conclusions}

Urban water demand represents a complex system, dependent on patterns and processes that emerge through multi-scale and cross-scale human-environment interactions. Humans hold a unique role because our distinctive characteristics of 
foresight and intentionality provide us the ability to build or erode resilience in coupled systems through the management strategies that we choose to implement (Holling et al. 2001). This paper reviews the progress that has been made over the last thirty years to improve understanding of urban water demand through theoretical and empirical advancements in representing, modeling, and simulating complex system behavior. The multiple threats of anthropogenic climate change, rapid urbanization, and increasing water scarcity have fúeled a steady increase in interest in water demand analysis (Figure 2.1) from an increasingly wide range of disciplines. Increased data availability and advances in technology and computing power have allowed for the development of sophisticated models able to incorporate spatially-explicit data and simulate human agency through complex decision-making and social diffusion submodels. Although, tangible progress has been made in improving the capabilities of water demand modeling in the five themes investigated in this review, significant limitations remain. Originally, methodologies were constrained by data lacking sufficient temporal or spatial information. Today, data characterized by both long temporal scales and spatially explicit information are available, but methodologies that are able to incorporate this type of data and take advantage of its rich information to elucidate relationships at multiple scales still need to be developed. ABMs are one methodology leading the way in this arena, but there is room for improving the transparency of the internal system structure and the variable ințeractions. 
Furthermore, a common criticism of both ABMs and SDMs is the trade-off that has occurred between parsimony and highly-parameterized, data-hungry models.

The main findings of this review are: 1) space becomes increasingly more important, as spatial analysis of patterns and processes is made possible by increases in the availability of spatially-explicit data and advancements in GIS and spatial quantitative analysis; 2) research examining system complexity is improved as the disciplines contributing theory and methods increase; 3 ) ability to isolate, quantify and examine sources and magnitudes of uncertainty has improved; and 4) capability of dynamic models to simulate water demand under alternative future scenarios has affected a recent shift away from deterministic modeling approaches. 


\section{Modeling the Impact of Land Use and Climate Change on Neighborhood- Scale Evaporation and Nighttime Cooling: A Surface Energy Balance Approach}

\section{Introduction}

Worldwide, cities face a number of challenges to meet the housing, commerce and infrastructure demands of new residents while maintaining an urban environment that is healthy and comfortable and protects natural resource provisions, such as water supply and air quality. Cities experiencing population growth have a choice to either increase density in their core through infill and vertical development or to incorporate rural and less developed land along the peri-urban fringe, a process known as sprawl. Two priorities in sustainable urban growth are mitigating the urban heat island (UHI) and reducing per capita water consumption. The process of urbanization produces radical changes in the physical and chemical characteristics of the surface and atmospheric properties of an area. Urban landscapes are characterized by complex mixtures of land use and land cover types, which affect the surface energy balance (Q* $+\mathrm{Q}_{\mathrm{F}}=\mathrm{Q}_{\mathrm{H}}+\mathrm{Q}_{\mathrm{E}}+\Delta \mathrm{QS}_{\mathrm{S}}\left(\mathrm{W} \mathrm{m}^{-2}\right)$; as presented in Oke 1987). The urban climate is an aggregation of micro-climates, each of which is dominated by the characteristics of its immediate surroundings (Oke, 1987). Local-scale land use and land cover characteristics, such as city centers, parks, and residential areas, produce distinct alteràtions in net radiation $\left(\mathrm{Q}^{*}\right)$, anthropogenic heating $\left(\mathrm{Q}_{\mathrm{F}}\right)$, heat storage $\left(\Delta \mathrm{Q}_{\mathrm{S}}\right)$, and 
sensible $\left(\mathrm{Q}_{\mathrm{H}}\right)$ and latent heating $\left(\mathrm{Q}_{\mathrm{E}}\right)$, producing significantly different climates than surrounding rural areas. Causes of the UHI phenomenon have been well documented (see (Souch and Grimmond 2006) for a review) and include: reduced evaporation from vegetation removal; reduced longwave energy loss due to limited sky-view factor; anthropogenic heating; increased heat storage and decreased reflectivity due to the type of building materials used; and altered patterns of local airflows due to building geometry and urban canyons (Piringer et al. 2007).

In urban settings, complex interactions between the human modified landscape and the surface energy balance occur at multiple spatial and temporal scales, resulting in variable local climates, such that urban dwellers experience a range of climates across different parts of the city at different times of the day (Coutts et al. 2007; Xu et al. 2008; Hart and Sailor 2009). Water availability plays a significant role in modulating the microclimate through the size and variability of urban evaporation. In the surface energy balance, water appears as the latent heat flux $\left(\mathrm{Q}_{\mathrm{E}}\right)$, which is the energy required for the state change from liquid water to water vapor (evaporation) to occur. In urban residential areas, water availability depends not only on the natural precipitation regime but also on human external water use, primarily lawn and garden irrigation and the presence of pools. In the context of the UHI, evaporation is especially important because it acts as a natural cooling mechanism. Energy that is consumed in the process of evaporating water is no longer available to be partitioned to the sensible heat flux $\left(\mathrm{Q}_{\mathrm{H}}\right)$, which effectively limits the amount of energy available 
to heat the surrounding air. Vegetation is a major source of water vapor in urban areas. Summertime irrigation has been found to increase latent heat flux threefold as compared to non-irrigated areas (Arnfield 2003).

In climates that receive limited summer season precipitation, humans replace the quantity of water evaporated with external water consumption to maintain residential vegetation and to keep pools and water features filled. In Phoenix, Arizona an analysis of the effect of the UHI on water consumption concluded that for every 1 ${ }^{\circ} \mathrm{F}$ increase in the average June low temperature, households consumed an average of 290 more gallons of water over the course of the month (Guhathakurta and Gober 2007). The type of vegetation present is also an important determinant of the urban thermal environment. In Portland, Oregon, canopy cover was the primary factor separating warmer regions from cooler regions (Hart and Sailor 2009). Thus, the urban microclimate both influences and is influenced by human behavior and decision-making, due to the complex interactions among land cover and land use characteristics and water availability that produce the variable patterns of daytime heating and nighttime cooling that are experienced throughout an urban area.

Although the primary causes of the UHI are well understood, the exact nature of the relationship among land use and land cover characteristics, climate, and the amount of energy partitioned into sensible, latent, and storage heat fluxes remains unknown (Hart and Sailor 2009; Gober et al. 2010). Anthropogenic climate change and land development, which determines urban land cover and irrigation decisions, 
introduce additional complexity and uncertainty. The purpose of this research is to quantify the effect of combined land cover change and climate change on summer season external water consumption and nighttime cooling in nine residential neighborhoods with distinct socioeconomic and land use characteristics. The nine neighborhoods are located in Hillsboro, a suburban city on the western edge of the Portland metropolitan area (Figure 3.1).

This research employs a surface energy balance model, the Local-Scale Urban Meteorological Parameterization Scheme (LUMPS) version 5 (Grimmond and Oke 2002; Loridian et al. 2010), to calculate hourly scale sensible, latent, and storage fluxes during the month of August under multiple plausible future scenarios of urban development and climate change. Surface energy balance models have been used in numerous locations worldwide (Figure 3.2), but most previous research projects have focused primarily on urban-rural comparisons (Cleugh and Oke 1986; Christen and Vogt 2004; Xu et al. 2008), comparisons across cities (Grimmond and Oke 2002), or changes in one location under multiple scenarios (Mitchell et al. 2007). Using surface energy models to evaluate alternative future land developments is a relatively new feature of UHI research (Mitchell et al. 2008; Gober et al. 2010) and to the author's knowledge, climate change scenarios have not been used as model input in previous studies. This paper represents a significant contribution to the literature because 1) it is an intra-urban analysis of changes in nine small-scale neighborhoods with varying land cover characteristics, 2) it employs fine-scale water consumption data geo-coded 
to each household, 3) it examines an area of the Portland region that is expecting intense future urban development and population growth, and 4) it integrates temperature data from locally down-scaled Global Climate Models (GCM).

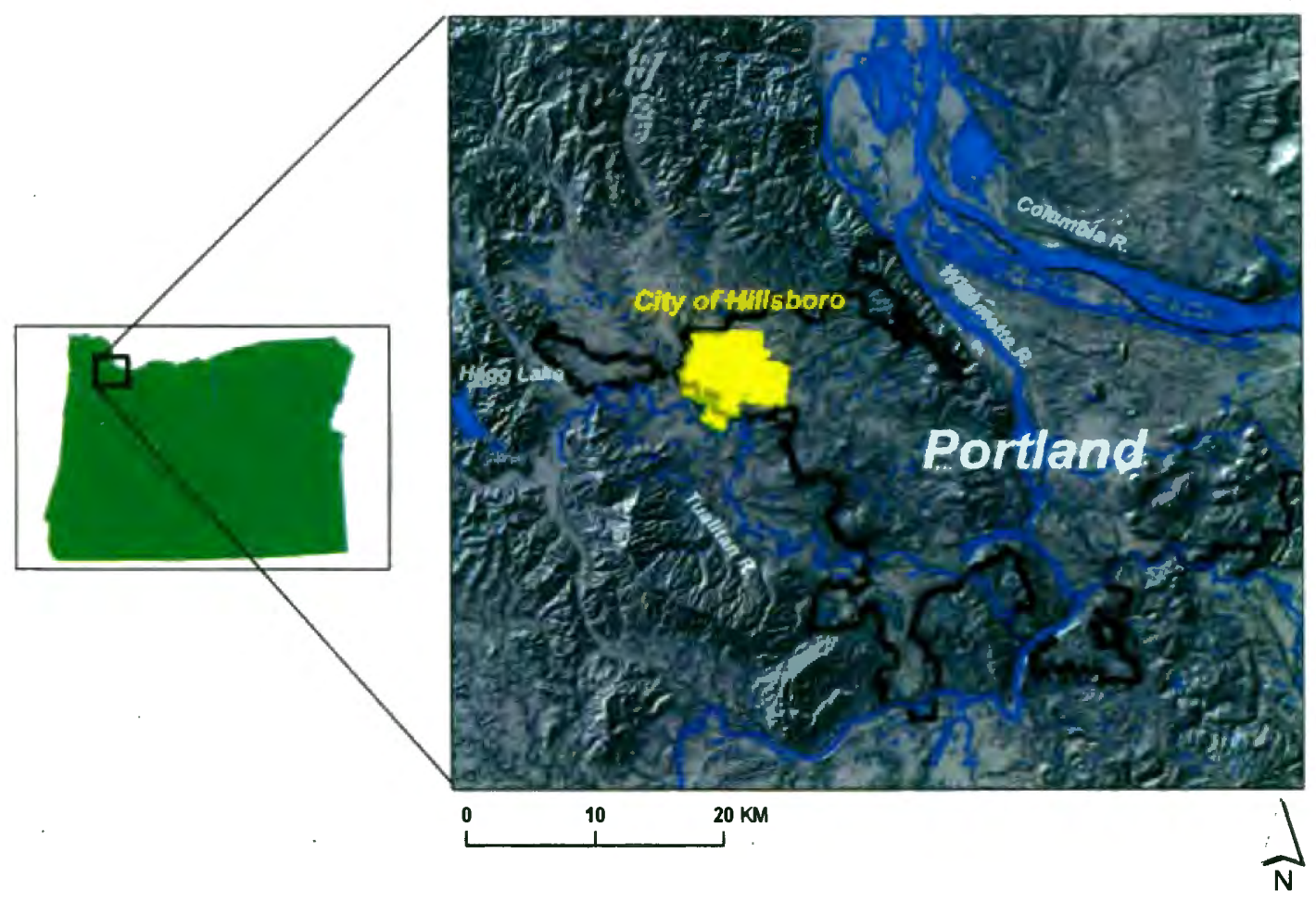

Figure 3.1: Map of the Portland metropolitan area, shows the unique urban growth boundary (UGB) and highlights the study area, City of Hillsboro, located on the western edge of the metropolitan area. 


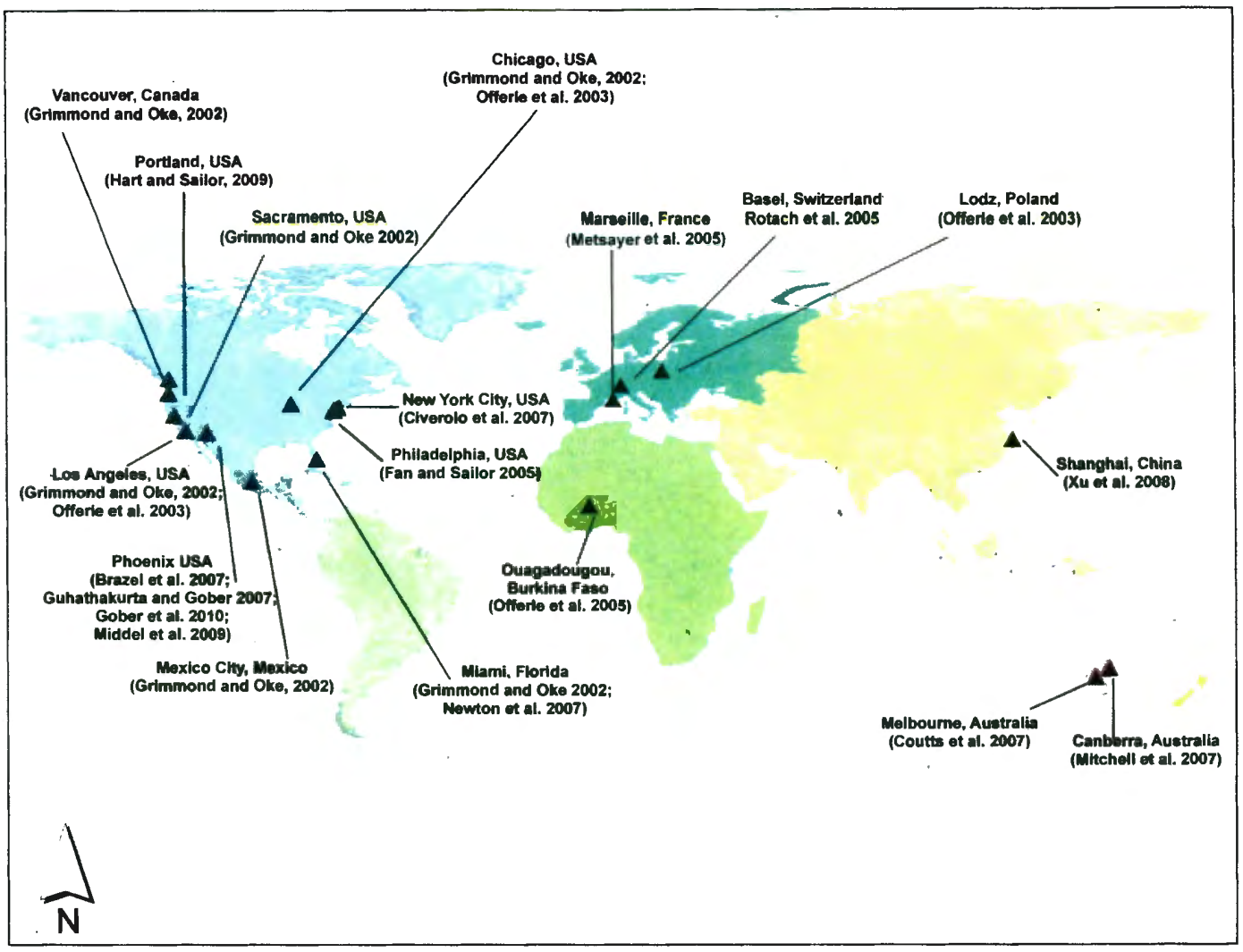

Figure 3.2: Map of previous empirical research of the surface energy balance and urban heat island in cities throughout the world

\section{Background}

The literature describing the impacts of urbanization on the local surface energy budget is generally in consensus on five significant modifications caused by the heterogeneous 3D form of the urban canopy (Masson 2006). The first effect is the trapping of net all-wave radiation in the canopy. For example, observations of localscale energy balance fluxes made over a residential district in Ouagadougou, Burkina 
Faso found that net all-wave radiation increased with urbanization owing to higher albedo, lower heat capacity, and increased thermal conductivity of the bare dry soil compared to the urbanized surface (Offerle et al. 2005). The second impact is high storage uptake during the day, due to the high thermal properties of the building materials and the urban surface characteristics (Oke 1987; Arnfield 2003; Masson 2006; Coutts et al. 2007; Piringer et al. 2007). Evaluating sites of varying density, Coutts et al. (2007) found a positive correlation between increased urban density and increased heat storage. The third effect is the generation of a positive turbulent heat flux to the atmosphere at night, sustained by large releases of heat stored in the urban fabric from the previous day (Masson 2006; Coutts et.al. 2007; Piringer et al. 2007). The fourth modification is general favoring toward sensible heat over latent heat due to reduced vegetation in densely urban areas, which can intensify the UHI effect especially during the evening (Oke 1987; Grimmond and Oke 2002; Offerle et al. 2005; Masson 2006; Coutts et al. 2007; Piringer et al. 2007). Finally, the fifth effect is the possibility of experiencing large anthropogenic heat fluxes $\left(\mathrm{Q}_{\mathrm{F}}\right)$ in dense urban areas (Grimmond and Oke 2002; Masson 2006; Xu et al. 2008).

A wide range of strategies have been posed to mitigate urban warming. The availability of moisture is one of the most important controls on the urban climate (Oke 1987) and has been shown to reduce heating in heavily irrigated areas. During summer, sensible heat and heat storage are generally the dominant fluxes because latent heat is small, constrained by water availability from precipitation, irrigation and 
vegetation cover (Coutts et al. 2007). Research suggests that purposefully altering the surface energy balance, for example increasing urban greenspace, is one method to mitigate extreme urban heating (Coutts et al. 2007; Grimmond 2007; Mitchell et al. 2008). Results in Basel, Switzerland showed that as green space increased, latent heat fluxes became more dominant while the sensible heat storage fluxes decreased (Coutts et al. 2007). Mitchell et al. (2008) examine a series of urban design scenarios that explore the impact of vegetated Water Sensitive Urban Design (Wong 2006) features on the urban water balance; microclimate, and overall energy consumption for a mainly residential suburb of Canberra, Australia. The authors contend that their results confirm the potential role of passively controlling the urban microclimate through suburban design that purposefully maximizes evaporation. Another option is installing vegetated roofs, which can act as a thermal insulation layer, potentially reducing household air conditioning usage during hot summer days (Mitchell et al. 2008). Coutts et al. (2007) also argue that the integration of rooftop gardens increase the evaporative fraction of the surface energy budget, which would help to reduce surface temperatures. Other options include changing the material properties of individual buildings or even the spatial arrangements of buildings to create larger separations (Grimmond 2007). Mitchell et al. (2008) found that combining water detention ponds, wetlands, grass swales and vegetated roofs with no reduction in garden watering yielded the highest rate of evaporation and the largest effect on the maximum daily temperature, making the area about $0.5^{\circ} \mathrm{C}$ cooler than a conventional 
suburban design. Stone and Norman (2006) outline three physical planning strategies to induce urban cooling: choosing paving and roofing materials to increase surface reflectivity, increasing tree canopy, and reducing heat waste. Notably, an important tradeoff exists between championing irrigated urban green-space to mitigate urban heating and the increase in external water consumption necessary to maintain the additional vegetation during hot, dry weather (Giober et al. 2010).

\section{Local Scale Urban Meteorological Parameterization (LUMPS) Model}

The local-scale urban meteorological parameterization scheme (LUMPS) (Grimmond and Oke 2002) is a model designed to calculate the storage heat flux $\left(\Delta \mathrm{Q}_{\mathrm{S}}\right)$, and the turbulent sensible $\left(\mathrm{Q}_{\mathrm{H}}\right)$ and latent $\left(\mathrm{Q}_{\mathrm{E}}\right)$ heat fluxes in the urban environment. The model is based on the surface energy balance equation: $\mathrm{Q}^{*}+\mathrm{QF}_{\mathrm{F}}=$ $\mathrm{Q}_{\mathrm{H}}+\mathrm{Q}_{E}+\Delta \mathrm{Q}_{S}\left(\mathrm{~W} \mathrm{~m} \mathrm{~m}^{-2}\right)$, though the anthropogenic heat flux $\left(\mathrm{Q}_{F}\right)$ is ignored. Grimmond and Oke (2002) explain that the reason $\mathrm{Q}_{\mathrm{F}}$ is not included is an attempt to save input requirements, decrease uncertainty, and not cause a double counting effect because the other parameters measured in the surface energy balance already account for the anthropogenic heat flux. The model is based on the assumption that heat fluxes can be modeled using net all-wave radiation, surface cover information, roughness based on height and density, and standard weather observations, including air temperature, humidity, wind speed and pressure: The model evaluates a "neighborhood response," which is described as a box with side lengths between $10^{2}-$ 
$10^{4}$ meters, at an hourly temporal scale. The model is able to predict spatial and temporal variability of heat fluxes that occur both within and between urban areas with an acceptable level of accuracy (Grimmond and Oke 2002; Xu et al. 2008).

Grimmond and Oke (2002) evaluated the LUMPS model for seven North American cities, using local meteorological data and varied urban land use sites, including central city, light industrial and low- to medium-density residential housing. The vegetative surface cover varied from 5-60 percent between the sites. The authors' major findings for the seven cities studied were that under low wind conditions, the storage heat flux $\left(\Delta \mathrm{Q}_{\mathrm{s}}\right)$ is the most important at the downtown and light industrial sites. At these dry and built over sites, heat storage changes sequester at least 50 percent of daytime net all-wave radiation. In the first one to two hours of night time, the release of the daytime heat reservoir produces an upward-directed flux that is initially larger than the net all-wave radiation. At the light industrial sites, storage heat flux is the greatest daytime heat sink, although sensible heat flux is also significant representing approximately 40 percent of net all-wave radiation. At the residential sites, sensible heat flux is the greatest sink, though latent heat flux, sustained by garden irrigation and/or precipitation, is significant. The surface cover, most notably the fraction vegetated and irrigated, exerts an important control on the latent heat flux. Thus, cities with a very dry summer and a ban on irrigation had extremely low levels of latent heat flux because the areas were water stressed and potential evaporation was low (Grimmond and Oke 2002). 


\section{Methods and Data}

\section{A. Study Area}

The Portland metropolitan area in Oregon, USA is forecasted to have significant future population growth of an additional one million residents by the year 2030 (Metro 2010). Unique in the U.S., Portland has an urban growth boundary (UGB) that is designed to control sprawl and promote dense development within the urban core. Although the UGB has previously been successful at constraining sprawl (Kline and Alig 1999), the challenge of accommodating one million new residents will potentially lead to an expansion of the boundary to incorporate surrounding rural land for development. An empirical analysis of patterns of urban heating found that the UHI is significant in Portland during the summertime, as daytime temperatures vary by $5.5^{\circ} \mathrm{C}$ across the urban area (Hart and Sailor 2009).

This research focuses specifically on the suburban city of Hillsboro which is located on the western edge of the UGB (Figure 3.1). Hillsboro is the fifth largest city in the state of Oregon with an estimated population of 89,000 people (City of Hillsboro 2008). Hillsboro is one of the main suburbs of Portland and has experienced rapid population growth of nearly $25 \%$ between April 1, 2000, and July 1, 2006, far exceeding the $8.2 \%$ growth rate of the state of Oregon (U.S. Census Bureau 2009). Faced with the dual uncertainties of future population growth and climate change, water managers in Hillsboro have questioned the capacity of the current water supply 
to meet future summer season peak demand. The climate of the Pacific Northwest (PNW) is maritime temperate with cool, rainy winters and warm, dry summers, during which residential water demand sharply increases because residential external water consumption increases to maintain vegetation and fill water features. Peak summer water demand corresponds with the low-flow period for rivers in the PNW (Oregon Water Resources Department 2010), which may be exacerbated in the future due to increased summer season temperature (Figure 3.3a) and evaporation, and possibly decreased precipitation (Figure 3.3b) as a result of climate change. The type and intensity of urban development that occurs may further exacerbate urban heating, which is especially uncomfortable at night, due to the lack of central air conditioning in homes throughout the Portland metropolitan area.

Table 3.1: Descriptive statistics for the nine study area neighborhoods, including external water use, socio-economic, and land-use variables.

\begin{tabular}{|l|r|r|r|r|r|r|r|r|}
\hline $\begin{array}{c}\text { Neighbor- } \\
\text { hood } \\
\text { (Water } \\
\text { Use } \\
\text { Category) }\end{array}$ & $\begin{array}{c}\text { House } \\
\text {-holds }\end{array}$ & $\begin{array}{c}\text { Area } \\
\left.\mathbf{k m}^{2}\right)\end{array}$ & $\begin{array}{c}\text { Avg. } \\
\text { Property } \\
\text { Value } \\
\mathbf{( \$ )}\end{array}$ & $\begin{array}{c}\text { Avg. } \\
\text { Building } \\
\text { Size } \\
\text { (SQFT) }\end{array}$ & $\begin{array}{c}\text { Avg. } \\
\text { Lot } \\
\text { Size } \\
\text { (acres) }\end{array}$ & $\begin{array}{c}\text { Avg. } \\
\text { Year } \\
\text { Built }\end{array}$ & $\begin{array}{c}\text { Indoor } \\
\text { Water } \\
\text { Use } \\
(\mathbf{2 0 0 7})\end{array}$ & $\begin{array}{c}\text { Summer- } \\
\text { time } \\
\text { External } \\
\text { Water } \\
\text { Use } \\
(\mathbf{2 0 0 7 )}\end{array}$ \\
\hline High 1 & 222 & 0.502 & 518,717 & 2,860 & 0.39 & 1982 & .19 .60 & 70.17 \\
\hline High 2 & 431 & 0.495 & 339,900 & 2,041 & 0.2 & 1989 & 20.73 & 51.17 \\
\hline High 3 & 258 & 0.553 & 320,084 & 1,996 & 0.31 & 1976 & 20.34 & 41.57 \\
\hline Average 1 & 699 & 0.641 & 262,224 & 1,647 & 0.12 & 1987 & 19.22 & 32.39 \\
\hline Average 2 & 464 & 0.556 & 234,567 & 1,473 & 0.23 & 1958 & 20.87 & 31.01 \\
\hline Average 3 & 616 & 0.647 & 253,554 & 1,573 & 0.21 & 1982 & 22.05 & 31.65 \\
\hline Low 1 & 550 & 0.438 & 300,647 & 1,768 & 0.08 & 1977 & 14.61 & 19.20 \\
\hline Low 2 & 521 & 0.507 & 218,779 & 1,447 & 0.14 & 1948 & 18.33 & 26.33 \\
\hline Low 3 & 354 & 0.515 & 272,950 & 1,793 & 0.07 & 1959 & 17.76 & 28.68 \\
\hline
\end{tabular}




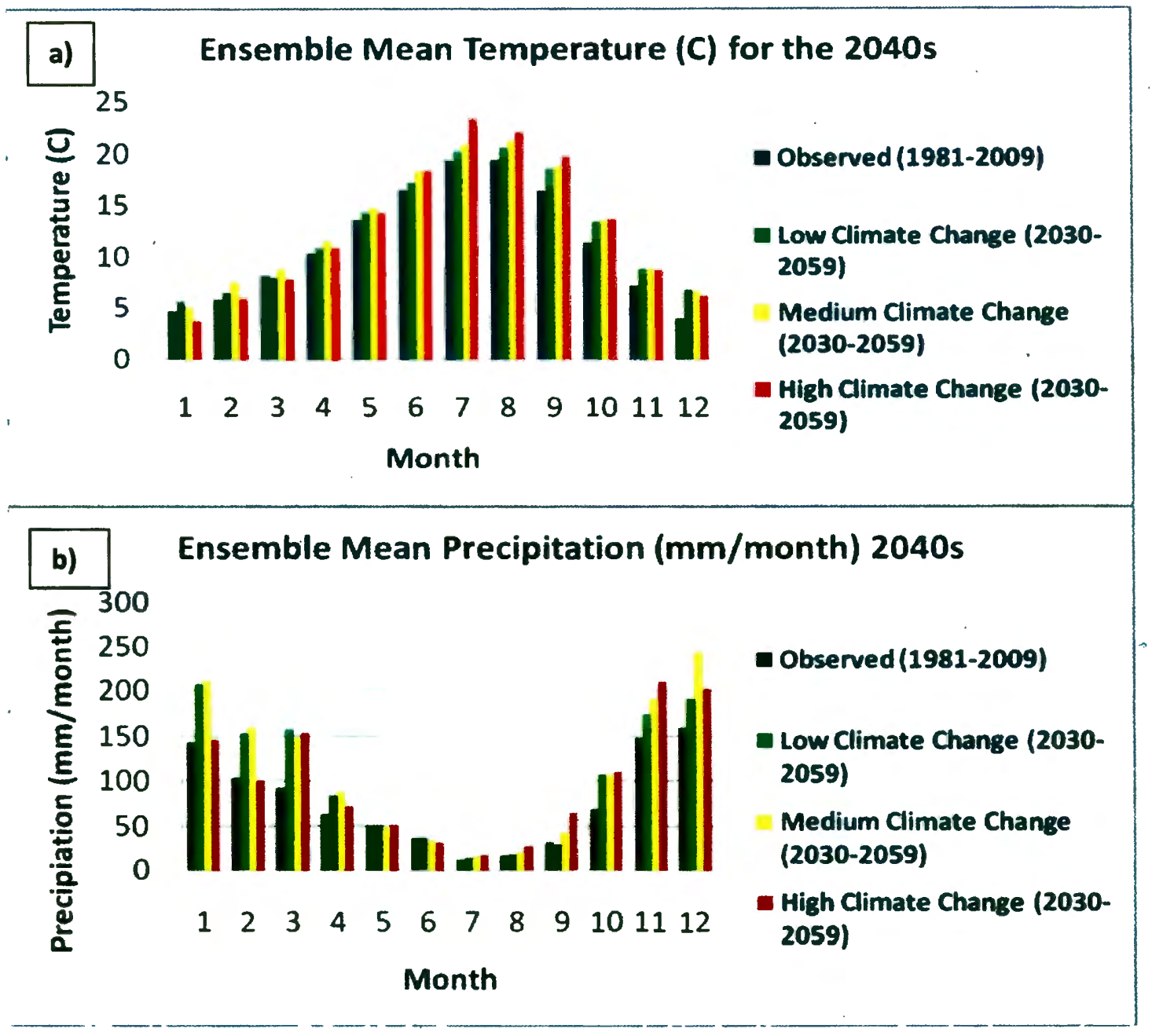

Figure 3.3: Ensemble mean for each month of the year 2040 based on 3 downscaled GCMs (low = PCM, medium $=$ IPSL, high $=$ HadCM) for the period 2030-2059, the historical record (1981-2009) is included for comparison, for a) temperature $(C)$ and $b$ ) precipitation ( $\mathrm{mm} / \mathrm{month}$ )

To examine the effect of land cover change and climate change scenarios on rates of evaporation and nighttime cooling, I delineated nine urban residential neighborhoods throughout the City of Hillsboro based on household level external 
water consumption (Figure 3.4). Following Gober et al. (2010), I assume that the LUMPS modeled evaporation is a proxy for external water consumption, thus these terms will used interchangeably throughout this paper. Gober et al. (2010) compared the responses of the surface energy balance in ten urban census tracts in Phoenix to urban development scenarios, but the study areas were chosen based on land cover characteristics, defined as mesic residential, xeric residential, and industrial. In this study, household level water consumption was chosen as the method of neighborhood selection due to water managers' concerns regarding future peak water demand, the availability of fine-scale water consumption data geo-coded to each household, and knowledge that a perfect correlation does not exist between high external water consumption and heavily vegetated neighborhoods. The nine neighborhoods selected for this study are divided into three categories of summertime external water consumption, high, average, and low, and are characterized by different socioeconomic indicators (Table 3.1), such as average property value, average lot size, and average year the house was built, and varying proportions of vegetation and impervious surface cover. To determine external water use from the aggregate water consumption data provided by the City of Hillsboro, I divided total water use into its two components, base use and seasonal use (Maidment et al. 1985; Zhou et al. 2000; Syme et al. 2004; Gato et al. 2007; House-Peters et al. 2010). This method assumes indoor water use to be equal to the base use, defined as winter use (November + December + January + February water use) $/ 4$ ), and external water use to be equal to 
the seasonal use, defined as [((July + August + September + October water use $) / 4)-$ base use]. Finally, it is important to note that the extent of the neighborhood size was limited by the assumption inherent in the LUMPS model that the surface energy balance is calculated for a local area with no side length longer than 10 kilometers.

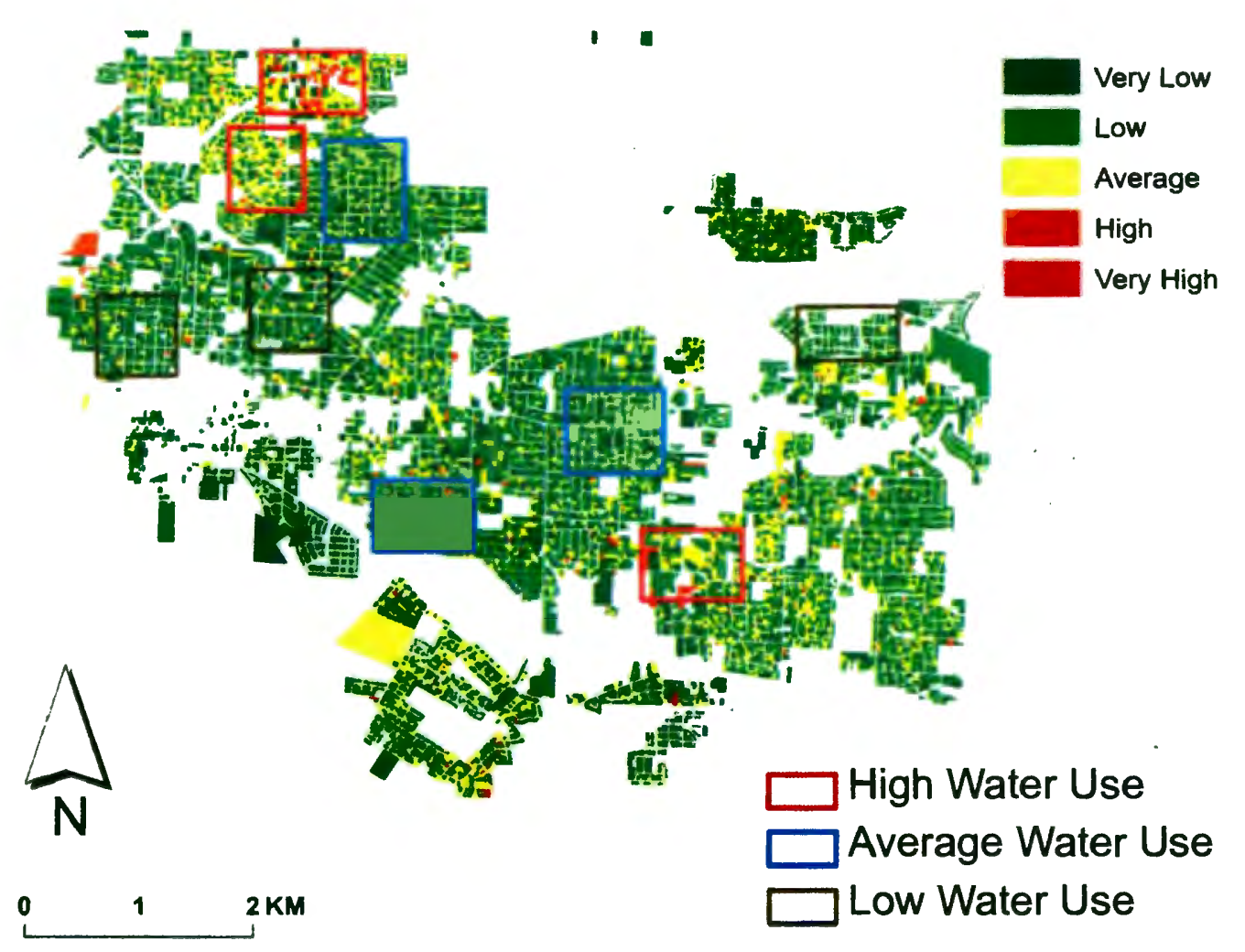

Figure 3.4: Map of the City of Hillsboro water service provider area, depicting the household-level summertime external water consumption for August 2007 and the location of the nine study area neighborhoods, as rectangular boxes 


\section{B. Meteorological Data}

The LUMPS model requires meteorological data and solar radiation data for each neighborhood at hourly time scales over the duration of a month. I obtained hourly-scale meteorological data (mean air temperature, precipitation, mean relative humidity, mean wind speed, mean wind direction, and station air pressure) for all nine study areas from the City of Hillsboro airport for August and September 2007 (NOAA National Climate Data Center 2010). I obtained hourly-scale measured direct incoming solar radiation data for August and September 2007 from the City of Hillsboro solar radiation observation station monitored by the University of Oregon (Solar Radiation Monitoring Laboratory 2010).

\section{Land Cover Analysis}

The LUMPS model requires land cover information for six aggregate land cover classes: buildings, impervious, bare soil, trees and shrubs, grass, and water. To determine the land cover fractions for each neighborhood, a GeoEye-1 satellite image of the Portland metropolitan area with a spatial resolution of 2.5 meters was acquired on August 19, 2009. The spectral range of the imagery includes panchromatic, blue, green, red, and near infrared bands. In urban areas, due to the complexity of the land cover and the tendency for spectral mixing, traditional pixel-based classification methods are insufficient to recognize and isolate fine-scale land cover patterns (Myint 
2009). To classify the land cover in the nine neighborhoods, I utilized Definiens Developer 8, an object-based classification software that employs segmentation algorithms to create homogenous image objects that can be classified using either nearest neighbor or expert-rule methods (Benz et al. 2004).

I employed a similar classification scheme to the one developed by Myint (2009) to derive the six classes of land cover data for central Phoenix, Arizona, for input in a previous LUMPS modeling study (Gober et al. 2010). I utilized the normalized vegetation index (NDVI), the principal components analysis (PCA) and the four spectral bands of the imagery. The land cover characteristics in western Oregon differ significantly from those in central Arizona. Residential neighborhoods in Hillsboro tend to have abundant vegetation, especially trees, which cause classification to be more difficult, because trees cast shadows, producing dark areas on the image that have no spectral data. To overcome the challenge of shadows and to improve the accuracy of discriminating between features with similar spectral responses, but significantly different height characteristics, such as building roofs and sidewalks, I incorporated Light Detection and Ranging (LiDAR) data into the classification methodology. LiDAR data captures both bare earth and highest hits surface elevations and was obtained from the Oregon LiDAR Consortium (DOGAMI 2009). Using ArcGIS version 9.3 (ESRI 2009), I subtracted the bare earth elevation raster from the highest hits elevation raster producing a surface feature height layer, which represents the elevations of urban structures and natural features, such as houses 
and trees. The surface feature height layer was added to the other image information in Definien's Developer, creating a height layer. Both nearest neighbor and expert rule methods were used to derive the six land cover classes. ArcGIS was employed to calculate the fractions of each land cover type within the extent of each pre-defined neighborhood. To classify shadow, I developed a rule based on the height layer, which classified shadows with a height above five feet as buildings and shadows with a height below five feet as grass. This rule was developed after extensive visual analysis of the image, which showed that most shadowed areas were either grass or building roofs, though misclassification of shadowed tree crowns and sidewalks did occur. Thus this method tends to underestimate tree canopy and impervious cover when using images with extensive areas of shadow. Table 3.2 presents the results from the land cover classification for each neighborhood. Once the land cover was classified, the neighborhoods were assigned to two groups, mesic or xeric, depending on the proportion of vegetation and impervious surfaces present (Figure 3.5). Mesic neighborhoods were defined as having more than 50 percent vegetation cover, calculated as the sum of the two classes, grass and trees. Xeric neighborhoods were defined as having more than 50 percent impervious land cover, calculated as the sum of the two classes, impervious and buildings. 
Table 3.2: Baseline land cover characteristics in the nine neighborhoods

\begin{tabular}{|l|r|l|r|r|r|r|r|}
\hline Neighborhood & $\begin{array}{l}\text { Building } \\
(\%)\end{array}$ & $\begin{array}{l}\text { Grass } \\
(\%)\end{array}$ & $\begin{array}{l}\text { Impervious } \\
(\%)\end{array}$ & $\begin{array}{l}\text { Soil } \\
(\%)\end{array}$ & $\begin{array}{l}\text { Trees } \\
(\%)\end{array}$ & $\begin{array}{l}\text { Water } \\
(\%)\end{array}$ & Category \\
\hline High 1 (\%) & 12.36 & 19.50 & 20.40 & 3.72 & 42.64 & 1.38 & Mesic \\
\hline High2 (\%) & 23.69 & 29.54 & 28.70 & 1.38 & 16.62 & 0.08 & Xeric \\
\hline High 3 (\%) & 10.89 & 17.75 & 12.93 & 7.04 & 51.04 & 0.09 & Mesic \\
\hline Average 1 (\%) & 22.66 & 21.38 & 26.19 & 4.45 & 25.31 & 0.01 & Mesic \\
\hline Average 2 (\%) & 23.18 & 19.60 & 28.05 & 7.11 & 22.00 & 0.05 & Xeric \\
\hline Average 3 (\%) & 23.46 & 14.76 & 27.02 & 5.00 & 29.75 & 0.02 & Xeric \\
\hline Low 1 (\%) & 23.47 & 6.59 & 41.55 & 4.24 & 24.15 & 0.00 & Xeric \\
\hline Low 2 (\%) & 35.39 & 16.60 & 26.77 & 6.89 & 14.31 & 0.04 & Xeric \\
\hline Low 3 (\%) & 26.01 & 19.80 & 25.96 & 8.00 & 20.05 & 0.15 & Xeric \\
\hline
\end{tabular}

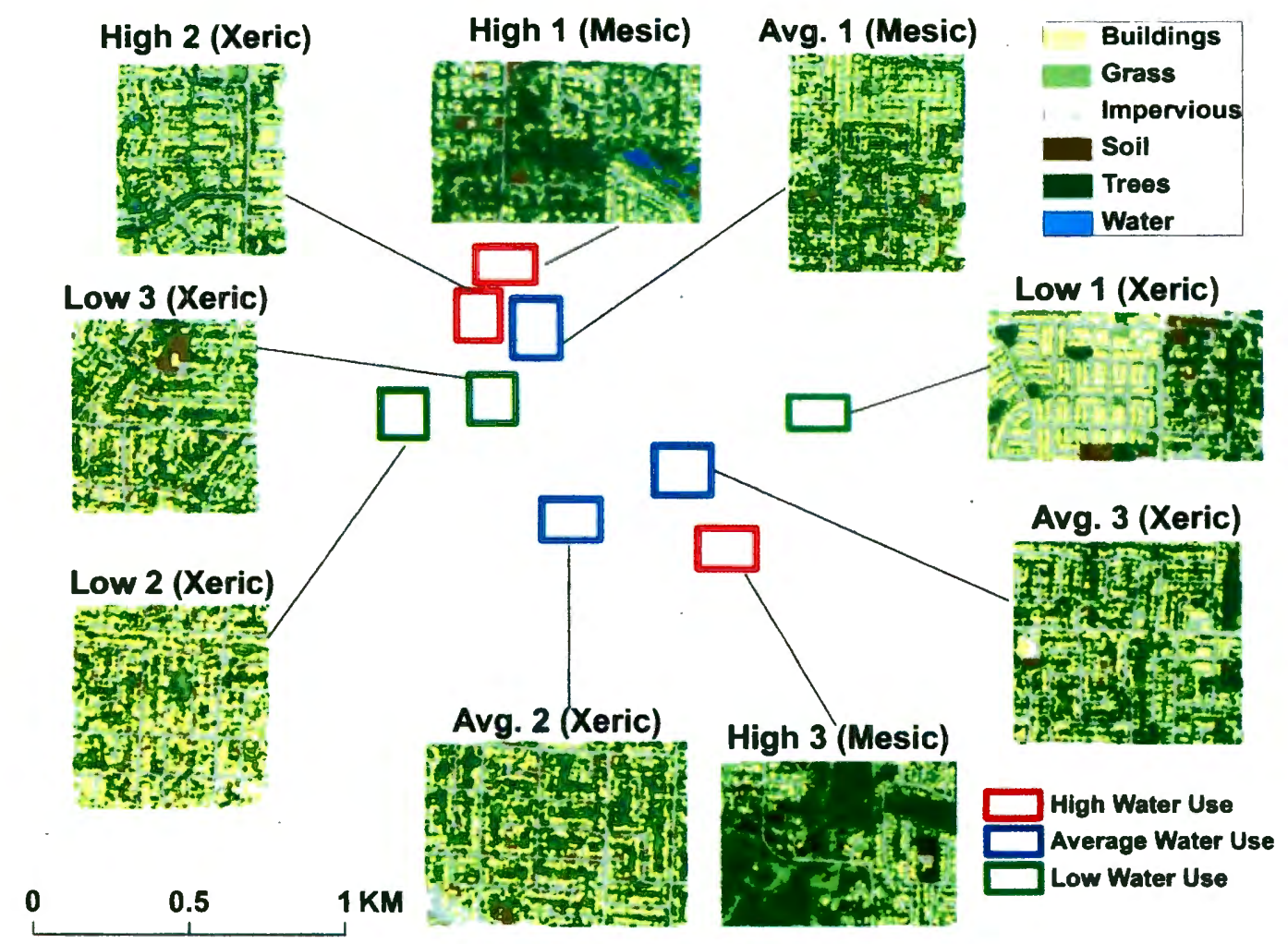

Figure 3.5: Object-based classification results for the nine Hillsboro neighborhoods 


\section{Climate Change Scenarios}

To model the impacts of climate change on evaporation and nighttime cooling, I obtained statistically downscaled data from three Global Climate Models (GCM), UKMO-HadCM3 (Gordon et al. 2000), IPSL-CM4 (Marti et al. 2005), and PCM (Washington et al. 2000), under the AlB emission scenario. The GCM are derived from scenarios performed for the International Panel on Climate Change (IPCC) Fourth Assessment Report and were statistically downscaled for the City of Hillsboro by the Climate Impacts Group at University of Washington using bias correction and spatial downscaling (Salathé et al. 2007). The original resolution of the global models is between 100-300 kilometers, but to capture local topography to assess more accurate local-scale climate impacts, a spatial resolution of 15 kilometers is needed. The statistical downscaling method (described in detail in Wood et al. 2002) first biascorrects the data based on quantile maps of the monthly statistical distribution of temperature and precipitation for the observed period 1950-1999, and then uses the 'dynamical scaling' method (Widmann et al. 2003) to downscale the precipitation data and the Salathé (2005) method to downscale the temperature data.

An additional challenge of incorporating the GCM data into the LUMPS model to simulate the surface energy balance under climate change scenarios was the temporal step of the data. The GCM data contains daily observations however the LUMPS model requires hourly-scale measurements. Because there is high uncertainty 
in projecting future precipitation and wind speed at a fine, hourly temporal resolution, I used only the temperature data for the climate change scenarios. Thus, all other meteorological variables were based on observed data for August 2007 and the results from the climate change simulations represent only GCM modeled change in temperature.

Temporal downscaling of climate data is a complex process, especially in areas of varied topography, such as Western, Oregon. To simplify the process, I calculated the ensemble mean temperature for each day of August for the period 2030-2059, to represent the climate of the 2040s, and for each day of August for the period 19802009 , to represent the baseline observed climate. I calculated the difference in temperature for each day in the 2040s compared to the observed baseline and then applied the daily temperature change value, derived in the previous step, to the hourly recorded temperature for the month of August, 2007 (Table 3.3). For example, if the temperature change between the baseline period and the 2040 s was a $1.4^{\circ} \mathrm{C}$ increase on August 1, 1.4 degrees would be added to each hour of the August 1, 2007 data. Due to limited data availability, only one set of meteorological data was used for the study area. I applied the same temporally downscaled future temperature data to all nine neighborhoods in the study area. The average annual change in temperature for April through September in the 2040s under the low scenario (PCM) is $+0.8^{\circ} \mathrm{C}$, under the medium scenario (IPSL) is $+1.8^{\circ} \mathrm{C}$, and under the high scenario (HadCM) is 3.0 ${ }^{\circ} \mathrm{C}$. The processes of spatially and temporally downscaling the climate data introduces 
uncertainty into the analysis, but is reasonable for analysis comparing outcomes based on multiple future scenarios rather than forecasting accurate point predictions for the future period.

Table 3.3: Ensemble mean temperature data for input in the LUMPS model

\begin{tabular}{|l|l|l|l|l|l|l|l|l|l|l|l|l|}
\hline & \multicolumn{10}{|c|}{ Ensemble Mean Temperature (degrees Celsuis) by Month } \\
\hline & J. & F. & M. & A. & M. & J. & J. & A. & S. & O. & N. & D. \\
\hline $\begin{array}{l}\text { Refer- } \\
\text { ence } \\
\text { Period } \\
(1981- \\
\text { 2009) }\end{array}$ & 4.6 & 5.8 & 8.1 & 10.3 & 13.6 & 16.5 & 19.4 & 19.4 & 16.5 & 11.4 & 7.2 & 4.0 \\
\hline $\begin{array}{l}\text { PCM } \\
\text { (low } \\
\text { climate } \\
\text { change) } \\
\text { (2030- } \\
\text { 2059) }\end{array}$ & 5.5 & 6.5 & 8.0 & 10.9 & 14.4 & 17.3 & 20.3 & 20.5 & 18.6 & 13.5 & 8.8 & 6.7 \\
\hline $\begin{array}{l}\text { IPSL } \\
\text { (med. } \\
\text { climate } \\
\text { change) } \\
\text { (2030- } \\
\text { 2059) }\end{array}$ & 5.1 & 7.6 & 8.8 & 11.5 & 14.8 & 18.3 & 20.9 & 21.2 & 18.9 & 13.6 & 8.8 & 6.6 \\
\hline $\begin{array}{l}\text { HadCM } \\
\text { (high } \\
\text { climate } \\
\text { change) } \\
\text { (2030- } \\
\text { 2059) }\end{array}$ & 3.8 & 6.0 & 7.9 & 10.9 & 14.4 & 18.5 & 23.4 & 22.1 & 19.9 & 13.8 & 8.8 & 6.3 \\
\hline
\end{tabular}

\section{E. Land Cover Change Scenarios}

The effect of land cover change on neighborhood-scale evaporation and nighttime cooling is examined for two future scenarios, urban sprawl and urban densification. The two scenarios are based on spatially-explicit alternative land cover 
scenarios created by the Pacific Northwest Ecosystem Research Consortium (PNWERC) for regional analysis of the entire Willamette River Basin in the year 2050 (Baker et al. 2004; Hulse et al. 2004). The scenarios are value-based assumptions about future policy, urban development and the spatial distribution of land use that occurs both within the urban growth boundaries and in the rural, agricultural and forest lands. The scenarios are the result of thirty months of lay and expert stakeholder input and although each scenario is based on different policy and human behavior assumptions, plausibility was a fundamental criterion of the scenario design. These scenarios have been used for climate change impact assessment on surface water hydrology in an adjacent geographic area (Franczyk and Chang 2009) and the Tualitan River basin, which includes this study area (Praskievicz and Chang 2010).

The urban sprawl scenario used in this analysis is based on the PNW-ERC Development 2050 scenario, which assumes a loosening of current land use laws and greater reliance on market-oriented approaches for land and water use decisions, which prioritizes short-term economic gain over long-term ecological function. Under this scenario, future urban growth would spill beyond the UGB characterized by residential densities of approximately 6.2 homes per acre. In contrast, the urban densification scenario used in this analysis is based on the PNW-ERC Conservation 2050 scenario, which prioritizes the maintenance of ecosystem services and limits future growth to the extent of the UGB, thus protecting rural, agricultural, and forest 
lands. To contain future growth within the UGB, residential density is increased to 9.3 homes per acre.

Data processing was necessary to utilize these regional-scale land cover scenarios at the neighborhood-scale. An important limitation of this dataset is the large spatial scale for which it was created, in order to represent the entire Willamette river basin. The 30 meter spatial resolution of each raster cell provides data that is too coarse to be appropriate for use at the small, neighborhood-scale. To overcome this limitation, I used ArcGIS to clip the three available river basin scale land cover scenarios, the Development 2050, Conservation 2050 and a base-line, status-quo scenario, Plan Trend 2050, to the extent of the Hillsboro city boundary (Figure 3.6). To determine the land cover fractions of each neighborhood under each of the future urban development scenarios, I first calculated the land cover fractions in the six target land cover categories (soil, water, grass, trees, buildings, and impervious) of each of the three PNW-ERC scenarios once they were clipped to the Hillsboro city boundaries. I then compared the urban sprawl and urban densification scenarios to the status-quo scenario (ex. (\% grass in urban sprawl scenario - \% grass in status quo scenario) and (\% grass in urban densification scenario - \% grass in status quo scenario)) to determine the percent of change in the six land cover classes. To utilize the land cover scenarios for the nine neighborhoods, I applied the same fraction of change observed for the city-scale to each of the nine neighborhoods. Thus, the percentage of change applied to each neighborhood was the same, but the baseline 
land cover condition (derived from the satellite image classification and analysis) for each neighborhood was different. Under the urban sprawl scenario, the land cover change calculated at the city-scale is a $3 \%$ decrease in building fraction, a $1 \%$ decrease in impervious cover, a $2 \%$ increase in grass cover, and a $2 \%$ increase in tree canopy. Alternately, under the urban densification scenario, the land cover change is a $3 \%$ increase in building fraction, a $1 \%$ increase in impervious cover, a $2 \%$ decrease in grass, and a $2 \%$ decrease in tree canopy (Table 3.4 ).

\section{F. LUMPS Model Calibration and Validation}

I calibrated the LUMPS model individually for each of the nine neighborhoods for the month of August 2007 and validated the model with data from September, 2007. To validate the model, I aggregated the geo-coded household-level external water consumption data to one average value for each neighborhood for the entire month of September, 2007. The latent heat flux ( $\left.\mathrm{Q}_{\mathrm{E}}\right)$ output of the LUMPS model can be used to calculate the amount of evaporation that occurs in the neighborhood over the course of the month. Following the method used in Gober et al. (2010), I assume that this evaporation measure is directly comparable to external water consumption, thus the model performance can be validated by graphing the modeled evaporation against the observed external water consumption (Figure 3.7). 

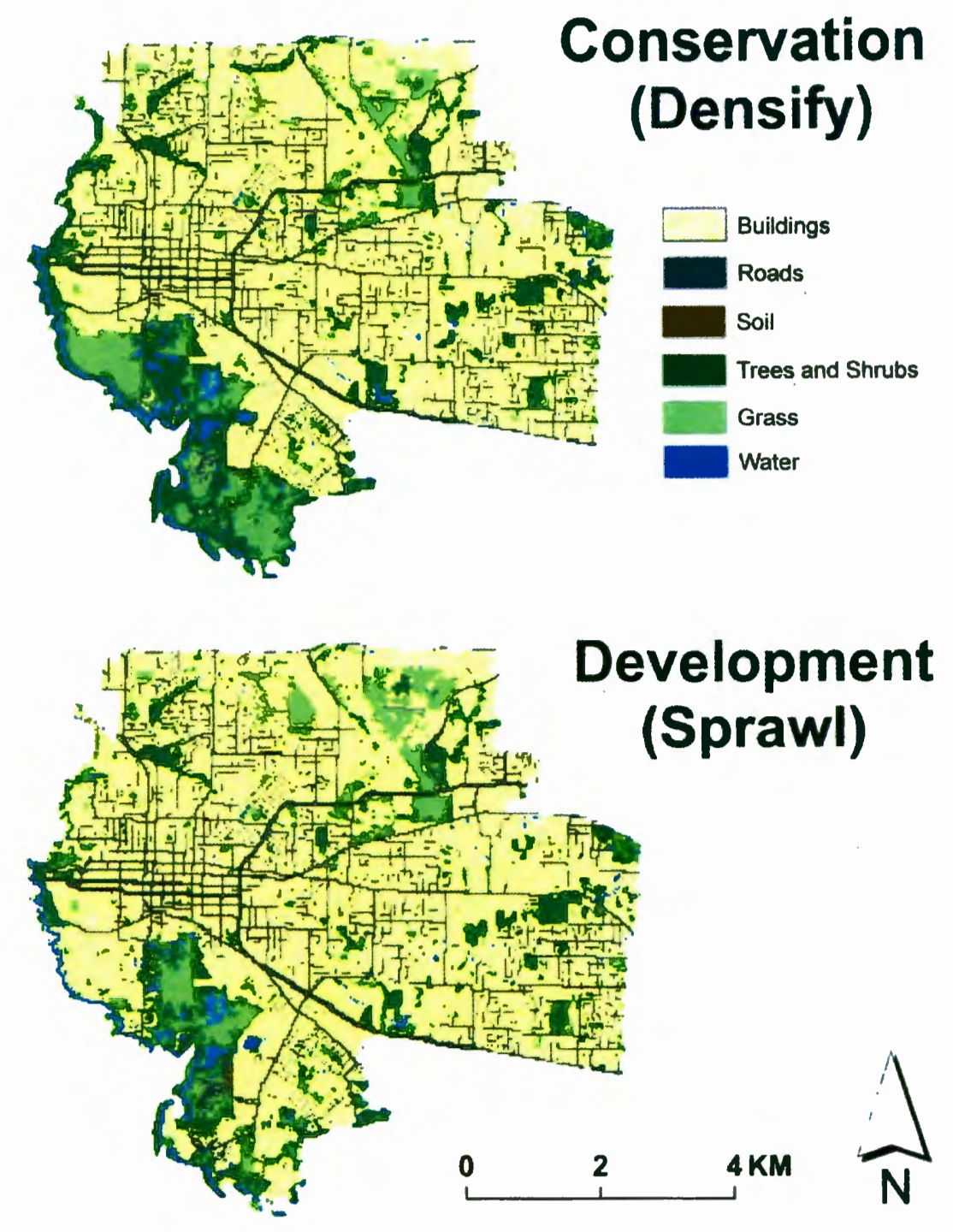

Figure 3.6: Land-use change scenarios for the 2040s for the City of Hillsboro (adapted from Hulse et al. 2004) 
Table 3.4 Land cover fractions for each neighborhood under the two land cover change scenarios, sprawl (sp) and densification (de)

\begin{tabular}{|c|c|c|c|c|c|c|c|c|}
\hline $\begin{array}{l}\text { Neighbor- } \\
\text { hood }\end{array}$ & $\begin{array}{c}\text { Building } \\
\text { (fraction) }\end{array}$ & $\begin{array}{l}\text { Imper- } \\
\text { vious } \\
\text { (fraction) }\end{array}$ & $\begin{array}{l}\text { Soil } \\
\text { (frac- } \\
\text { tion) }\end{array}$ & $\begin{array}{l}\text { Trees } \\
\text { (frac- } \\
\text { tion) }\end{array}$ & $\begin{array}{l}\text { Grass } \\
\text { (frac- } \\
\text { tion) }\end{array}$ & $\begin{array}{c}\text { Water } \\
\text { (frac- } \\
\text { tion) }\end{array}$ & $\begin{array}{l}\text { Total } \\
\text { Vege- } \\
\text { tated } \\
\text { Fraction }\end{array}$ & $\begin{array}{c}\text { Total } \\
\text { Imper- } \\
\text { vious } \\
\text { Fraction }\end{array}$ \\
\hline low1 (sp) & 0.205 & 0.406 & 0.042 & 0.261 & 0.086 & 0.000 & 0.347 & 0.610 \\
\hline low1 (de) & 0.265 & 0.426 & 0.042 & 0.221 & 0.046 & 0.000 & 0.267 & 0.690 \\
\hline low 2 (sp) & 0.325 & 0.259 & 0.069 & 0.164 & 0.186 & 0.0004 & 0.350 & 0.584 \\
\hline low 2 (de) & 0.385 & 0.279 & 0.069 & 0.124 & 0.146 & 0.0004 & 0.270 & 0.664 \\
\hline low 3 (sp) & $0.230^{\circ}$ & 0.250 & 0.080 & 0.221 & 0.218 & 0.002 & 0.439 & 0.480 \\
\hline low 3 (de) & 0.290 & 0.270 & 0.080 & 0.181 & 0.178 & 0.002 & 0.359 & 0.560 \\
\hline avg 1 (sp) & 0.197 & 0.252 & 0.044 & 0.273 & 0.234 & 0.00007 & 0.507 & 0.449 \\
\hline avg 1 (de) & 0.257 & 0.272 & 0.044 & 0.233 & 0.194 & 0.00007 & 0.427 & 0.529 \\
\hline avg $2(s p)$ & 0.202 & 0.271 & 0.071 & 0.240 & 0.216 & 0.0005 & 0.456 & 0.473 \\
\hline $\operatorname{avg} 2$ (de) & 0.262 & 0.291 & 0.071 & 0.200 & 0.176 & 0.0005 & 0.376 & 0.553 \\
\hline $\operatorname{avg} 3(s p)$ & 0.205 & 0.261 & 0.050 & 0.318 & 0.168 & 0.0002 & 0.486 & 0.466 \\
\hline avg 3 (de) & 0.265 & 0.281 & 0.050 & 0.278 & 0.128 & 0.0002 & 0.406 & 0.546 \\
\hline high 1 (sp) & 0.094 & 0.194 & 0.037 & 0.446 & 0.215 & 0.014 & 0.661 & 0.288 \\
\hline high 1 (de) & 0.154 & 0.214 & 0.037 & 0.406 & 0.175 & 0.014 . & 0.581 & 0.368 \\
\hline high 2 (sp) & 0.207 & 0.277 & 0.014 & 0.186 & 0.315 & 0.001 & 0.502 & 0.484 \\
\hline high 2 (de) & 0.267 & 0.297 & 0.014 & 0.146 & 0.275 & 0.001 & 0.422 & 0.564 \\
\hline high 3 (sp) & 0.079 & 0.119 & 0.070 & 0.530 & 0.198 & 0.0009 & 0.728 & 0.198 \\
\hline high 3 (de) & 0.139 & 0.139 & 0.070 & 0.490 & 0.158 & 0.0009 & 0.648 & 0.278 \\
\hline
\end{tabular}




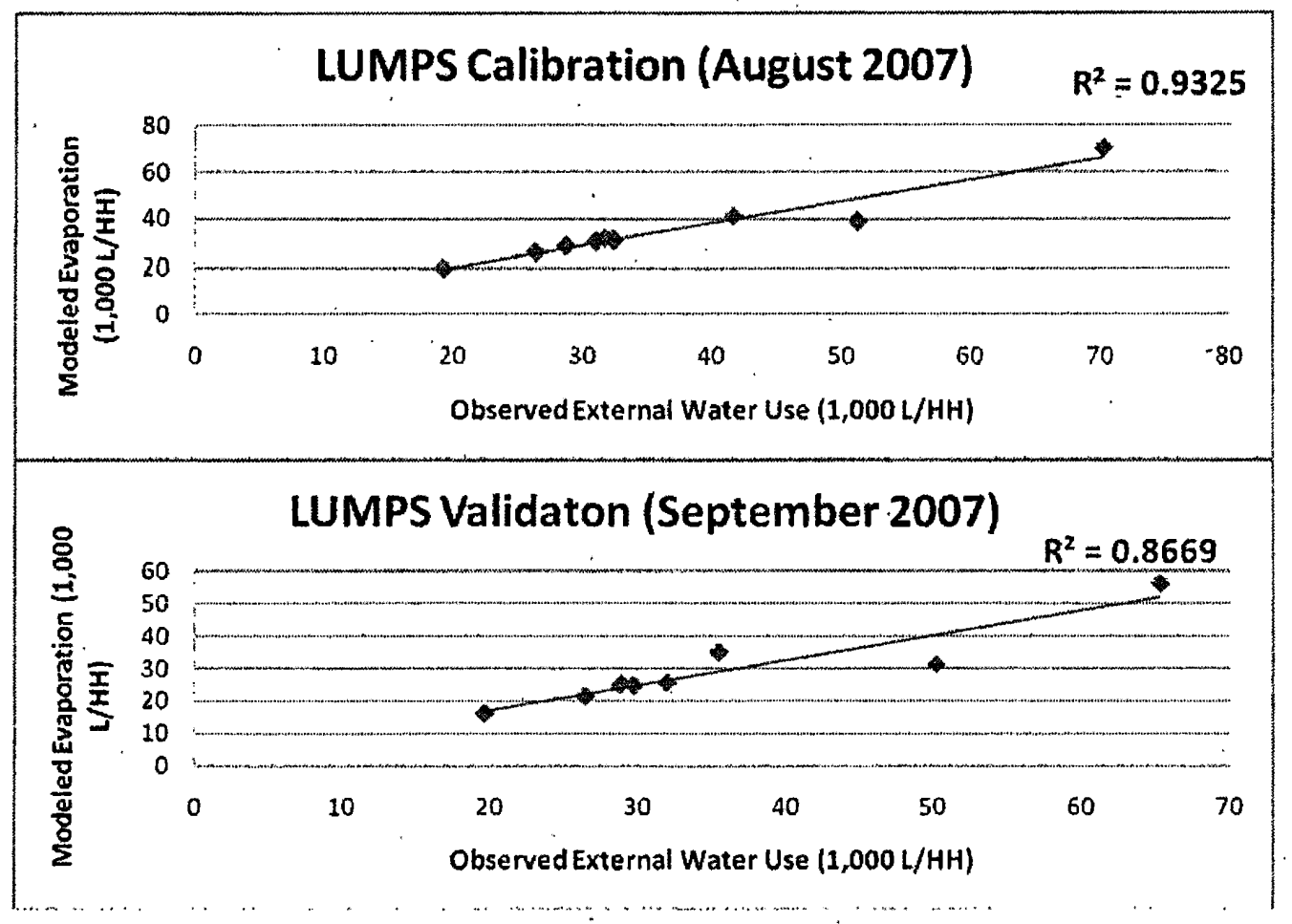

Figure 3.7: Calibration of the LUMPS model based on August 2007 data and validation based on September 2007 performance using the calibrated parameters

The LUMPS model has several parameters that can be adjusted to better represent the actual conditions in the study area. To calibrate the model, I adjusted the irrigated fraction for the land cover classes, grass, trees and impervious, for each neighborhood (Table 3.5). During the month of August, the study area experiences very little natural precipitation and evapotranspiration rates are high. Irrigated grass cover is set at 100 percent and is the one parameter that is held constant across all neighborhoods. This rationale for this parameterization is that the land cover classification is based on an image from mid-August, during the dry season, thus if 
grass is green enough to be classified based on its ndvi value, it is irrigated. The fraction of trees and shrubs and impervious surfaces that are irrigated varies with human behavior and preconceived notions about the amount of water that vegetation needs to survive. The LUMPS model is not able to explicitly incorporate human behavior, especially the common mismatch between the perceived vegetation water demand and actual ecological vegetation water demand. Research has shown a strong tendency for people to overestimate the amount of water needed to maintain residential vegetation during the summer (Fox et al. 2005), often causing the extra water to flow onto the sidewalk or street. Thus, to calibrate the LUMPS model for neighborhoods with high water consumption, but low vegetation fractions, I increased the percentage irrigated for the classes "trees and shrubs" and "impervious surfaces". This method also accounts for external water use activities that do not directly replace water lost through evaporation, such as car washing, hosing down sidewalks, and using the sprinklers for recreation purposes. 
Table 3.5: Irrigated land cover fraction parameters calibrated for each neighborhood for the month of August, 2007

\begin{tabular}{|c|c|c|c|c|}
\hline & \multicolumn{4}{|c|}{ Calibration Parameters } \\
\hline Neighborhood. & $\begin{array}{c}\text { Grass } \\
\text { (fraction } \\
\text { irrigated) }\end{array}$ & $\begin{array}{c}\text { Tree } \\
\text { (fraction } \\
\text { irrigated) }\end{array}$ & $\begin{array}{c}\text { Impervious } \\
\text { (fraction } \\
\text { irrigated) }\end{array}$ & $\begin{array}{l}\text { Irrigated (total } \\
\text { fraction) }\end{array}$ \\
\hline Low 1 & 1 & 0.5 & 0.7 & 0.48 \\
\hline Low 2 & 1 & 0.8 & 0.7 & 0.47 \\
\hline Low 3 & 1 & 0.2 & 0.2 & 0.29 \\
\hline Average 1 & 1 & 0.8 & 1) & 0.68 \\
\hline Average 2 & 1 & 0.5 & 0.6 & 0.48 \\
\hline Average 3 & 1 & 0.7 & 0.8 & 0.57 \\
\hline High 1 & 1 & 0.3 & 0.8 & 0.49 \\
\hline High 2 . & 1 & 0.3 & 0.8 & 0.57 \\
\hline High 3 & & 0.1 & 0.1 & $\overline{0.2}$ \\
\hline
\end{tabular}

\section{G. Data Analysis}

To derive evaporation (a proxy for external water consumption) and the nighttime cooling measurements, I employed the method developed by Gober et al. (2010). I used the modeled latent heat flux values to estimate monthly evaporation and used the modeled sensible heat flux for the hours $10 \mathrm{pm}$ to $2 \mathrm{am}$ to calculate the nighttime cooling rate. I calculated in the absolute change in evaporation and 
nighttime cooling for each neighborhood between the individual and combined land use and climate change scenarios and the current baseline. The LUMPS model was run a total of 12 times per neighborhood. I created a scatter plot to determine if any relationship exists between evaporation and nighttime cooling and how the relationship responds to changes in land cover and temperature. Finally, to address a gap in the literature and elucidate the influence of vegetation type (ie. grass or trees) on neighborhood-level water consumption and nighttime cooling, I graphed the fraction grass cover and the fraction tree canopy and shrubs in each neighborhood against the modeled external water consumption and nighttime cooling for each land cover scenario.

\section{Results and Discussion}

\section{A. Nine Neighborhood Average Response}

A number of patterns and general trends emerged when I analyzed the average absolute changes in evaporation (Figure 3.8a) and nighttime cooling (Figure 3.8b) from the baseline across all nine neighborhoods in response to the land cover and climate change scenarios. Under the temperature increase scenarios, external water consumption increased to meet increasing evaporation rates and nighttime cooling decreased due to increased available heat energy. The sprawl land use scenario resulted in an increase of 1,265 liters of external water use per household for the month of August to maintain increased amounts of vegetation due to the larger 
residential lot sizes. However, the increase in water consumption under the sprawl scenario created a positive tradeoff balanced by increased nighttime cooling of nearly a half degree Celsius over the course of the night. In contrast, the densification scenario, characterized by reduced residential vegetation and lot sizes, results in a decrease in external water consumption a reduction in nighttime cooling. The reduction in nighttime cooling is a result of limiting the amount of water available for evaporation, causing available energy to be partitioned into sensible rather than latent heat flux, raising the air temperature. Under the combined land cover and climate change scenarios, the combination of the sprawl scenario with the temperature increase exacerbates the increase in external water consumption, producing significant additional demand for water to maintain mesic landscapes in a future climate characterized by increased evaporative demand. Dense development concomitant with climate change constrains increases in water consumption, but exacerbates nighttime UHI intensity, reducing nighttime cooling rates by more than $1{ }^{\circ} \mathrm{C}$ under HadCM, the most exaggerated climate scenario. 


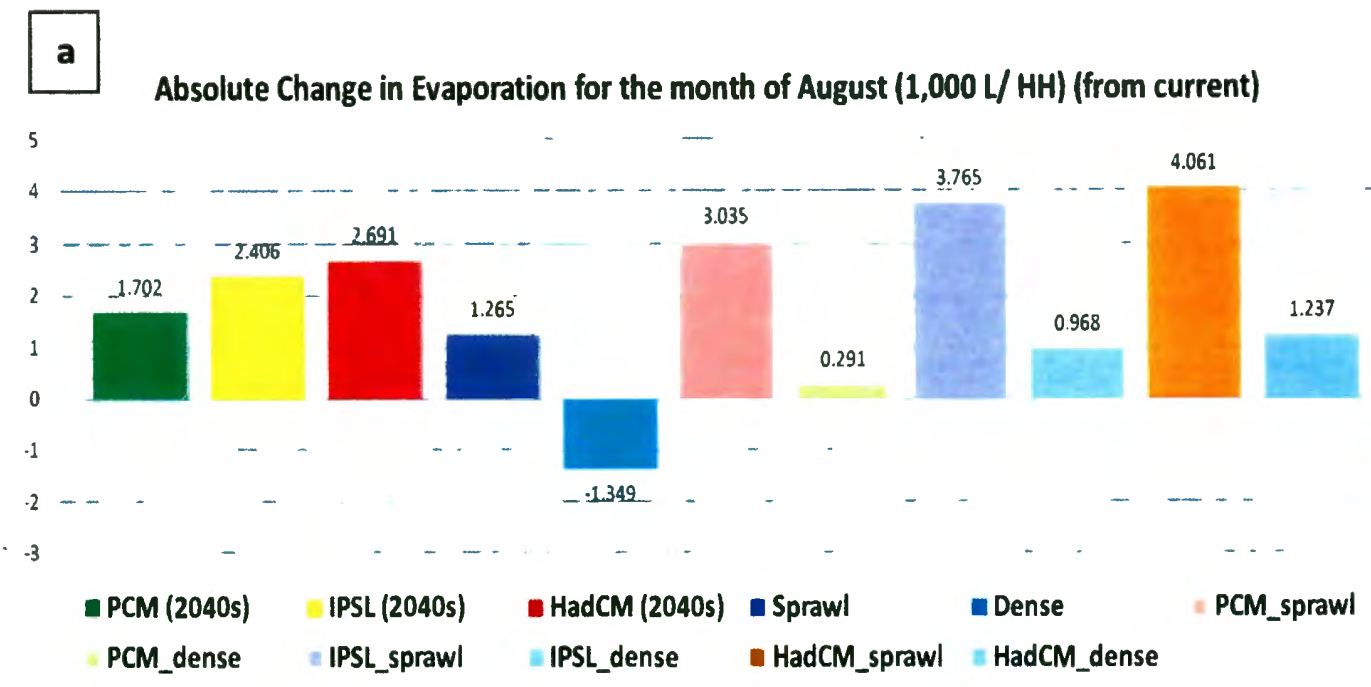

b Absolute Change in Cooling Rate for the month of August (from current) $\left({ }^{\circ} \mathrm{C} / \mathrm{hr}\right.$ )

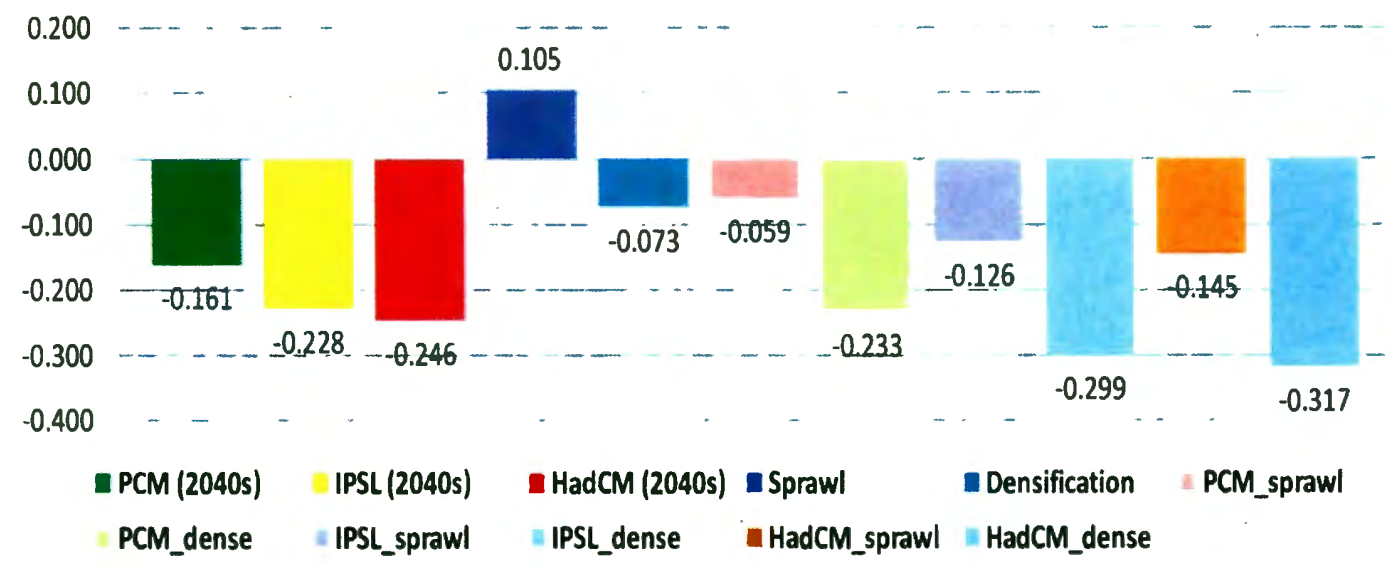

Figure 3.8: Nine neighborhood average response to scenarios; a) Average absolute change in evaporation $(1,000 \mathrm{~L} /$ household) from the baseline across all nine neighborhoods in response to each of the future scenarios; b) Average absolute change in nighttime cooling rate $\left({ }^{\circ} \mathrm{C} /\right.$ hour $)$ from the baseline across all nine neighborhoods in response to each of the future scenarios. 


\section{B. Land Cover Category Response to Scenarios}

Analysis of the neighborhood responses by land cover category group, mesic or xeric, suggests that neighborhoods with varying land cover patterns have distinct responses to climate change and land cover change scenarios in terms of evaporation (Figure 3.9a) and nighttime cooling (Figure 3.9b) rates. Mesic neighborhoods exhibit increased sensitivity to climate change, because they experience an increase in evaporation nearly two times greater than that of xeric neighborhoods yet show a greater absolute decrease in nighttime cooling rate. Thus, mesic neighborhoods may be especially maladapted to future climate change because as temperatures increase, evaporative demand becomes so great that the trade-off between increasing moisture availability in the local boundary climate and nighttime cooling benefits is diminished. It is important to note that these measures are absolute change from the baseline scenario, thus the mesic neighborhoods will probably still be cooler than the xeric neighborhood, it is just that the absolute change is greater. 


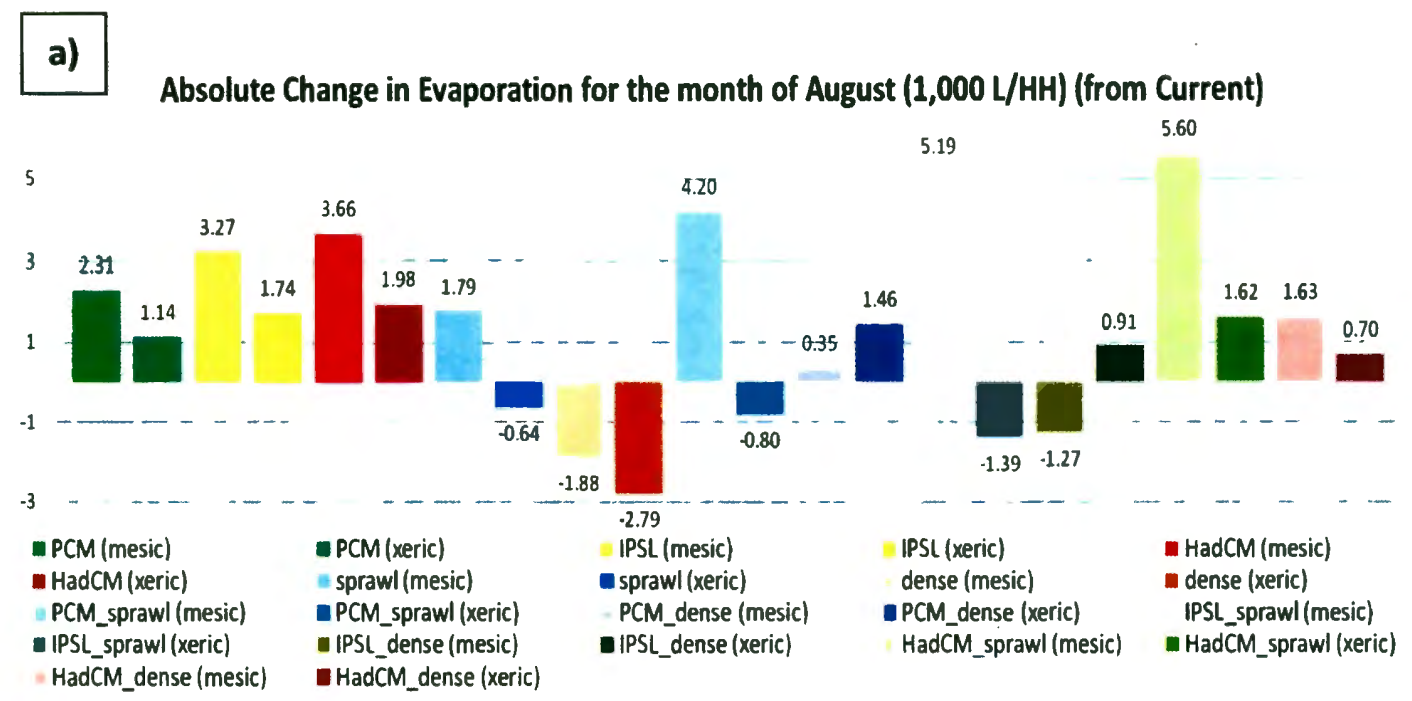

\section{b)}

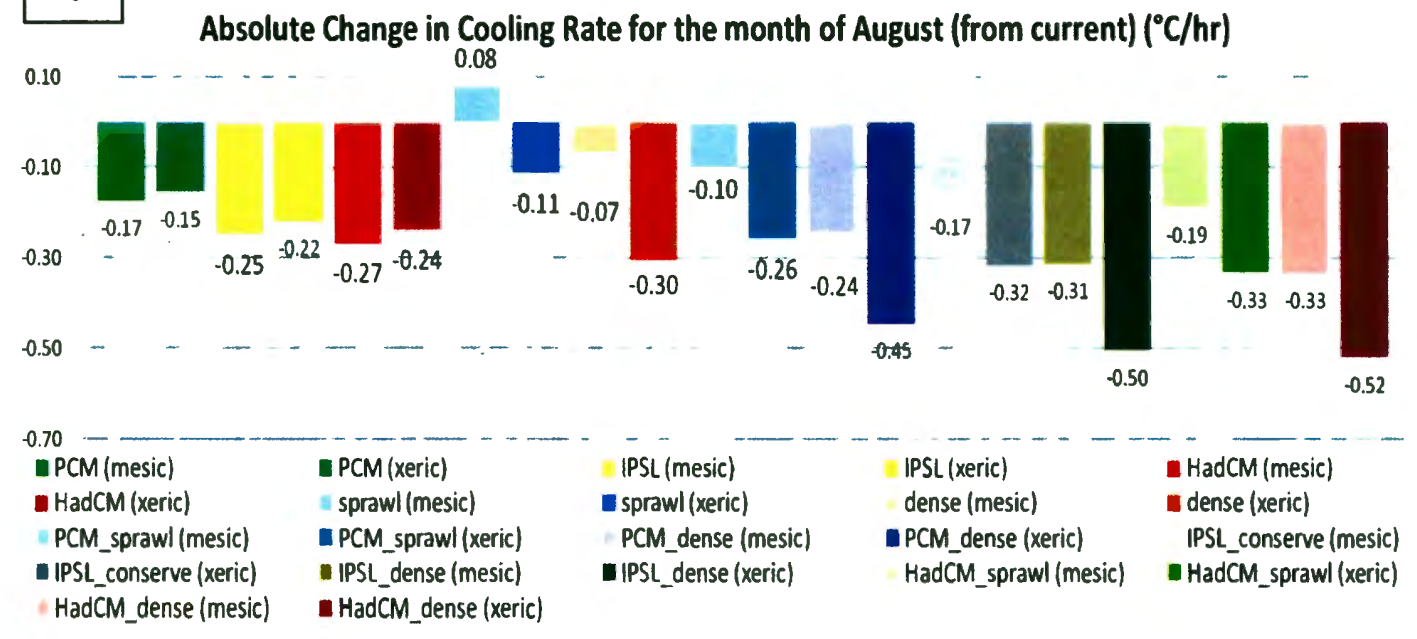

Figure 3.9: Response to scenarios by land cover category (mesic and xeric); a) Average absolute change in evaporation ( $1,000 \mathrm{~L} /$ household) from the baseline in mesic and xeric neighborhoods in response to each of the future scenarios; b) Average absolute change in nighttime cooling rate $\left({ }^{\circ} \mathrm{C} /\right.$ hour $)$ from the baseline in mesic and xeric neighborhoods in response to each of the future scenarios.

Under the sprawl scenario, the mesic and xeric neighborhoods produce divergent response patterns. The mesic neighborhoods exhibit an increase in 
evaporation and an increase in nighttime cooling, similar to the whole study area result in section 5.A, but xeric neighborhoods respond with decreased evaporation and decreased cooling. This conflicting response may be a result of the fact that some neighborhoods that were only slightly xeric or slightly mesic switched categories after the sprawl land cover fractions were applied (Table 3.4). Alternately, it is possible that for some extremely xeric neighborhoods, the relatively conservative increase in vegetation under the sprawl scenario did not significantly affect evaporation due to the continued dominance of built and impervious surfaces which more effectively partition energy into storage and sensible heat fluxes. The densification scenario results in reduced evaporation in both the mesic and xeric neighborhoods, but reduces nighttime cooling most in the xeric neighborhoods, suggesting that future dense development in already xeric neighborhoods will produce an increasingly uncomfortable environment for residents (Gober et al. 2010).

The combination of land cover and climate change scenarios produce unexpected results. First, in xeric neighborhoods, increases in temperature and increases in density produce results that are more discouraging than originally hypothesized. For example, the future scenario that combines PCM temperature change and increased urban density, results in an increase of over 1,000 liters of water per household per month and a decrease in nighttime cooling of almost $2{ }^{\circ} \mathrm{C}$ from $10 \mathrm{pm}$ to $2 \mathrm{am}$. This magnitude of increase in the UHI intensity in the Portland metropolitan area is further aggravated by the fact that many homes do not have 
central air conditioning, increasing the vulnerability of sensitive populations to heatrelated health impacts. The second surprise is that the temperature increase under the HadCM climate scenario results in an increase in water consumption under both land cover scenarios in both mesic and xeric neighborhoods. This finding does not hold true in either the PCM or IPSL climate scenarios, indicating that a temperature-related tipping point exists. Once this threshold is crossed, it seems that no matter which type of land use planning is developed, water demand will increase and nighttime cooling rates will decrease, further degrading urban sustainability. This surprising result may also be the result the approach used to temporally downscale the climate data. The temporal downscaling of the climate data was achieved by adding the same amount of temperature increase to each hour of the day, although it is unlikely that daytime and nighttime hours would experience the exact same amount of temperature increase over the course of a day. Thus, the nighttime cooling rate results may be affected by an exaggerated amount of nighttime cooling under the climate change scenarios.

\section{Water Use Group 'Response to Scenarios}

The response of the neighborhoods to the scenarios can be further analyzed by categorizing the neighborhoods based on current patterns of external water consumption (Figure 3.4). The modeled absolute change in evaporation (Figure 3.10a) and nighttime cooling (Figure 3.10b) under the temperature change simulations support the basic hypothesis that high water use neighborhoods will respond to 
increased temperature with the most dramatic increases in external water consumption and the most reduced nighttime cooling rate. Interestingly, under the sprawl scenario, regardless of climate change, it is the average water use neighborhoods that respond with the most efficient tradeoff between water use and nighttime cooling. For example, under the sprawl scenario, the average absolute change in evaporation in the average use neighborhoods is an increase of 940 liters of water per household for the month of August. This is the least increase in water use of any group, and it is concurrent with a $0.17^{\circ} \mathrm{C} /$ hour increase in nighttime cooling rate, the largest increase in cooling of any group. Finally, under the urban densification scenario, high water use neighborhoods experience the greatest external water use savings but show only minor reductions in nighttime cooling, an efficient tradeoff. However, when densification is combined with the warming scenarios, the highest water use neighborhoods actually respond with the highest external water use increases and the most reduced nighttime cooling rates. This result implies that the high water consumption neighborhood group is more sensitive to increases in temperature than increases in urban density. 
Absolute Change in Evaporation for the month of August (1,000 L/ HH) (from Current)

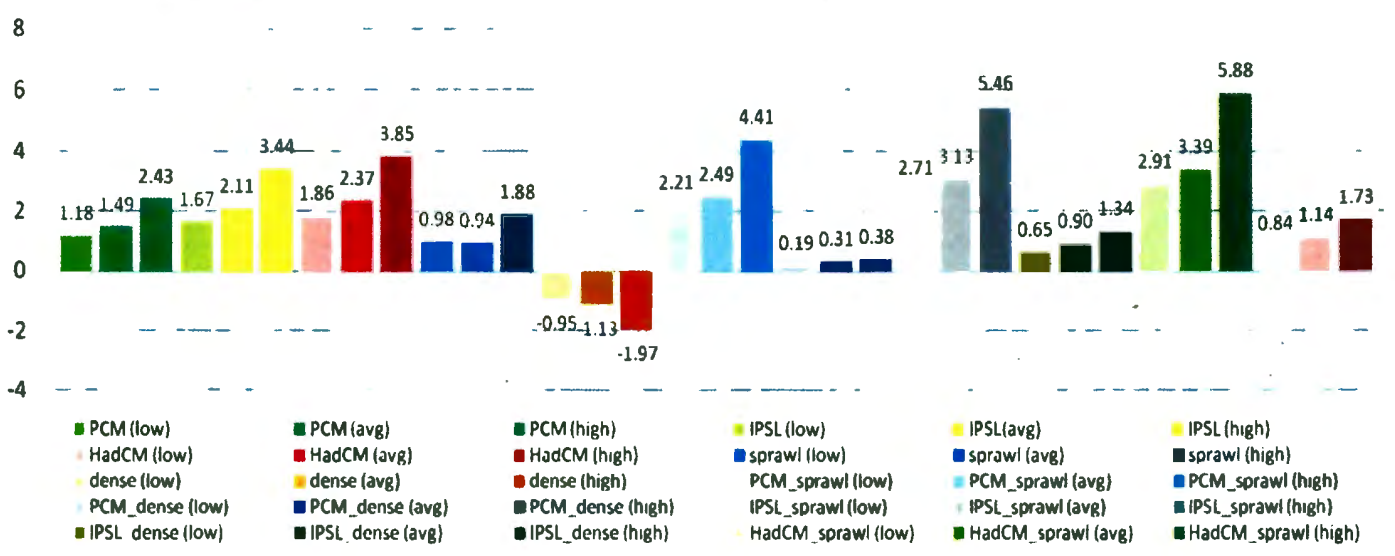

b

Absolute Change in Cooling Rate for the month of August (from current) $\left({ }^{\circ} \mathrm{C} / \mathrm{hr}\right)$

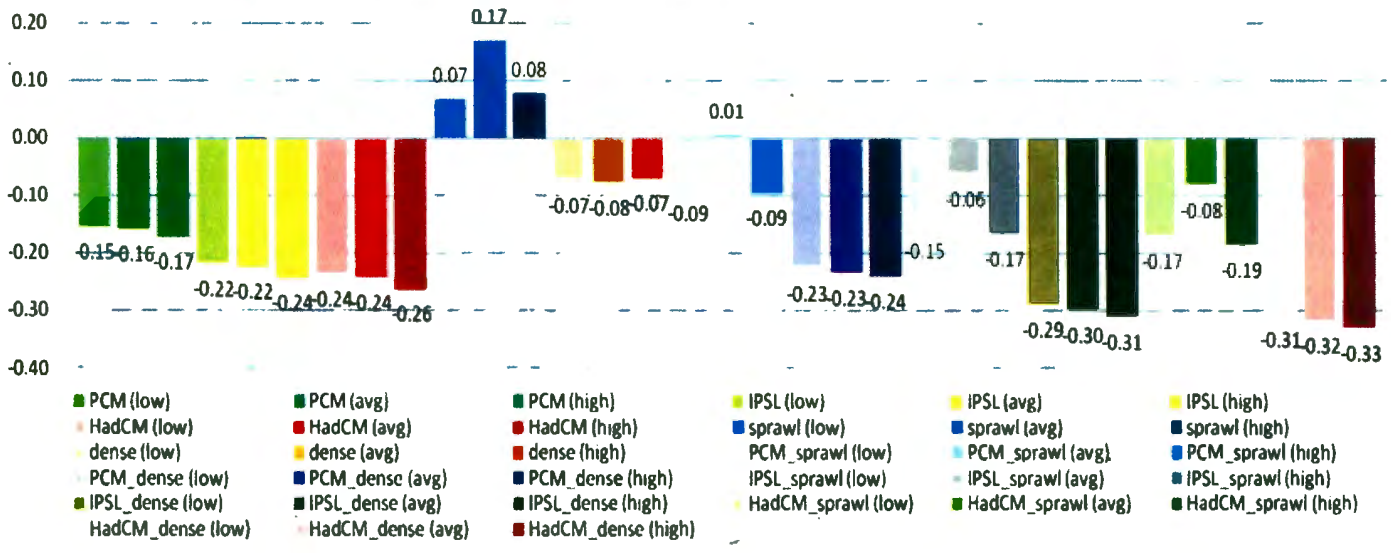

Figure 3.10: Response to scenarios by water consumption group (low, average, and high external water use); a) Average absolute change in evaporation (1,000 L/ household) from the baseline in low, average, and high external water consumption neighborhoods in response to each of the future scenarios; b) Average absolute change in nighttime cooling rate $\left({ }^{\circ} \mathrm{C} /\right.$ hour $)$ from the baseline in low, average, and high external water consumption in response to each of the future scenarios. 

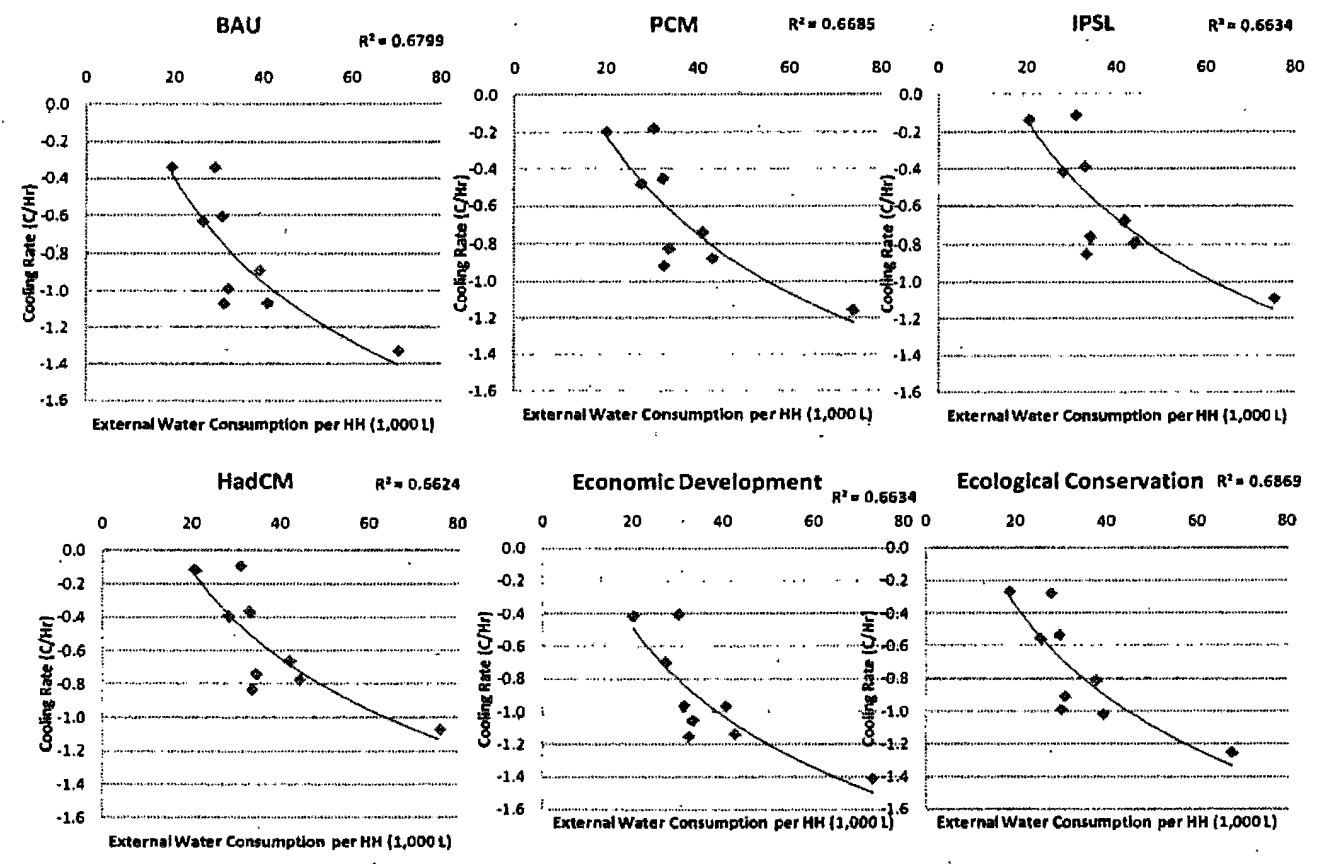

PCM_Economic Deveiopment

PCM_Ecological Conservation

IPSL_Economic Development
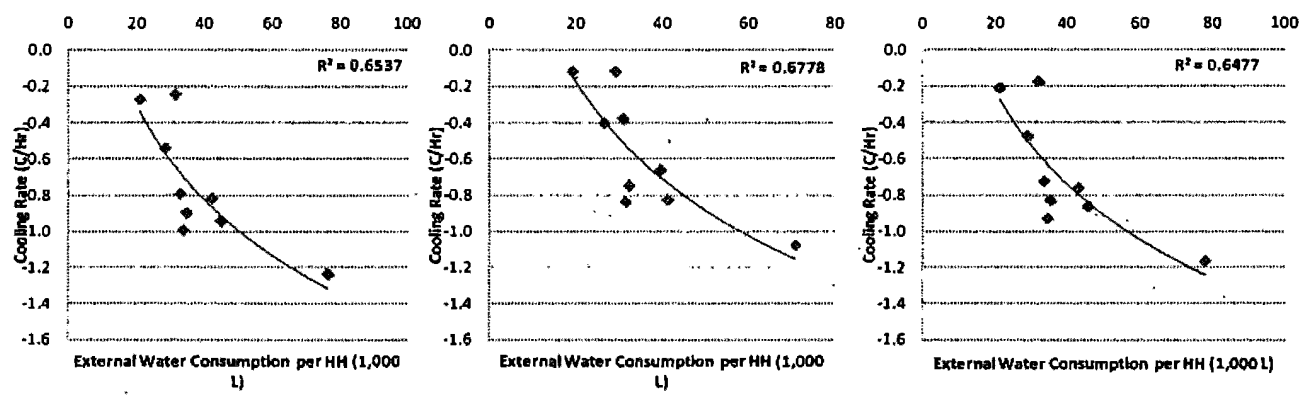

IPSL_Ecological Conservation
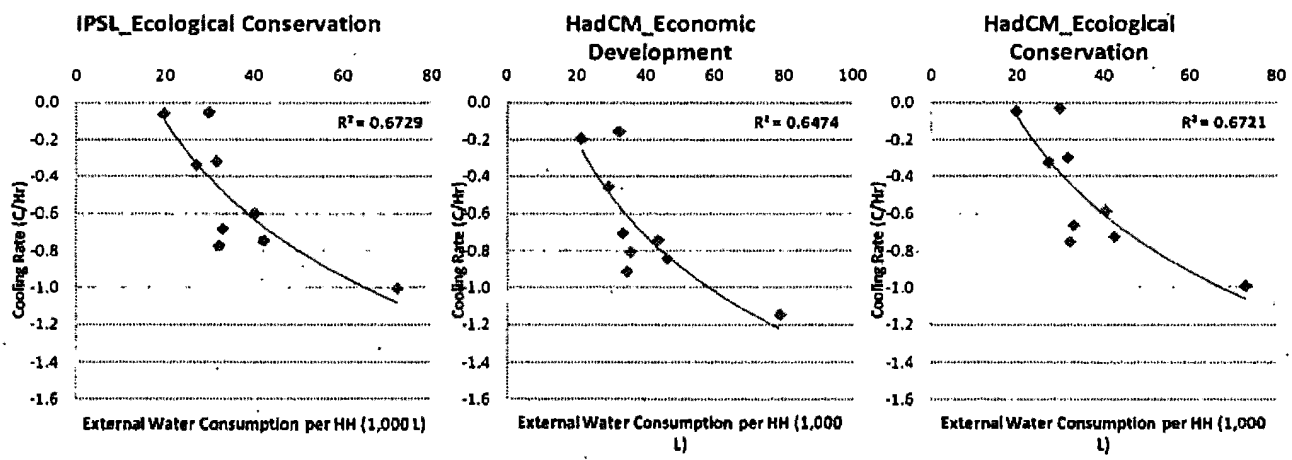

Figure 3.11: Relationship between external water consumption $(1,000 \mathrm{~L} / \mathrm{HH})$ and cooling rate $\left({ }^{\circ} \mathrm{C} / \mathrm{Hour}\right)$ under eảch alternative future scenario 
To examine the relationship between evaporation and nighttime cooling, I graphed the individual neighborhood responses to each scenario (Figure 3.11). The relationship is best modeled by a nonlinear function, which implies that a threshold exists beyond which continuing to increase external water consumption does not illicit an equal cooling response. This result agrees with Gober et al. (2010) findings that adding water is an inefficient strategy for reducing temperatures in densely vegetated neighborhoods in Phoenix, Arizona.

This analysis recognizes that a perfect correlation between the amount of vegetation cover present and the amount of water consumed does not exist. Urban water demand is a complex system influenced by both human systems, in terms of societal norms, values, and regulations, and natural systems, in terms of climate and ecological water requirements. Thus, high water consumption neighborhoods do not have to be characterized by heavy vegetation cover, because people may choose to use water for car washing or recreation, purposes not directly related to replacing water lost to evaporation.

\section{Influence of Vegetation Type and Land Cover Fraction}

An area of limited understanding is the influence of specific types of vegetation cover on the amount of energy partitioned into either the latent or sensible heat fluxes in the surface energy balance equation. I investigated this relationship by 
plotting the fraction grass and the fraction tree cover in each neighborhood against the modeled external water use under the baseline (Figure 3.12a), urban sprawl (Figure 3.13a), and urban density (Figure 3.14a) scenarios. The data points were best fit by a nonlinear curve and in all land cover scenarios the relation was strongest between the fraction trees and external water use, though the $R^{2}$ values were generally weak, ranging between 0.26 and 0.37 . The rate of change (slope of the line of best fit) between fraction grass and external water use is steeper than that between fraction tree cover and external water use for all scenarios, indicating that external water consumption increases more sharply in response to increasing grass cover than to increasing tree cover.

The type of vegetation cover also affects urban nighttime cooling rates, characterized by a negative relation. Similar to the external water use findings, the relation between fraction grass and nighttime cooling is best modeled with a nonlinear curve; however the relation between fraction tree cover and nighttime cooling is linear (Figures 3.12b, 3.13b, 3.14b). The relation between cooling rate and fraction trees is also the most significant with $R^{2}$ values ranging from 0.38 to 0.41 . This finding suggests that the relation between grass cover and cooling contains a threshold, beyond which adding more grass cover does not continue to produce the same cooling effects. Alternately, in the case of tree cover, there does not appear to be a threshold value, meaning that increases in tree cover will continue to produce increases in nighttime cooling at the same rate of change. 


\section{a) External Water Use}
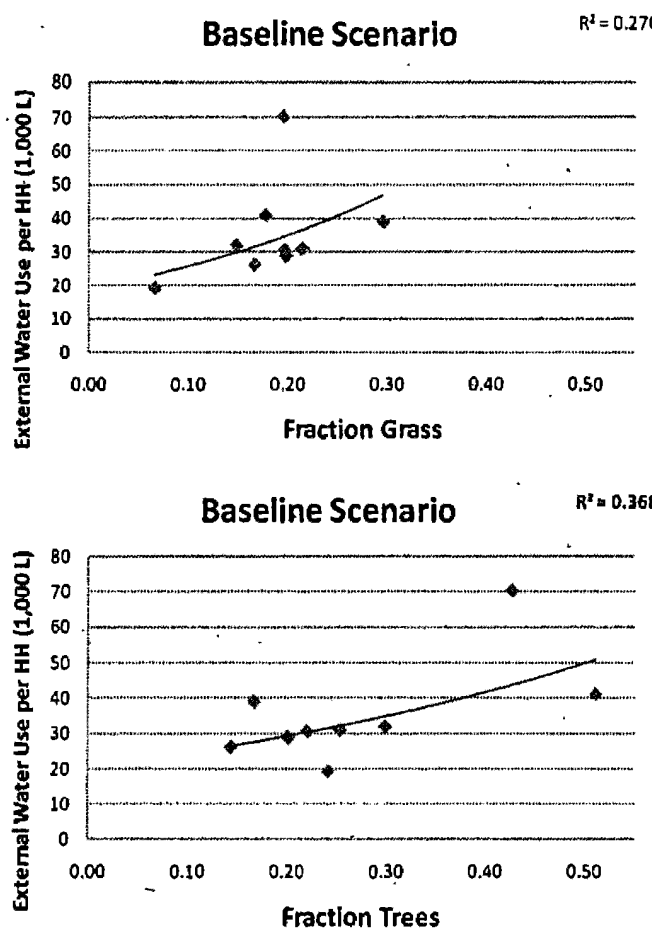

\section{b) Nighttime Cooling}

Baseline Scenario

$R^{2}=0.2039$

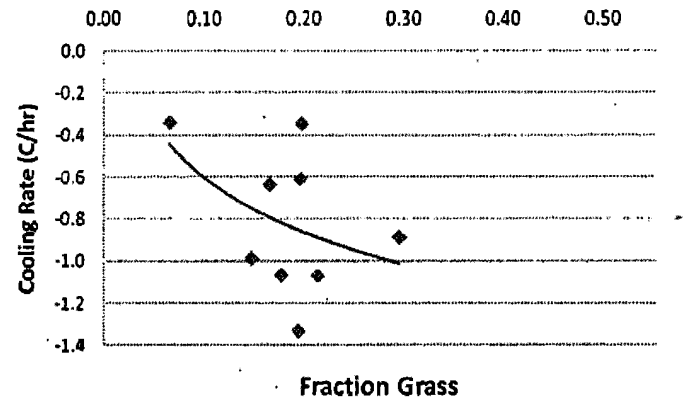

Baseline Scenario

$R^{2}=0.4094$

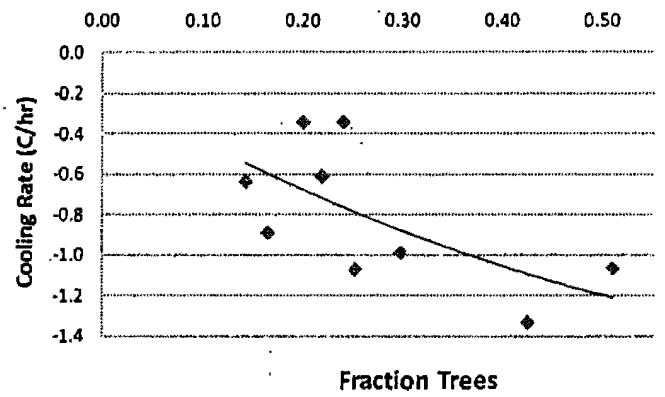

Figure 3.12: Relationship between vegetation cover (fraction grass and fraction trees) and external water use and cooling rate in the baseline scenario 


\section{a) External Water Use}

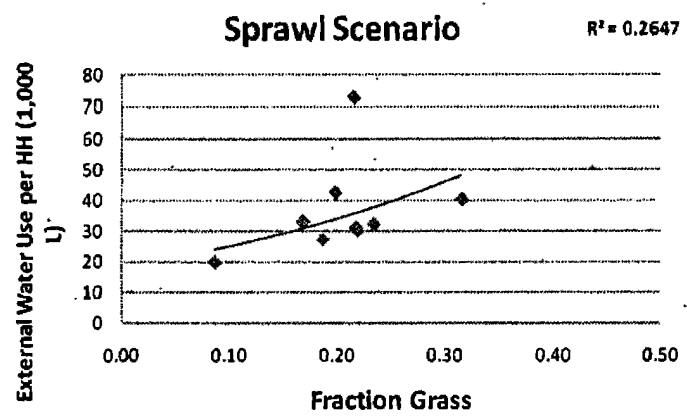

Sprawl Scenario

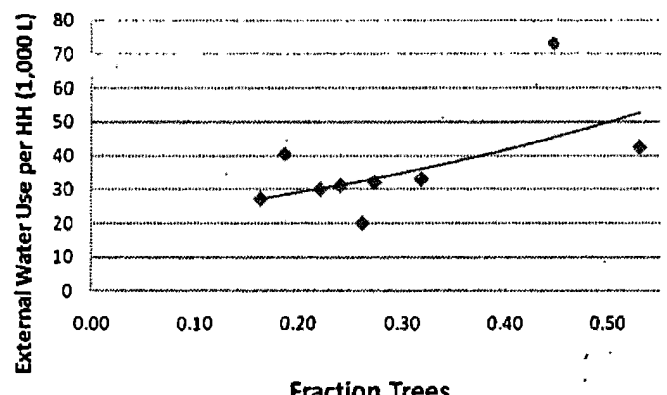

\section{b) Nighttime Cooling}

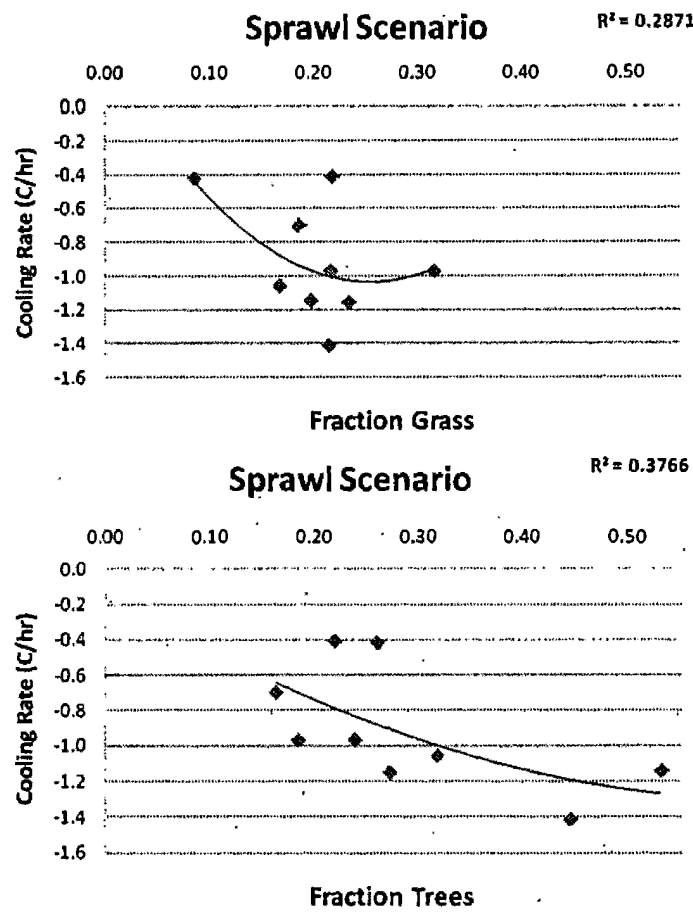

Figure 3.13: Relationship between vegetation cover (fraction grass and fraction trees) and external water use and cooling rate in the sprawl scenario 


\section{a) External Water Use}

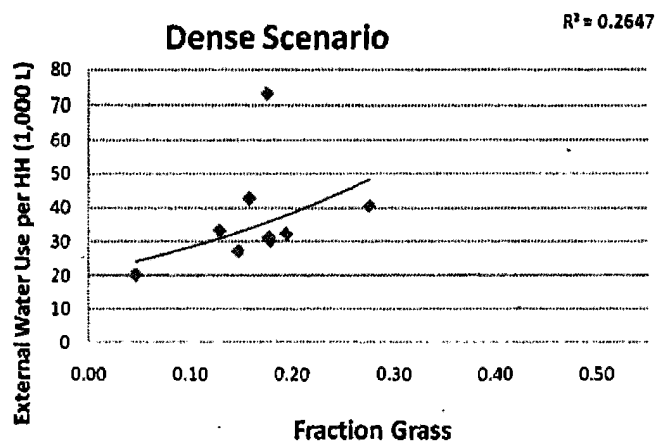

\section{Dense Scenario}

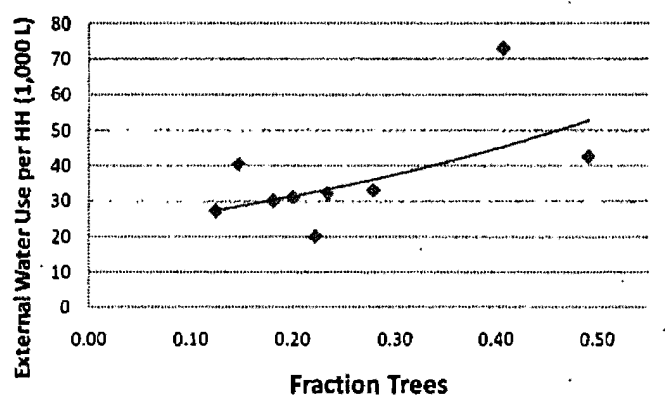

\section{b) Nighttime Cooling}
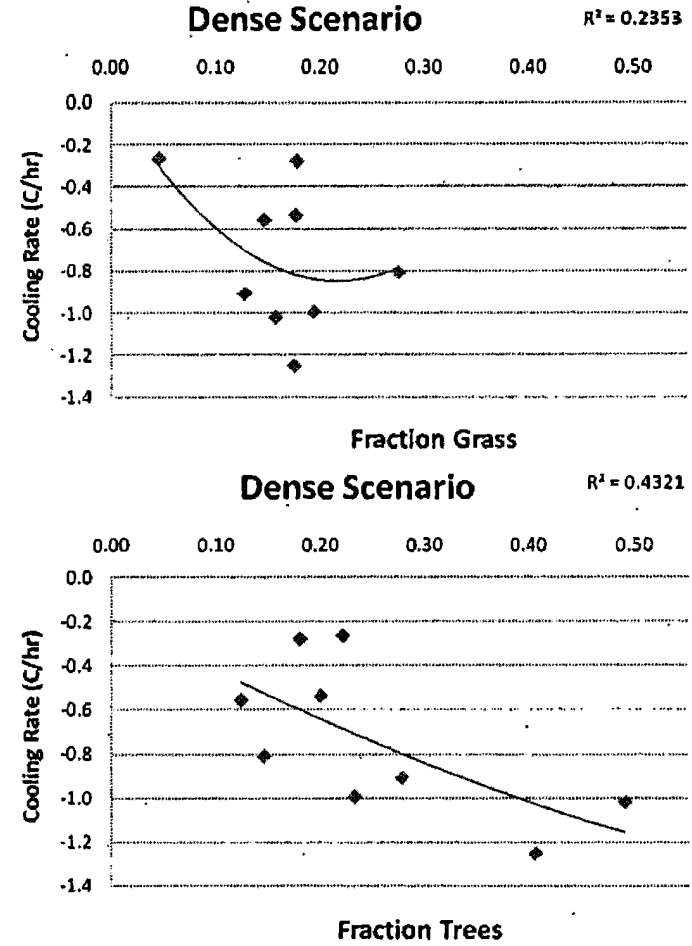

Figure 3.14: Relationship between vegetation cover (fraction grass and fraction trees) and external water use and cooling rate in the densification scenario 


\section{Conclusions}

This paper presents research findings from a surface energy balance modeling exercise designed to examine the impacts of climate change and land cover change on patterns of external residential water consumption and nighttime cooling in a suburban city within the Portland, Oregon metropolitan area. The results imply that land cover and water use are naturally intertwined at the neighborhood scale due to their prominence in affecting the local surface energy balance. Thus, urban land-use planning and water management must also be fully integrated to design cities that can accommodate future population growth and development while minimizing negative impacts to human health and natural resources. Furthermore, future development plans need to be spatially explicit and integrate current vegetation and water consumption patterns, so that already heavily developed neighborhoods do not experience increased future imperviousness. Instead, density should be increased in sprawling, highly vegetated neighborhoods, to reduce external water consumption, especially under future increases in summertime temperature due to climate change. Finally, in urban design plans, trees should be prioritized over grass for increased efficiency in promoting urban cooling while reducing external water consumption, as trees produce cooling through two mechanisms, shading and increased latent heat partitioning, and require limited irrigation inputs as compared to turf grass. 
In this study, there are a number of limitations that should be explicitly addressed. First, there is only one weather station, located at the Hillsboro airport, with a reliable record of hourly-scale meteorological data and only one station that collects hourly-scale incoming solar radiation data. Because the micro-climates throughout an urban area are variable, it would be ideal to have multiple locations collecting meteorological and solar radiation data. Second, the daily time step of the downscaled GCM data is also a limitation because the process to further downscale the data to an hourly time step introduces additional uncertainty into the modeling process. Third, there are some limitations associated with the LUMPS model. They are: 1) the model does not work well in areas with abrupt changes or significant spatial variability in land cover, 2) the study sites should be square to minimize advection, as advection is not accounted for in the model, 3) the size of the study site must be between $10^{2}-10^{4}$ square meters to correctly calculate the local-scale energy budget, 4) the mix of land cover should be homogeneous within the study site, 5) the meteorological data should be collected above roof height, but this type of data are only available with a flux tower, and 6) anthropogenic heat flux is not considered as an additional source of energy which causes an underestimation of the turbulent heat fluxes in urban environments (Grimmond and Oke 2002; Xu et al. 2008). 


\section{Utilizing System Dynamics Modeling to Examine the Impacts of Climate Change and Land Use Change on Municipal-Scale Residential Water Demand}

\section{Introduction}

Faced with the multiple challenges of rapid urbanization, population growth, natural climate variability, and anthropogenic climate change, there is a critical need to develop a comprehensive understanding of the coupled human and natural dynamics influencing urban water demand. Although the urban water demand literature has grown substantially over the previous decade, research that employs a coupled human and natural systems theoretical framework to examine water demand remains limited. Historically, research examined the human and natural components associated with urban water supply and demand independently. As discussed in chapter one, early models tended to be static and focused primarily on forecasting water demand at the municipal scale. These analyses established important relationships between urban residential water demand and a wide variety of social and ecological variables, including household size, income, education, age, garden design, property size, temperature, precipitation, and wind speed (Table 4.1). However, static models lack the capability to model dynamic responses to policy interventions and disturbances over time (Winz et al. 2009), are unable to provide insight into the complex structure of the urban hydrologic system, and are limited in their ability to 
represent the multiple interactions and feedbacks that exist between human and natural systems variables.

The primary objective of this research is to use system dynamics modeling (SDM) to evaluate the response of municipal-scale residential water demand to alternative future scenarios that incorporate changes in climate, land-use, and water management policy. The results of this research will advance our understanding of how human and natural system variables interact within and across scales to produce changes in the amount and timing of peak summertime water demand in western Oregon, USA. The central research questions addressed in this paper are: 1) How will indoor and outdoor residential water demand in the 2040s differ under combined climate, land use and policy scenarios? 2) To what extent will climate and land use change exacerbate peak summertime water demand? 3) Can policy regulations and conservation education mitigate the impact of predicted climate change on water demand? This research is significant because few water demand models combine all of the following variables: climate, vegetation, structural design, and demographics. Thus, this research represents an attempt to comprehensively model water demand taking into account a wide range of variables that are often analyzed individually rather than holistically. 
Table 4.1: Significant Variables in Determining Residential Water Demand

\begin{tabular}{|c|c|}
\hline Socio-Economic & $\begin{array}{l}\text { Household size (Zhang and Brown 2005; Dahan and Nisan 2007; } \\
\text { Domene and Sauri 2006; Wentz and Gober 2007). } \\
\text { - Income (Guhathakurta and Gober 2007; Kenney et al. 2008) } \\
\text { - Age of residents (Kenney et al. 2008) } \\
\text { - Number of.indoor water-using appliances (Zhang and Brown 2005) }\end{array}$ \\
\hline Climatic & $\begin{array}{l}\text { Precipitation (Maidment, Miaou and Crawford 1985; Gutzler and } \\
\text { Nims 2005) } \\
\text { Daily minimum temperature (Gutzler and Nims 2005; Guhathakurta } \\
\text { and Gober 2007) } \\
\text { Drought conditions (Balling, Gober and Jones 2008; House-Peters et } \\
\text { al. in press) }\end{array}$ \\
\hline Structural & $\begin{array}{l}\text { Size of house (Kenney et al. 2008; Chang et al. 2010) } \\
\text { Age of house (Guhathakurta and Gober 2007; Kenney et al. 2008; } \\
\text { Chang et al. 2010) } \\
\text { Size of property lot (Guhathakurta and Gober 2007; Wentz and } \\
\text { Gober 2007) } \\
\text { Housing density (Domene and Sauri 2006; Balling, Gober and Jones } \\
\text { 2008; Chang et al. 2010) }\end{array}$ \\
\hline Vegetation & $\begin{array}{l}- \text { Garden design (Domene and Sauri 2006; Wentz and Gober 2007) } \\
\text { Type of irrigation system (Endter-Wada et al. 2008) }\end{array}$ \\
\hline Behavior & - Consumer habits (Zhang and Brown 2005; Domene and Sauri 2006) \\
\hline
\end{tabular}

\section{Background}

Simply, coupled human and natural systems are integrated systems in which people interact with, depend on, and modify natural components of the environment (Liu et al. 2007). However, the dynamics of each separate system become fundamentally altered when the systems are coupled, driving unexpected, emergent behaviors through the introduction of strong, nonlinear feedbacks (Liu et al. 2007; Magliocca 2008). The explicit study of coupled human and natural systems has been attracting increased attention in interdisciplinary fields such as urban ecology (Grimm et al. 2000; Grimm et al. 2008; Pickett et al. 2008) and political ecology (Lebel et al. 2006; Robbins et al. 2008; Birkenholtz 2009; Mauro 2009). Quantifying the resilience 
of coupled human and natural systems is challenging because resilience relies on both natural processes and human management practices and interventions, which can act to increase or decrease resiliency through enhancing or destroying natural resources (Gunderson and Holling 2002; Adger 2006; Liu et al. 2007).

Previous research has examined the influence of social and ecological variables on residential water demand in a variety of urban environments worldwide, including arid (Balling and Gober 2005; Gutzler and Nims 2005; Wentz and Gober 2007; Balling et al. 2008; Kenney et al. 2008; Harlan et al. 2009), Mediterranean (Domene and Saurí 2006), temperate (Martinez-Espineira 2002; Praskievicz and Chang 2009; House-Peters et al. 2010; Chang et al. 2010) and humid (Zhang and Brown 2005) climates. This paper presents a brief review of the established literature, focusing first on climatic determinants of water use and second on socio-economic and cultural determinants.

\section{A. Influence of Natural System Variables}

Despite the broad literature analyzing the relationship between atmospheric conditions and water consumption, our understanding of the possible influence of climate variability on water demand remains incomplete, compounded by the fact that the influence of climate variables, such as temperature and precipitation, tends to vary by climatic regime (Gutzler and Nims 2005). Studies of climate variability and residential water consumption in Phoenix, Arizona, found that per capita water use 
significantly increases during periods of high temperatures and droughts and decreases with higher precipitation (Balling and Gober 2006). Balling et al. (2008) similarly reported finding that the strongest correlate is the drought variable. In a study of Albuquerque; New Mexico, Gutzler and Nims (2005) found that over $60 \%$ of the variation in year-to-year changes in summer residential water demand was accounted for by interannual temperature and precipitation changes when using a linear regression model, with precipitation being the primary correlate. Although Maidment et al. (1985) argued that rainfall is the climatic variable that most significantly influences urban water use, the literature is inconclusive regarding the exact precipitation factor (total amount, duration, or time between events) that best explains the variation in water consumption. In a study of the impacts of the urban heat island effect in Phoenix, Arizona, Guhathakurta and Gober (2007) found that an increase in daily low temperatures by one degree Fahrenheit is associated with an average monthly increase in single-family residential water use of 290 gallons.

An important trend in the literature is progress toward determining the exact nature of spatial variations in climatic sensitivity. Although research has shown that hot-dry weather generates higher demands for water than cool-wet conditions, the nature of the demand relationship between weather and demand for water remains uncertain (Kenney et al. 2008). One source of this uncertainty is figuring out which climate factor (precipitation, maximum temperature, evapotranspiration) is the best predictor of water demand. This uncertainty is evident in a study of Phoenix, Arizona (Balling 
et al. 2008), which found that one third of census tracts had little to no sensitivity to climate, while one tract had over $70 \%$ of its monthly variance in water use explained by climatic conditions. Further evidence of a geographic pattern in climate sensitivity is the ratio of summer versus winter water use. Across the city of Phoenix, singlefamily water use averages a twofold increase during summertime peak demand as compared to the low use winter months. Research substantiates that the most climate sensitive neighborhoods are characterized by large lots, a high occurrence of pools, a large proportion of non-native vegetation, and higher than average incomes and property values (Balling et al. 2008; House-Peters et al. 2010).

\section{B. Influence of Human System Variables}

A number of studies have analyzed the significance of socio-economic and land use variables in an attempt to predict urban municipal water consumption. A study by Kenney et al. (2008) in Aurora, Colorado, found that high volume water users tend to be wealthier and older and live in newer and larger homes than other customers. Other studies have shown that structural efficiencies associated with new homes and higher-density urban development reduce the impact of immediate shortages, and also bring long-term benefits by reducing infrastructure costs and augmenting supply (Balling et al. 2008). In an analysis of residential property characteristics, Guhathakurta and Gober (2007) found the most significant determinants of water use to be lot size and age of housing. Design-oriented analyses of water consumption 
have gone one step further, anticipating the change in water consumption that would accompany certain types of urban development. For example, in Phoenix, Arizona, each 1,000 square foot increase in average lot size produces a 1.8 percent increase in water consumption (Guhathakurta and Gober 2007). In Portland, Oregon, a 25 percent reduction in average residential building size is associated with an annual reduction of 25 million liters of water. Additionally, without changing the size of the building, an increase in residential density by just one household per acre would reduce annual water consumption by 1.6 million liters (Shandas and Parandvash 2010).

The significance of the independent demographic variable of household size has been substantiated in many studies, but confusion persists regarding whether the overall effect of the variable is increased or decreased water use (Zhang and Brown 2005; Domene and Saurí 2007; Wentz and Gober 2007). In Phoenix, Arizona, Wentz and Gober (2007) found an increase in water use as the size of the household increased, because more water was being used for bathing, laundry, toilet flushing and dishwashing. Domene and Sauri (2007) agree that household size is an important factor in determining consumption in Barcelona, Spain, but argue that for an equal population, more water per capita is consumed in smaller rather than larger households because small households cannot realize the opportunities for water saving associated with economies of scale. However, Dahan and Nisan (2007) found that residential water consumption in Jerusalem, Israel, exhibits almost no economies of scale with regard to household size for households greater than two people because each 
additional member consumes the same quantity of water regardless of total household size.

Growing urban water demand, from increases in suburban developments, population growth, and the uncertainty of climate change have caused renewed attention to both indoor and outdoor water conservation for the residential and commercial sectors. Recent additions to water conservation literature focus on advancing understanding of human behavior in an attempt to identify key factors that either encourage or constrain people from engaging in resource conservation efforts and environmentally sustainable behaviors (Kurtz et al. 2005; Atwood et al. 2007; Endter-Wada et al. 2008; Miller and Buys 2008; Webb et al. 2009). Research demonstrates that although attitudes may express concern for high water consumption, these feelings do not always translate into changed behaviors (Askew and McGuirk 2004; Head and Muir 2006; 2007; Randolph and Troy 2008; Miler and Buys 2008). Randolph and Troy (2008) explored water use awareness in Sydney and found that only twenty percent of respondents knew how much water they were actually using, although most respondents believed that they used an average or below average amount of water compared with others in Sydney. Miller and Buys (2008) recognize a similar situation in their results, which is that although many survey respondents claimed to have environmentally friendly attitudes, these were not reflected in their day-to-day external home water use behaviors. 
Although external water use is often one of the first areas targeted by water utilities for conservation efforts and restrictions, residents tend to resist changing their external water use behavior, namely irrigation practices, as the garden is often seen as a cultural product and an extension of the home and the overall living space (Askew and McGuirk 2004). Human perceptions of and desires for lush, green spaces drive landscaping choices, which determine the resulting size and composition of household gardens, thus directly impacting the amount of water required to maintain the verdant landscape. Randolph and Troy (2008) report that although there appears to be a major potential for water conservation with respect to garden use, only 56 percent of the surveyed residents described changing their garden water practices to reduce external water consumption during a drought. One reason people defy water use restrictions and refrain from implementing water sensitive garden practices is because the act of watering the garden is often associated with relaxation, tranquility, and meditation (Syme et al. 2004; Head and Muir 2007). For example, in Eastern Australia, interview participants reported a desire to increase water features in their gardens, equating a water rich environment with serenity, tranquility and peacefulness (Head and Muir 2007). Thus, there is an inherent contradiction between aspirations to conserve water and the pleasure derived from well-watered, verdant environments.

A study in Sydney, Australia, which sought to involve a wide range of community stakeholders in a dialogue about water conservation, concluded that water use and management are strongly connected with social, economic, cultural, spiritual 
and political factors (Webb et al. 2009). Atwood et al. (2007) examined residents' satisfaction with conservation efforts, such as the promotion of xeriscaping and restrictions on lawn watering in Ontario, Canada, and fourd that the most important variables in influencing the residents' assessments of the program were the neighborhood in which they lived, their gender, and their stated attitude toward the environment. Endter-Wada et al. (2008) found that the primary factor affecting wasteful watering is programmed irrigation systems. Although these systems were designed to achieve water efficiency, in reality, residents use them as a way to save both time and labor, rather than to save water.

Recent attention in the literature has been focused on evaluating the role of community values and the cultural and historical norms surrounding water use behavior in order to gauge the potential for community acceptance of water sensitive urban design, water conservation, and mandatory regulations (Miller and Buys 2008; Brown et al. 2009; Wong and Brown 2009). Miller and Buys (2008) translate the theory of social capital, the idea that behavior is dependent on prevailing community norms, values and behaviors, to patterns of residential water consumption because a person can potentially adopt either desirable or undesirable behaviors through close relationships with neighbors. The authors argue that although social capital has the potential to be useful in remedying community challenges, such as fostering water conservation in a high use area, it can also be a pitfall and hinder the success of a conservation effort (Miller and Buys 2008). For example, the aesthetic desire to live 
in a neighborhood with attractive, green lawns may take priority in neighbor relations over the more seemingly remote issue of a vulnerable water supply source. Wong and Brown (2009) contend that community acceptance and broad political support are fundamental for enhancing conservation implementation rates and the receptivity of communities to following an ecologically sustainable lifestyle.

\section{Study Area}

Municipal water for the City of Hillsboro is supplied by the Tualatin River (Figure 3.1). During the summer the city also relies on the Hagg Lake and Barney reservoirs to meet peak demand, which corresponds with the low flow season for the Tualatin River. Following a drought scare in 2001, the City of Hillsboro water provider instituted an aggressive conservation plan, which resulted in a 20 percent reduction in per capita residential water use between 2002 and 2007. However, overall daily water production did not decrease due to the steady population growth over the same period. Predicting a high rate of continued growth in the future, the City of Hillsboro has created a 50-year water demand projection based on urban development forecasts and expected population growth. The projected demand for water outpaces the current available supply from the dual sources of the river and the reservoir. Hillsboro is an appropriate location for this type of research because it is balancing the dual uncertainties of future population growth and the potential for the 
summer water flow in the Tualatin River to be negatively affected due to climate change over the next 50 years (Franczyk and Chang 2009).

\section{Data and Methods}

\section{A. Data}

This research employs a dynamic simulation model, CCDomestic (Downing et al. 2003) to estimate residential water demand. The conceptual model framework allows for the integration of multiple human and natural variables while elucidating the linkages and feedbacks between variables through a stock and flow diagram model structure (Figure 4.1). To simulate indoor and outdoor residential water consumption in the historical and future periods, the CCDomestic model requires data from five general categories: population, climate, outdoor water consumption behaviors, indoor water consumption behaviors, and total water demand (Table 4.2).

I acquired the demographic data, including population, household size, and income estimates for the period 1980-2050 from the U.S. Census Bureau and the PSU Population Research Center. Monthly-scale observed temperature and precipitation data for the period 1981-2009 was obtained from the Hillsboro airport meteorological station, available online through the National Climate Data Center (NCDC) (2010). The potential evapotranspiration (PET) data was calculated using the Blaney Criddle equation, $P E T=D_{a n n}{ }^{*}\left(0.46^{*} T+8\right)$, where $D_{a n n}$ is monthly average daylight hours and $\mathrm{T}$ is temperature $\left({ }^{\circ} \mathrm{C}\right)$. Carbon dioxide concentration data for the historical period was 
obtained from the National Oceanic and Atmospheric Administration's (NOAA)

Global Monitoring Division (Thoning et al. 2007). To determine the indoor and outdoor water consumption behavior in Hillsboro, I conducted a water use survey with 103 heads of household (see section 4.B). To calibrate the model for applicability in western Oregon and to validate the model's ability to recreate the historical record, I obtained municipal-scale, monthly residential water production data from the City of Hillsboro water provider for the period 1995 to 2008.

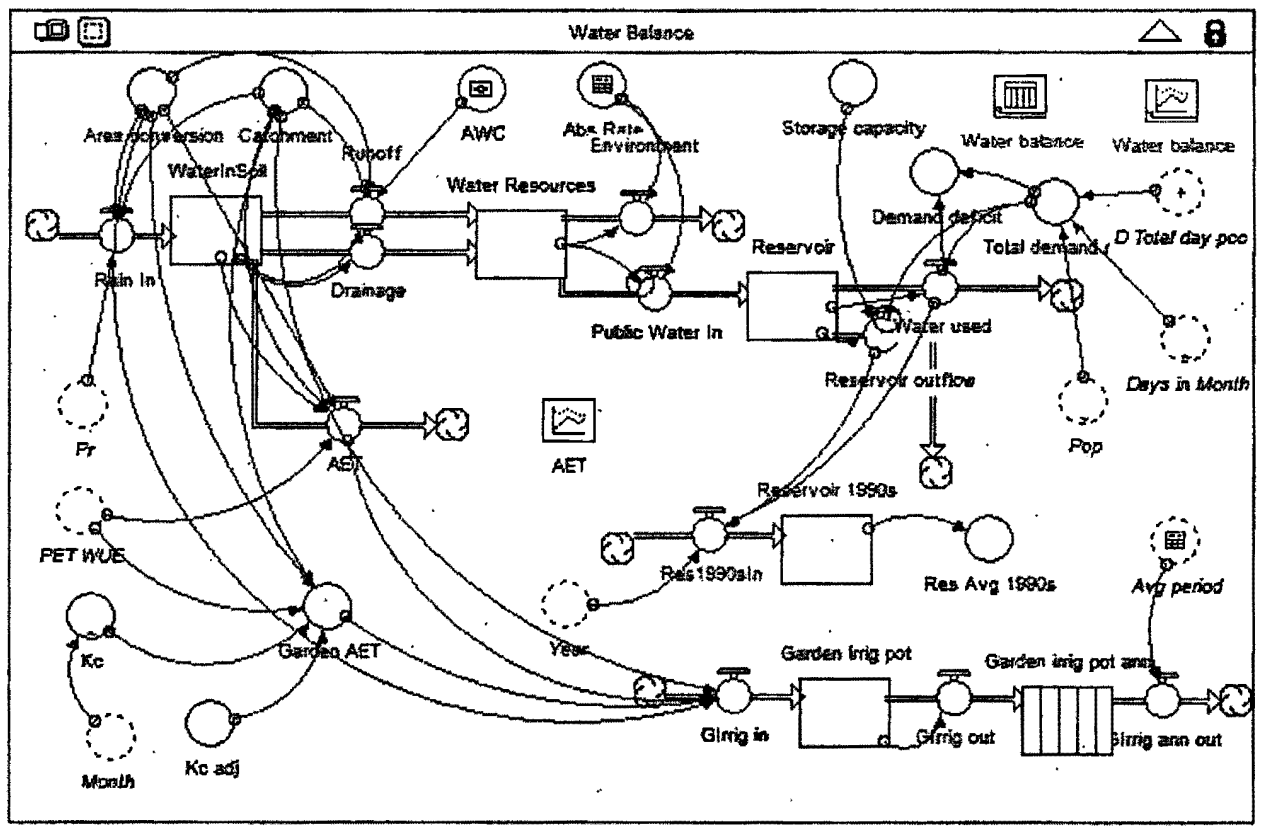

Figure 4.1: The Water Balance component of the CCDomestic model, conceptualized as a flow diagram, where rectangular boxes indicate stocks, lines represent material flows, and circles represent converters. (Visualized with STELLA software) 
Table 4.2: CCDomestic model data requirements and data sources

\begin{tabular}{|c|c|c|}
\hline & Variable & Source \\
\hline Population & $\begin{array}{ll}\text { - Population } \\
\text { - Average household size } \\
\text { - Income }\end{array}$ & $\begin{array}{l}\text { US Census Bureau } \\
\text { PSU Population } \\
\text { Research Center }\end{array}$ \\
\hline Climate & $\begin{array}{ll}\text { - Observed (1981-2009) and projected } \\
\text { (2030-2059) temperature } \\
\text { - Observed (1981-2009) and projected } \\
\text { (2030-2059) precipitation } \\
\text { - } \quad \text { potential evapotranspiration (PET) } \\
\text { - Carbon dioxide concentration }\end{array}$ & $\begin{array}{l}\text { National Climate } \\
\text { Database } \\
\text { Hillsboro Airport } \\
\text { Climate Impacts Group }\end{array}$ \\
\hline $\begin{array}{l}\text { Total Water } \\
\text { Demand }\end{array}$ & $\begin{array}{l}\text { - } \quad \text { Monthly Residential Water Production } \\
\text { - Average consumption for indoor uses } \\
\text { - Average.consumption for outdoor uses }\end{array}$ & $\begin{array}{l}\text { City of Hillsboro } \\
\text { Household Survey }\end{array}$ \\
\hline $\begin{array}{l}\text { Outdoor } \\
\text { Water Use }\end{array}$ & $\begin{array}{l}\text { - } \quad \text { Percent of households with gardens } \\
\text { - Irrigation practices } \\
\text { - Water features }\end{array}$ & Household Survey \\
\hline $\begin{array}{l}\text { Indoor Water } \\
\text { Use }\end{array}$ & $\begin{array}{l}\text { - } \text { Bathing Frequency } \\
\text { - } \quad \text { Appliances } \\
\text { Water-saving technology }\end{array}$ & Household Survey \\
\hline
\end{tabular}

To simulate future scenarios, I acquired statistically downscaled Global Climate Model scenarios with temperature and precipitation data for the period 20302059 from the Climate Impacts Group at the University of Washington (a more detailed description of this data is provided in Chapter III, section 4.D). Projections of land use and policy decisions for the future period were derived from two scenarios, Development 2050 and Conservation 2050, developed by the Pacific Northwest Ecosystem Research Consortium (Baker et al. 2004; Hulse et al. 2004). These scenarios contain comprehensive descriptions of the future, including municipal water conservation targets to be achieved through a combination of voluntary and mandatory 
water use reduction policies. Water conservation planning information for the City of Hillsboro was also obtained from the Joint Water Consortium (JWC), which coordinates conservation efforts for five partner water providers located in the western region of the Portland metropolitan area (JWC 2009).

\section{B. Survey Methods}

To establish a baseline of current indoor and outdoor residential water use behavior, I surveyed 103 heads of household who are residents of the City of Hillsboro and receive their water from the city provider, rather than from a personal well. The survey instrument consists of 39 questions, divided into three main sections: indoor water use, outdoor water use, and socio-economic information (Appendix A). The survey was originally distributed online $(\mathrm{n}=11)$ via email list-servs provided by Homeowner Associations (HOA), but this method garnered limited success. The majority of the surveys were given in-person $(n=92)$ over the course of six months at locations throughout Hillsboro, including the farmer's market and the central library. The sampling method was semi-random and self-selected. Ojeda et al. (2008) describe various biases that may occur during the process of survey development and implementation. Although I tried to limit bias, in this study, population choice bias was a factor because people chose to take the survey based solely on intrinsic motivation. Thus the survey participants who self-selected to complete the survey may be more civically active and aware of urban resource issues than the general 
population. A comparison of the socio-economic characteristics of the sample population to the entire Hillsboro population (Figure 4.2) reveals that the sample population tended to be more affluent, more likely home owners than renters, ethnically diverse, and to have attained a higher level of education.

\section{Sample apopulation}
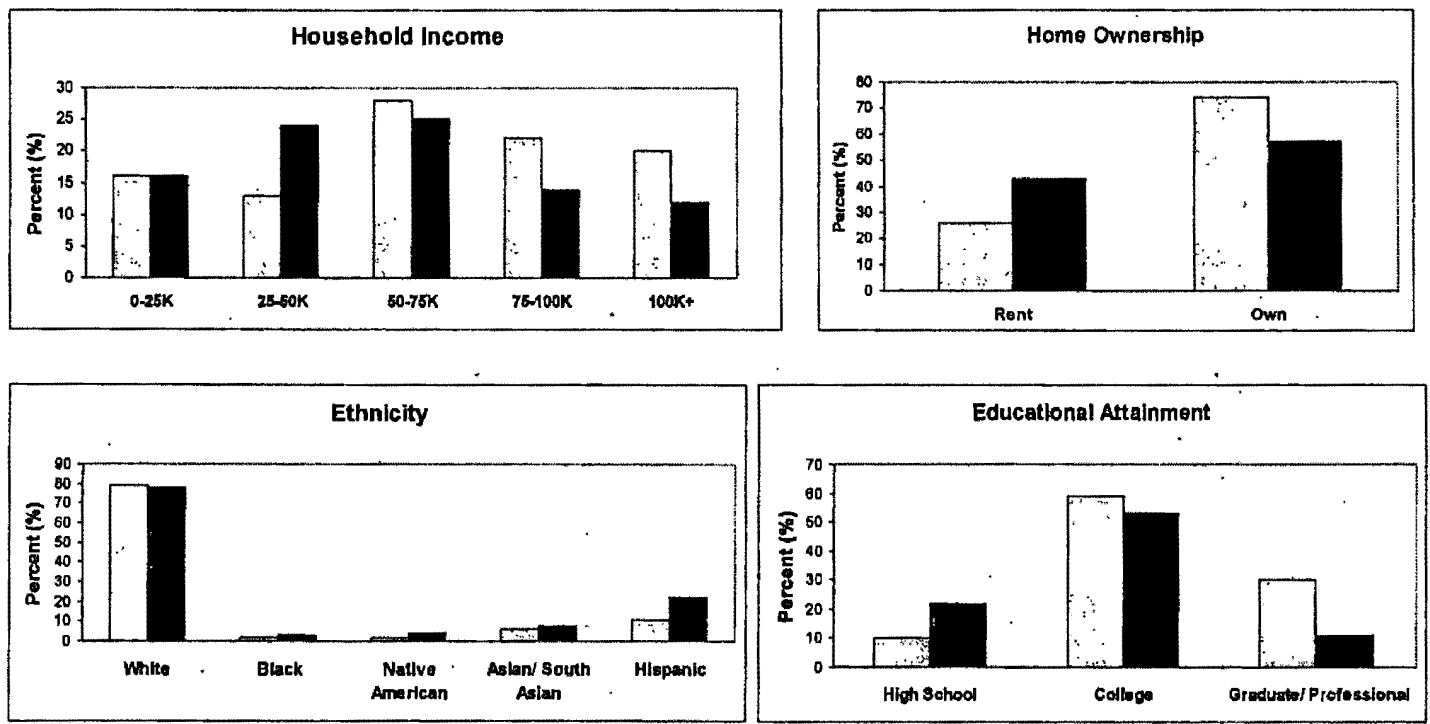

Figure 4.2: Comparison of socio-economic indicators of the sample population $(n=103)$ to the entire Hillsboro population

Data processing and analysis was required to convert the raw survey response data into input for the CCDomestic model. Using water audit brochures (Maryland Department of the Environment 2003; Payson Water Department 2007), I compiled 
average water use values for both traditional and low-flow appliances, such as toilets, faucets, showerheads, hoses, and sprinklers. Based on the responses for family size, the number of water using appliances present in the home, and the frequency and length of use, I calculated daily indoor and outdoor water consumption per household surveyed. To ensure that the calculated results accurately represented the observed water use, I compared the average survey derived indoor and outdoor water consumption to the average water bill records of indoor and outdoor water consumption across the entire Hillsboro population. Water billing records only contain one water use value, which represents both indoor and outdoor consumption. To determine indoor and outdoor water use from the aggregate value, I used the popular method of dividing water use into its two components, base use and seasonal use (Maidment et al. 1985; Zhou et al. 2000; Syme et al. 2004; Gato et al. 2007; House-Peters et al. 2010). This method assumes indoor water use to be equal to the base use, defined as winter use $(($ November + December + January + February water use $/ 4)$, and the outdoor water use to be equal to the seasonal use, defined as [((July + August + September + October water use) /4) - base use].

The survey-response calculations for indoor water use, 227. gallons per household per day, matched closely to the observed average indoor water use across the study area, 210 gallons per household per day. However, the outdoor water use calculated from the survey, 83 gallons per household per day, did not correspond closely to the observed average outdoor water use, 176 gallons per household per day. 
There are several reasons for the disparities between the observed and calculated water use values. The slight exaggeration of indoor water use could be based on the sample population characteristics, as affluence has been found to be correlated with increased water consumption (Kenney et al. 2008; Harlan et al. 2009). The significant underestimation of outdoor water use may be the result of a number of factors including: 1) the widespread use of automatic sprinkler systems in the study area (estimated at $45 \%$ ), which detach people from the process of outdoor water consumption, thus they are less likely to be able to accurately quantify the amount of time that sprinklers are running and the total amount of water consumed per use; 2) the survey was conducted during the late autumn and winter seasons when outdoor water use is limited, thus respondents were less likely to accurately identify their summer outdoor water use; 3) respondents wanted to appear more conservation-oriented in their survey results than their actual behaviors suggest; and 4) the people who chose to take the survey are already invested in water conservation activities, such as planting native and drought resistant gardens, and thus do not consume as much water for outdoor activities as the average household in the study area. To overcome the underestimation of outdoor use, I adjusted the values for per minute sprinkler water consumption by a factor of 2 across all households, which produced a more realistic outdoor water use calculation of 166 gallons per household day. 


\section{Scenario Development}

In the natural resources literature, scenario analysis has become an increasingly common and complex approach for explicitly considering plausible environmental futures (Liu et al. 2007; Garb et al. 2008). Changes in response to various exogenous stressors and internal dynamics of coupled human and natural systems are inevitable, thus Holling (2001) recommends connecting the monitoring of conditions in the present and past to policies and actions that can be used to evaluate different futures. Scenarios represent storylines about how relevant events might unfold in the future and can be used to parameterize models of biophysical and social processes (Garb et al. 2008). This research utilizes climate change and urban development scenarios to examine how changes in the biophysical and built environment will impact municipalscale water demand in the future.

The climate change scenarios consist of three statistically downscaled GCM scenarios, UKMO-HadCM3 (Gordon et al. 2000), IPSL-CM4 (Marti et al. 2005), and PCM (Washington et al. 2000), with the A1B emission scenario. The GCM are derived from scenarios performed for the International Panel on Climate Change (IPCC) Fourth Assessment Report and were statistically downscaled for the City of Hillsboro using a methodology developed by Climate Impacts Group (Salathé et al. 2007) (detailed information is provided in Chapter 3, section 4.4). For the 2040s, the mean of the 30-year future period, 2030-2059, the HadCM scenario represents the 
largest increases in temperature and evapotranspiration, the IPSL represents a middle of the road climate change scenario, and the PCM scenario is the most conservative.

The urban development scenarios are based on spatially-explicit alternative land cover scenarios (Figure 3.5) created by the PNW-ERC for regional analysis of the Willamette River Basin in the year 2050 (Baker et al. 2004; Hulse et al. 2004) (see chapter 3 , section 4.5 for a detailed explanation). The future land use and policy components of the scenarios are integrated in the CCDomestic model to evaluate impacts to residential water consumption based on management decisions that either prioritize the economic market of the ecosystem. The urban sprawl scenario assumes a loosening of current land use laws and greater reliance on market-oriented approaches for land and water use decisions, prioritizing short-term economic gain over long-term ecological function. In contrast, the urban densification scenario prioritizes the maintenance of ecological services, which are protected through mandated conservation-oriented behaviors. For example, the densification scenario assumes that municipal water conservation practices result in a 10 percent increase in in-stream water rights by 2050 , which is obtained by an 8 percent reduction in municipal per capita water consumption rates. In addition to policy decisions, the type of urban form that exists also affects residential water use behavior (Guhathakurta and Gober 2007; Shandas and Parandvash 2010). Under the urban sprawl scenario, the decrease in residential density to 6.2 homes per acre, the increase in home building and lot size, and the 4 percent increase in vegetation, has the potential to result in 
significant increases in both indoor and outdoor water consumption. Alternately, under the urban densification scenario, residential density increases to 9.3 homes per acre, home building and lot size decreases and there is a 4 percent decrease in overall vegetative cover, which I hypothesize will lead to decreased indoor and outdoor water consumption.

\section{CCDomestic Model}

System dynamics models (SDMs) represent an improvement over traditional statistical models for examining coupled human and natural system dynamics. SDMs seek to represent the complexity and dynamism inherent in coupled human and natural systems and are able to integrate a wide range of input parameters, capture key interrelationships in the system, enhance understanding of the system structure, and reveal how a system changes over time, including how it responds to management intervention.(Downing et al. 2003; Chu et al. 2009; Winz et al. 2009). The stock and flow modeling interface of SDMs allow for visualization of the system structure, including the feedback lops, relationships between variables, and temporal delays, which improves the ability to investigate the effects of different intervention strategies through simulation (Ford 1999). Winz et al. (2009) rely on SDM tools for modeling and dynamically simulating the change in water resources over time, as a method to provide an informed basis for proactive management strategies, which enhance the ability of managers to maximize the adaptive capacity of the system to build resilience 
in face of future uncertainty. An important limitation of SDMs is that it is not designed to be used as a predictive, forecasting model to produce exact future values. Instead, the modeling exercise is meant to increase understanding of the system and is best interpreted through output comparison from multiple scenarios of system parameterizations.

The CCDomestic model was originally developed for use in the Stockholm Environment Institute's "Climate Change and Demand for Water" project which aimed to systematically evaluate the impacts of climate change and economic scenarios on future domestic water use in England and Wales (Downing et al. 2003). The dynamic simulation model uses empirical data on twenty micro-components of indoor and outdoor water demand (Table 4.3), including ownership of water-using appliances, the volume per-use for each appliance, and the frequency of baths and showering. Table 4.3 presents the micro-component of demand input data under the current scenario and for two future scenarios, urban sprawl and urban densification. I derived the current data for each micro-component of demand from analysis of the survey responses, using water audit data (Maryland Department of the Environment 2003; Payson Water Department 2007) to calculate exact water volumes. The data for the sprawl and densification scenarios are based on the PNW-ERC urban development scenarios (Baker et al. 2004; Hulse et al.2004) and the JWC water conservation planning report, which contains Hillsboro specific conservation targets and previous achievements. In this modeling exercise, I intend the sprawl and densification 
scenarios to represent two extreme cases, to demonstrate the upper and lower bounds of possibility for future water demand.

Table 4.3: Change in the micro-components of demand between the current period and each future urban development scenario

\begin{tabular}{|l|c|c|c|}
\hline \multicolumn{1}{|c|}{ Micro-components of Demand } & Current & Sprawl & Densification \\
\hline 1. Volume of non-climate sensitive Use (L/day) & 50 & $40(-20 \%)$ & $60(+20 \%)$ \\
\hline 2. Car ownership (\% of population) & 75 & $65(-13 \%)$ & $80(+7 \%)$ \\
\hline $\begin{array}{l}\text { 3. Frequency of car washing (washes per person } \\
\text { per day in a month) }\end{array}$ & 0.06 & $0.05(-17 \%)$ & $0.07(+17 \%)$ \\
\hline 4. Volume of water per car wash (L) & 150 & $100(-33 \%)$ & $200(+33 \%)$ \\
\hline 5. Shower ownership (\% of population) & 95 & $80(-16 \%)$ & $90(-5 \%)$ \\
\hline 6. Low-flow shower ownership (\% of population) & 70 & $85(+21 \%)$ & $75(+7 \%)$ \\
\hline 7. Bath ownership (\% of population) & 85 & $85(0 \%)$ & $85(0 \%)$ \\
\hline $\begin{array}{l}\text { 8. Frequency of baths (baths per person per day in } \\
\text { a month) }\end{array}$ & 0.1 & $0.05(-50 \%)$ & $0.15(+50 \%)$ \\
\hline $\begin{array}{l}\text { 9. Frequency of low-flow shower use (low-flow } \\
\text { showers per person per day in a month) }\end{array}$ & 0.5 & $0.7(+40 \%)$ & $0.5(0 \%)$ \\
\hline $\begin{array}{l}\text { 10. Frequency of shower use (showers per person } \\
\text { per day in a month) }\end{array}$ & 0.9 & $0.7(-22 \%)$ & $0.9(0 \%)$ \\
\hline 11. Volume of water per bath (L) & 136 & $136(0 \%)$ & $136(0 \%)$ \\
\hline 12. Volume of water per shower (L) & 120 & $90(-25 \%)$ & $120(0 \%)$ \\
\hline 13. Volume of water per low-flow shower (L) & 60 & $50(-17 \%)$ & $60(0 \%)$ \\
\hline 14. Volume of miscellaneous use (L/day) & 36 & $29(-19 \%)$ & $43(+19 \%)$ \\
\hline 15. Sprinkler ownership (\% of population) & 50 & $40(-20 \%)$ & $60(+20 \%)$ \\
\hline $\begin{array}{l}\text { 16. Garden water feature ownership (\% of } \\
\text { population) }\end{array}$ & 10 & $10(0 \%)$ & $10(0 \%)$ \\
\hline 17. Volume of water per sprinkler use (L) & 1,000 & $500(-50 \%)$ & $1,500(+50 \%)$ \\
\hline $\begin{array}{l}\text { 18. Frequency of sprinkler use (per person per day } \\
\text { in a month) }\end{array}$ & 0.05 & $0.03(-40 \%)$ & $0.07(+40 \%)$ \\
\hline $\begin{array}{l}\text { 19. Frequency of refilling garden water feature } \\
\text { (per person per day in a month) }\end{array}$ & 0.05 & $0.03(-40 \%)$ & $0.07(+40 \%)$ \\
\hline $\begin{array}{l}\text { 20. Volume of water per refill of garden water } \\
\text { feature (L) }\end{array}$ & 100 & $50(-50 \%)$ & $150(+150 \%)$ \\
\hline
\end{tabular}

The CCDomestic model is a collection of connected sectors, or sub-models, that represent physical and human processes, such as climate and population growth, and calculate separate components of water demand, including garden demand and 
bathing demand. For example, the water balance model sector is presented in Figure 4.1. The calculation of demand is affected by the biophysical environment, because the micro-components of demand exhibit varying sensitivities to climate variables, namely temperature, precipitation, and evapotranspiration. The model assumes that some components of demand are not sensitive to climatic variations, including dish washing and clothes washing. Thus the calculation of these elements remains constant, unless directly affected by a policy intervention. However, for the microcomponents of demand that are climate sensitive, the model includes an accumulated degree day calculation, which represents the impact of prolonged warmer weather on the frequency of performing the activity, such as garden watering and car washing. Degree days represent the accumulation of days over course of a month with temperatures above the threshold of $17^{\circ} \mathrm{C}$. The temperature threshold is one parameter that can be adjusted to calibrate the climate sensitivity of the model. The submodel that estimates garden watering is based on soil moisture deficits and utilizes temperature, precipitation, and evapotranspiration data to determine the amount of water needed to maintain vegetation. This submodel includes a monthly coefficient that can be calibrated to adjust evapotranspiration based on the dominant type of vegetation present on residential property and the local climate regime. In Hillsboro, grass and shrubs are the dominant vegetation types and utilize the most water at the height of the growing season in mid to late summer, which also corresponds to the dry season, thus creating a peak in outdoor water demand for irrigation during the month 
of August. Other outdoor activities such as car washing and pool maintenance are also assumed to be climate sensitive, but account for only a minor portion of total residential demand.

To meet the objectives of this study, I used the CCDomestic model to simulate indoor, outdoor, and total water demand for the 2040s; defined as the monthly ensemble mean of the period 2030-2059, under three individual climate change, two individual urban development, and six combined climate change and urban development scenarios. To have a baseline to compare the changes in water demand under the future scenarios, I also simulated water demand for the reference period, defined as 1981-2009, and calculated the monthly ensemble mean for this period.

\section{Results and Discussion}

\section{A. Model Calibration and Validation}

To calibrate and validate the CCDomestic model for the Hillsboro study area, I used monthly municipal-scale residential water production data from the City of Hillsboro for the period 1995-2008. I parameterized the model based on the historical population and climate data and the current indoor and outdoor water use behavior data that I obtained from the survey. For the model to perform well for this study area, it was necessary to calibrate the climate driven model parameters. The model was initially developed to be used in England and Wales, which have humid summer climates. Western Oregon experiences a dry summer climate, characterized by warm 
temperatures but little precipitation. The two model parameters that I adjusted to achieve optimal results were the monthly crop coefficient $(\mathrm{Kc})$ values and the average monthly irrigation demand $(\mathrm{mm} / \mathrm{month})$, which are both used to calculate garden watering demand. The initial Kc values in the model were based on the Food and Agriculture Organization (FAO) values for grass in a humid summer climate. I adjusted these monthly values to reflect the FAO values for grass in a dry climate. For the monthly irrigation demand parameter, I increased irrigation demand for the summer months and decreased irrigation demand for the winter months to better reflect the increased potential evapotranspiration in the summertime in Hillsboro.

To test the performance of the model, I used the 1995-2001 production data for calibration and the 2002-2008 production data for validation. The results of the model calibration (Figure 4.3) and the validation (Figure 4.4) produced $\mathrm{R}^{2}$ values, a measure of the model's goodness of fit, of 0.697 and 0.567 . These results are significantly stronger than those obtained in the original study (Downing et al. 2003) which ranged from $\mathrm{R}^{2}=0.15$ to 0.48 for the seven study areas located in England and Wales. The overall model performance for recreating the reference period was acceptable for the scope of this research $\left(\mathrm{R}^{2}=0.61\right)$ (Figure 4.5) 


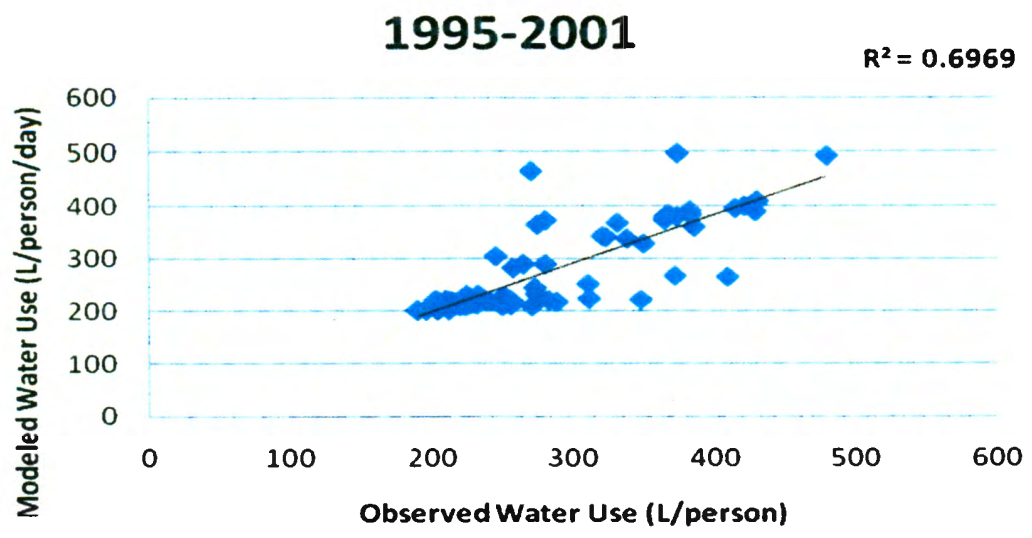

Figure 4.3: Calibration of the CCDOM model for the period 1995-2001

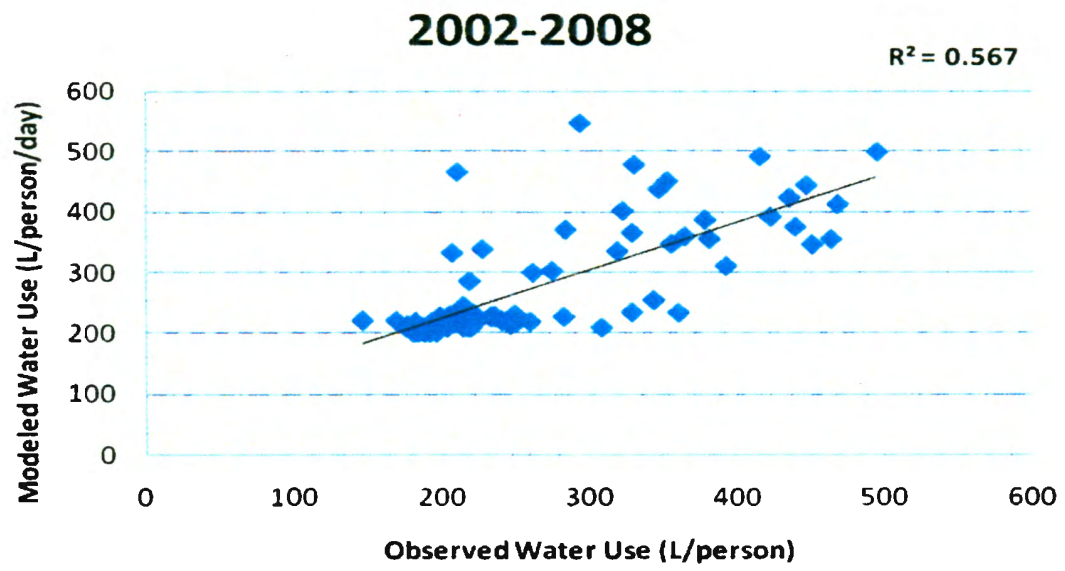

Figure 4.4: Validation of the CCDOM model for the period 2002-2008 
1995-2008

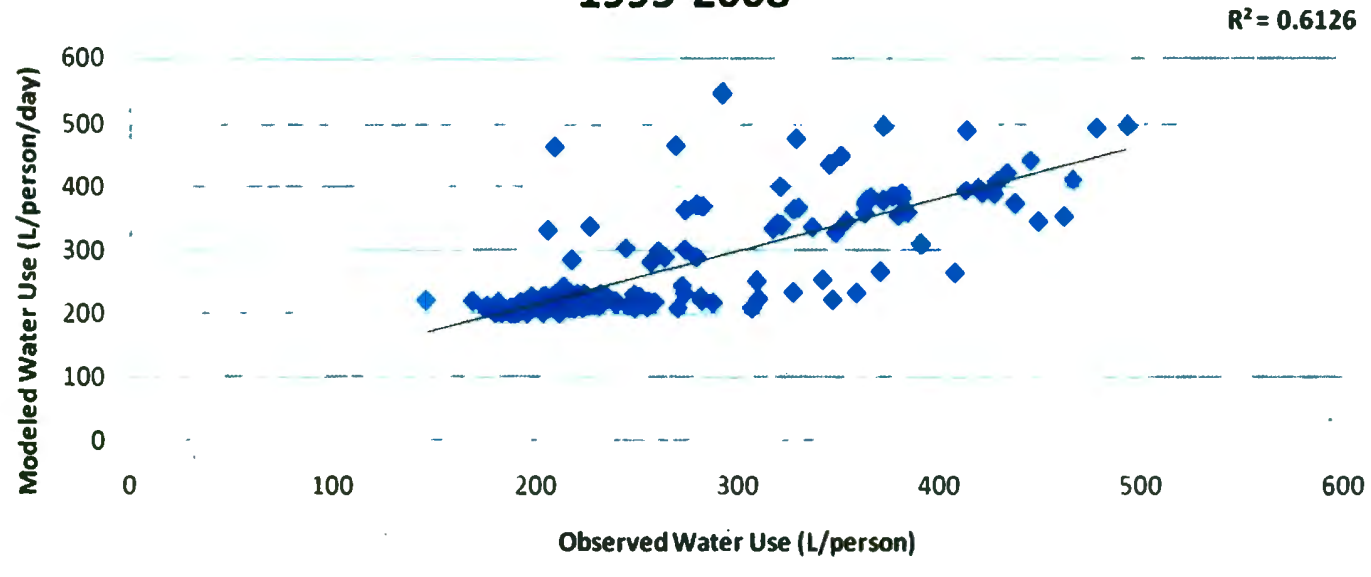

$600-$

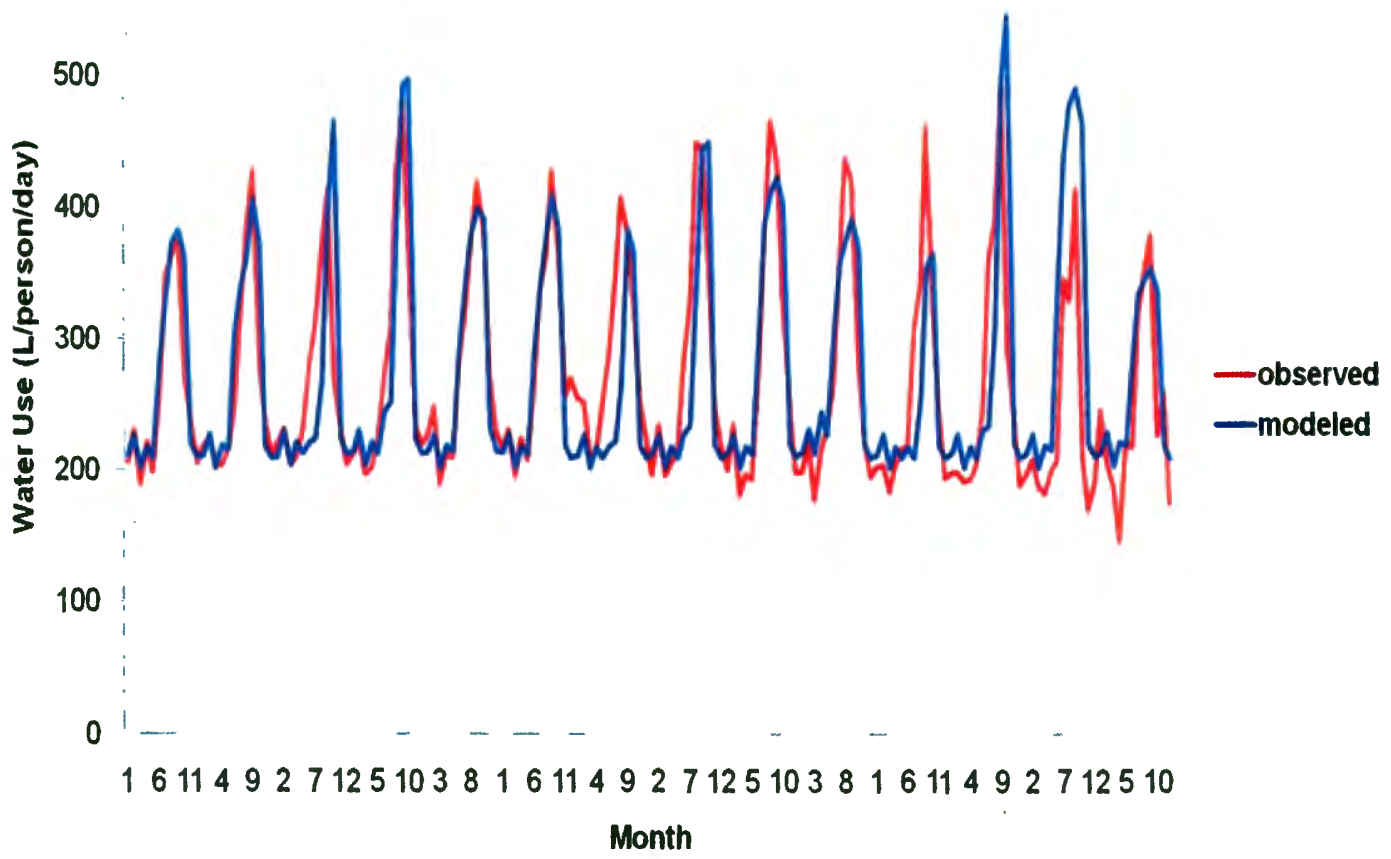

Figure 4.5: CCDOM model performance for the reference period 1995-2008 


\section{B. Indoor Water Use}

The most significant component of indoor water use is for washing and bathing. Indoor water demand is generally climate insensitive (varying only 25 L/person/day throughout the year), though prolonged periods of very hot weather, such as a summer heat wave, can induce a short-term increase in bathing. The results of the indoor water simulation (Figure 4.6) for the reference period illustrate a generally constant demand throughout the year of approximately 125 liters per person per day. The model simulations that incorporate urban development scenarios but rely on the historical climate data, produce a similar water use pattern to the reference period, maintaining a relatively constant demand throughout the year (Figure 4.6a). However, the amount of water demanded under the urban sprawl and urban densification scenarios differs significantly. The sprawl scenario produces an average water demand of 150 liters per person a day, while the urban densification scenario exhibits a reduced average demand of only 75 liters per person per day. The difference in demand is due to combined effects of water management policy and urban development. The lack of both voluntary and mandatory conservation programs and the increase in house size, due to reduced residential density, exacerbates water consumption in the sprawl scenario. The densification scenario assumes active conservation education, rebate and incentive programs for investing in water saving 
appliances, and increased residential housing density, thus generating reduced demand.

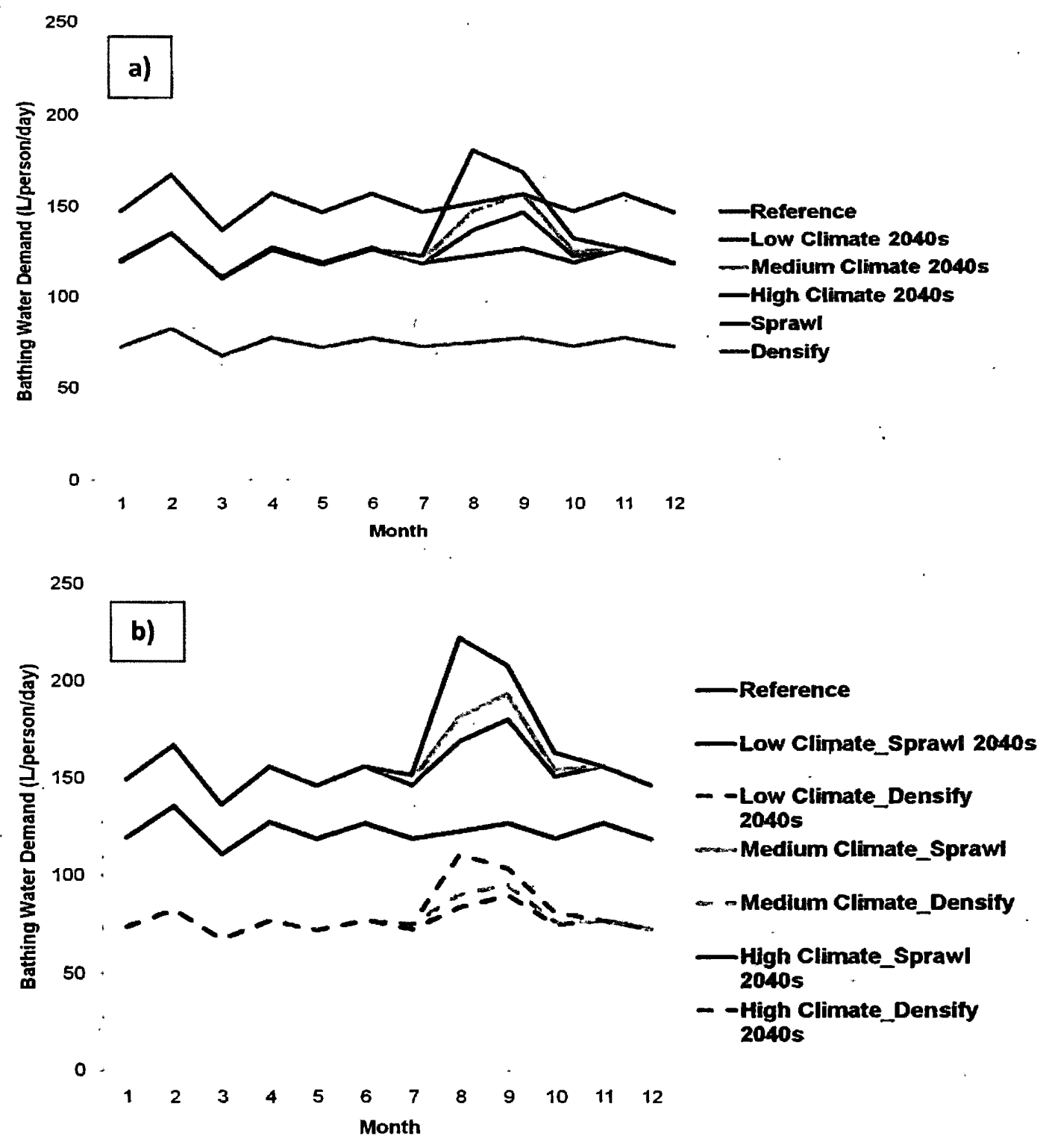

Figure 4.6: Indoor residential water demand under a) individual GCM and land use scenarios and b) combined GCM and land use scenarios 
The effect of the climate change scenarios on indoor water consumption (Figure 4.6a) is interesting because the increase in temperature during the summer months, specifically August and September, results in a new pattern of demand which includes a summer time peak in demand of 180 (L/person/day) in August increased from 126 (L/person/day) in August under the reference period. The variability of temperature, precipitation, and evapotranspiration in the climate change scenario data produces another interesting effect, which is an earlier peak, occurring in August, for the high (HadCM) climate scenario rather than in September for the low (PCM) and medium (IPSL) climate scenarios.

It is unlikely that climate change and urban development will occur in isolation of one another, thus I simulate combined scenarios (Figure 4.6b). The combined influence of climate, land use, and policy is evident in the results of the indoor water demand simulation. The magnitude of increase in demand mirrors the results from the individual urban development scenarios but also includes the peak summertime demand due to increased accumulated degree days above the $17^{\circ} \mathrm{C}$ threshold under the GCM climate projections. Current residential water demand management operates under an assumption of relatively constant indoor demand throughout the year. The results from this modeling exercise indicate that a shift in the timing and pattern of indoor demand may occur due to increased future temperatures that influence people to bathe more often and urban development plans that promote large, suburban homes and ignore conservation outreach. I performed a statistical analysis using a paired t- 
test to assess the significance of the results under the combined climate change and urban development scenarios (Table 4.4). For indoor water demand, the t-test results confirm that the demand generated by each combined scenario is statistically different.

Thus, indoor water demand is sensitive to both climate and urban development.

Table 4.4: Results of a paired t-test of the indoor demand modeling results under the combined climate change and urban development scenarios. Values shown in the table are $p$-values. If $p<0.05$, then the demand results of the two scenarios are significantly different (these cells are shaded).

\begin{tabular}{|c|c|c|c|c|c|c|}
\hline Indoor Water Demand & $\begin{array}{l}\text { Low } \\
\text { Climate } \\
\text { Densify } \\
\text { 2040s }\end{array}$ & $\begin{array}{l}\text { Low } \\
\text { Climate } \\
\text { Sprawl } \\
2040 \mathrm{~s}\end{array}$ & $\begin{array}{l}\text { Medium } \\
\text { Climate } \\
\text { Densify } \\
2040 \text { s }\end{array}$ & $\begin{array}{l}\text { Medium } \\
\text { Climate } \\
\text { Sprawl } \\
\text { 2040s }\end{array}$ & \begin{tabular}{|l|} 
High \\
Climate \\
Densify \\
2040s
\end{tabular} & $\begin{array}{l}\text { High } \\
\text { Climate } \\
\text { Sprawl } \\
\text { 2040s }\end{array}$ \\
\hline v. Reference Scenario & 0.0000 & 0,0000 & 0.0000 & 0.0000 & 00000 & 0,0000 \\
\hline v. Low Climate Densify & & 0.0000 & 0.0000 & 0.0000 & 0.0000 & 0,0000 \\
\hline v. Low Climate Sprawl & 00000 & & 0.0000 & 0.0000 & 00000 & 0.0000 \\
\hline v. Med. Climate Densify & 0,0001 & 600000 & & 00000 & 00000 & 0.0000 \\
\hline v. Med. Climate Sprawl & 0.0000 & 0.0001 & 000000 & & 00000 & 0.0000 \\
\hline v. High Climate Densify & 0.0000 & 00000 & 0.0000 & 000000 & & 0.0000 \\
\hline V. High Climate Sprawl & 0.0000 & 0.0000 & 0.0000 & 0000 & 00000 & \\
\hline
\end{tabular}

\section{Outdoor Water Use}

Water demand for external purposes, primarily irrigation, is characterized by a summertime peak, traditionally occurring in August, when evaporative demand is greatest and precipitation is minimal. Water managers anticipate this peak in water use $(139 \mathrm{~L} /$ person/day in the reference scenario) to ensure adequate supply to meet the demand. The results of the urban development scenarios demonstrate a wide range of 
summertime peak demand, from 26 (L/person/day) under the densify scenario to 275 (L/day/person) under the sprawl scenario (Figure 4.7a).

The increase in residential vegetation and outdoor area and the lack of regulation of external water consumption activities, under the sprawl scenario, produce an August peak demand (275 L/person/day) in the 2040s that is twice what is currently experienced (137 L/person/day). Conversely, the urban densification scenario illustrates an extreme reduction in outdoor water demand $(26 \mathrm{~L} /$ person/day), due to the reduction in residential vegetation, the reduction in lot size, and a conservation mandate regulating when, how often, and for how long residents are allowed to irrigate vegetation. Climate scenarios have little impact on the overall average amount of outdoor water demand. However, the increase in temperature in early summer under the GCM scenarios has an important effect, creating two distinct demand peaks, one in late June and the second in late August.

The simulations that combine climate change and urban development (Figure 4.7b) also produce unexpected results. Under the combined climate and densification scenario, the summertime peak water demand $(37 \mathrm{~L} /$ person/day) is similar to the demand generated from the densification scenario simulated under current climate conditions (26.34 L/person/day). However, the combined climate and urban sprawl scenario results in a highly exaggerated August peak demand of nearly 100 L/person/day liters more than the sprawl simulation under current climate (Figure 4.7a). Results of a paired t-test (Table 4.5) demonstrate that under combined climate 
change and urban development scenarios, outdoor water demand is more sensitive to urban development and policy decisions than to climate.
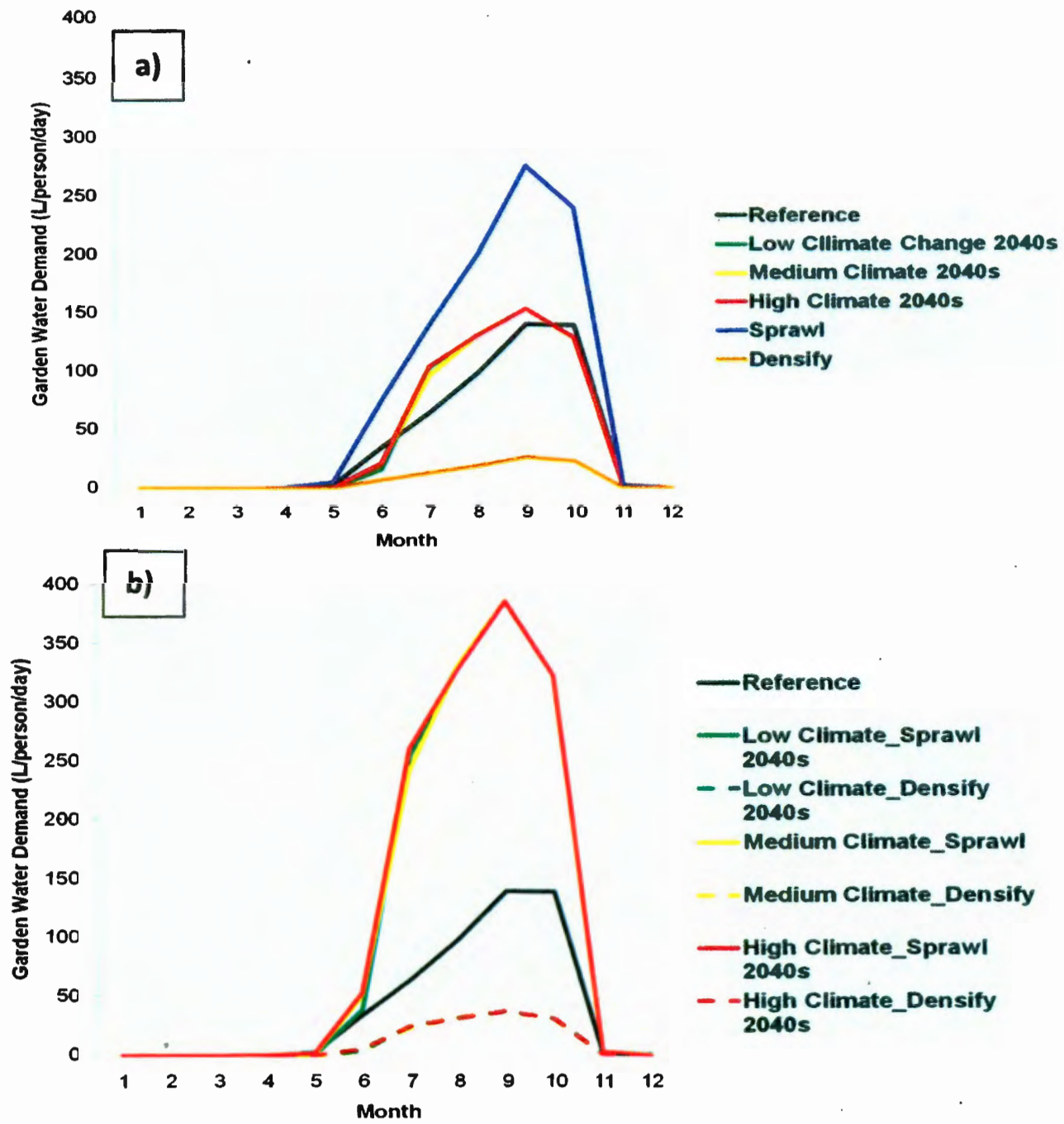

Figure 4.7: Outdoor residential water demand under a) individual GCM and land use scenarios and b) combined GCM and land use scenarios 
Table 4.5: Results of a paired t-test of the outdoor demand modeling results under the combined climate change and urban development scenarios. Values shown in the table are $p$-values. If $p<0.05$, then the demand results of the two scenarios are significantly different (these cells are shaded).

\begin{tabular}{|c|c|c|c|c|c|c|}
\hline Outdoor Water Demand & $\begin{array}{l}\text { Low } \\
\text { Climate } \\
\text { Densify } \\
\text { 2040s } \\
\end{array}$ & $\begin{array}{l}\text { Low } \\
\text { Climate } \\
\text { Sprawl } \\
\text { 2040s } \\
\end{array}$ & $\begin{array}{l}\text { Medium } \\
\text { Climate } \\
\text { Densify } \\
\text { 2040s } \\
\end{array}$ & $\begin{array}{l}\text { Medium } \\
\text { Climate } \\
\text { Sprawl } \\
\text { 2040s } \\
\end{array}$ & $\begin{array}{l}\text { High } \\
\text { Climate } \\
\text { Densify } \\
\text { 2040s } \\
\end{array}$ & $\begin{array}{l}\text { High } \\
\text { Climate } \\
\text { Sprawl } \\
\text { 2040s } \\
\end{array}$ \\
\hline v. Reference & 0,0000 & 0.0000 & 80000 & 0.0000 & 0,0000 & 00000 \\
\hline v. Low Climate Densify & & 000000 & 0.9760 & 200000 & 0.2734 & 00000 \\
\hline v. Low Climate Sprawl & 00000 & & 0,0000 & 0.9760 & 00000 & 0.2734 \\
\hline v. Med. Climate Densify & 0.9760 & 00000 & & 00000 & 0.2781 & 0.0000 \\
\hline v. Med. Climate Sprawl & 00000 & 0.9760 & 0.0000 & & 0.0000 & 0.2781 \\
\hline v. High Climate Densify & 0.2734 & 0.0000 & 0.2781 & 00000 & & 0.0000 \\
\hline V. High Climate Sprawl & 00000 & 0.2734 & 000000 & 0.2781 & 00000 & \\
\hline
\end{tabular}

\section{Total Water Use}

The results of the total water use simulations reveal a similar summertime pattern to the results from the outdoor water use simulations (Figure 4.8). Between November and May, water demand remains relatively constant, though demand is highest under the sprawl scenario (544 L/person/day) and lowest under the densification scenario (176 L/person/day), as would be expected. Beginning in May, all scenarios, except densification, exhibit an increasing trend in total water demand (Figure 4.8a). However, the month that water demand peaks, differs. For example, under high warming scenario (HadCM), total water demand exhibits an early peak in July (317 L/person/day), which was also evident in the indoor and outdoor demand patterns, and is due to the increased accumulation of high temperature days, which cross the temperature threshold increasing frequency of indoor and outdoor water use. 
The total water demand simulated under combined climate and urban development scenarios (Figure 4.8b) clearly demonstrates that combining increases in temperature and increases in residential vegetation causes an additive effect that exacerbates total water demand, resulting in midsummer demand $(708 \mathrm{~L} /$ person/day) that doubles our current peak consumption ( $359 \mathrm{~L} /$ person/day). The densification scenario illustrates that austere management and regulation and conscious urban planning can mitigate the pressures of population growth and climate change, reducing peak water demand $(215 \mathrm{~L} /$ person/day) below current levels. The paired t-test results for statistical significance (Table 4.6) reveal that the total demand results under each scenario are significantly different with the exception of the medium climate sprawl and low climate sprawl scenarios, whose results are not significantly different.

Table 4.6: Results of a paired t-test of the total demand modeling results under the combined climate change and urban development scenarios. Values shown in the table are $p$-values. If $p<0.05$, then the demand results of the two scenarios are significantly different (these cells are shaded).

\begin{tabular}{|c|c|c|c|c|c|c|}
\hline Total Water Demand & $\begin{array}{l}\text { Low } \\
\text { Climate } \\
\text { Densify } \\
\text { 2040s } \\
\end{array}$ & \begin{tabular}{|l|} 
Low \\
Climate \\
Sprawl \\
2040s \\
\end{tabular} & \begin{tabular}{|l} 
Medium \\
Climate \\
Densify \\
2040 s \\
\end{tabular} & \begin{tabular}{|l|} 
Medium \\
Climate \\
Sprawl \\
2040s \\
\end{tabular} & \begin{tabular}{|l|} 
High \\
Climate \\
Densify \\
2040s \\
\end{tabular} & \begin{tabular}{|l|} 
High \\
Climate \\
Sprawl \\
2040s \\
\end{tabular} \\
\hline v. Reference & 0,0000 & 00000 & 0.0000 & 00000 & 000000 & 00000 \\
\hline v. Low Climate Densify & & 00000 & 00003 & 000000 & 000000 & 000000 \\
\hline v. Low Climate Sprawl & 0,0000 & & 0.0000 & 0.1299 & 00000 & 200000 \\
\hline v. Med. Climate Densify & 00003 & 0.0000 & & 800000 & 00000 & oogooo \\
\hline v. Med. Climate Sprawl & 0.0000 & 0.1299 & 0,0000 & & 060000 & 0,0000 \\
\hline v. High Climate Densify & 0000 & 0,0000 & 00000 & 0.0000 & & 0,0000 \\
\hline V. High Climate Sprawl & 00000 & 0.0000 & 100000 & 00000 & 00000 & \\
\hline
\end{tabular}




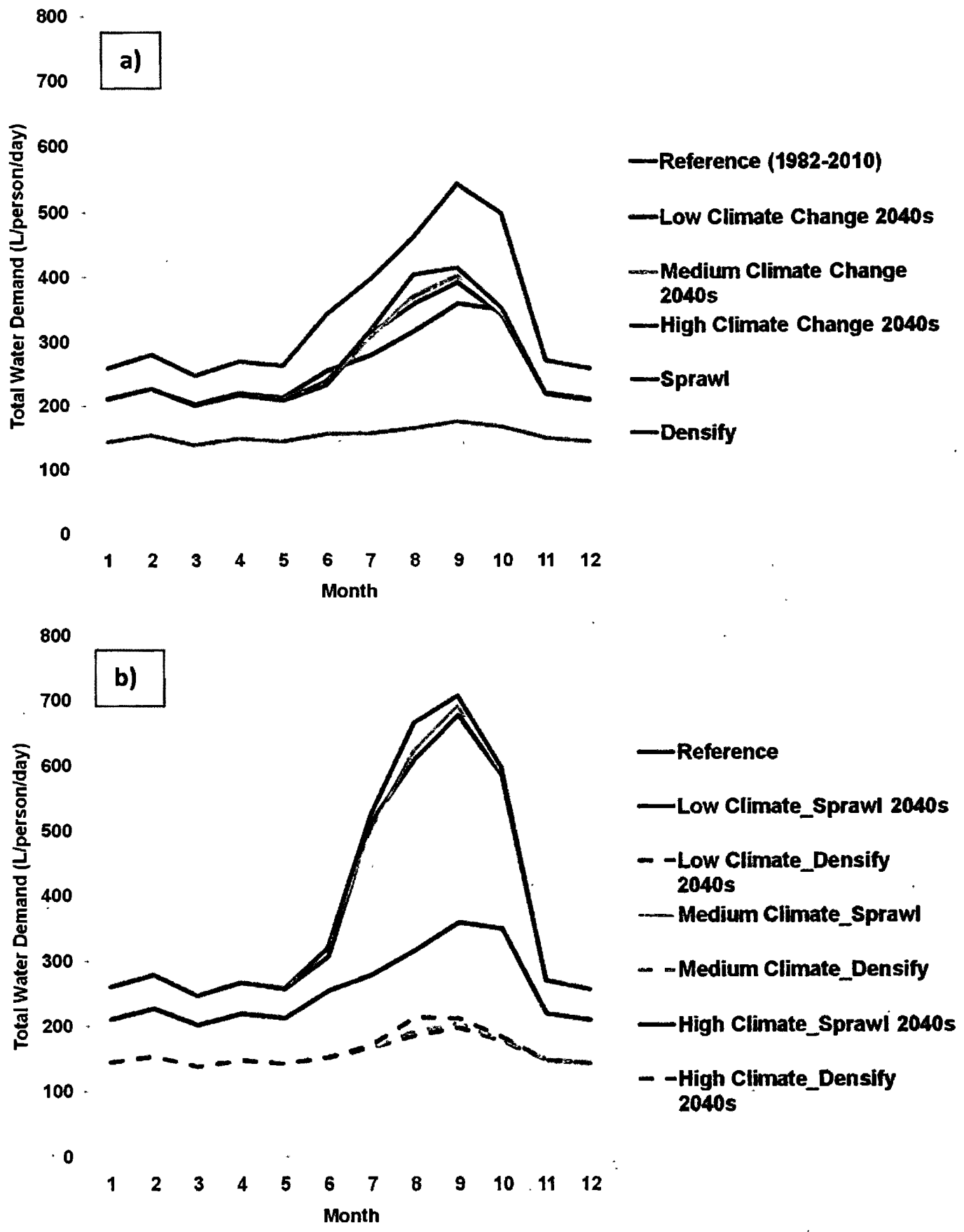

Figure 4.8: Total residential water demand under a) individual GCM and land use scenarios and b) combined GCM and land use scenarios 


\section{Conclusions}

To gain a comprehensive understanding of the effect of urban development, policy, and climate on water demand, I used a system dynamics model to simulate indoor, outdoor, and total residential water demand for the period 2030-2059 under five individual and six combined alternative future scenarios. The results highlight the complex interactions between biophysical and social drivers of water demand in an urban setting. The findings of this study suggest that at the municipal scale, water demand is highly sensitive to urban design scenarios due to the implications for policy and regulation, which impact water-use behaviors, perhaps even more than climate change. This conclusion reinforces Liu et al. (2007) inference that "well-designed regulations, policies, incentives, and governance structures can stimulate involvement of diverse populations in the understanding and management of coupled human and natural systems." Indoor water demand exhibited sensitivity to climate scenario, which produced an unexpected midsummer peak. The main conclusions of this research are: 1) Indoor water demand, which has historically been assumed climate insensitive, may exhibit a summertime peak demand under increased future temperatures due to climate change; 2) Dense urban development that limits lot size and vegetation concurrent with strict regulations regarding external water use can mitigate peak summer demand; 3) Peak outdoor water use is especially sensitive to urban sprawl and lax water conservation policies; and 4) Climate change may shift the 
timing of peak demand to earlier in the summer, due to hot, dry weather beginning in early, rather than midsummer in western Oregon. 


\section{Conclusions}

This thesis, organized as three discrete academic papers, traced the methodological developments of water resources research and examined the combined impacts of climate change and urban development on residential water demand at the neighborhood and municipal scale in Hillsboro, Oregon, a large suburb of Portland. To determine the influence of biophysical and social drivers on urban water demand at multiple scales, I used a neighborhood-scale surface energy balance model, the Localscale Urban Meteorological Parameterization Scheme (LUMPS) (Grimmond and Oke 2002), and a municipal-scale system dynamics model, CCDomestic (Downing et al. 2003). Within the urban environment, large scale processes and patterns result from the nesting of local system within regional and global systems (Liu et al. 2007).

Urban water demand represents a complex system, dependent on patterns and processes that emerge through multi-scale and cross-scale human-environment interactions. Humans hold a unique role because our distinctive characteristics of foresight and intentionality provide us the ability to build or erode resilience in coupled systems through the management strategies that we choose to implement (Holling et al. 2001). The complex interactions between the neighborhood and municipal scale are highly evident in the findings of this thesis and have important implications for urban planning and water management. Land cover and water use are highly intertwined and thus urban land-use planning and water management must also 
become fully integrated in order to increase resilience and effectively overcome the challenges of climate change and population growth while minimizing vulnerability to increasing water scarcity and over allocation of natural resources. Furthermore, future development plans need to be spatially explicit and integrate current vegetation and water consumption patterns, so that already heavily developed neighborhoods do not experience increased future imperviousness. Instead, density should be increased in sprawling, highly vegetated neighborhoods, to reduce external water consumption, especially under future increases in summertime temperature due to climate change. At the city-wide scale, findings suggest that increases in water demand from population growth and climate change can be mitigated by combining increased residential urban density with strict water conservation management. Under this type of scenario, there is a positive feedback between reduced vegetation and mandatory restrictions on irrigation that results in a significant reduction in peak summertime water demand. At the municipal scale this type of integrated land use planning and water management policy appears an effective solution. However, results from this research have shown that at the neighborhood scale increased urban density in already xeric neighborhoods is maladaptive, because the absolute change in external water consumption is insignificant but UHI intensity, especially in terms of reduced nighttime cooling, is exacerbated. Thus, by constraining human behavior through city-scale policy and land-use planning, cities may induce an unexpected shift in the coupled human and natural system, resulting in a more degraded local environment. 
The findings of this thesis support the need for comprehensive future research that focuses on the capacity for and effectiveness of decision-making at multiple scales of governance in regard to urban water management. Research that targets only sole sectors of water consumption and ignores the organizational and legal challenges of achieving integrated water management can draw only limited conclusions regarding the struggles faced by water managers. This criticism relates directly to this thesis, as the research focuses only on water demand from the residential sector, ignoring future changes in agricultural, industrial, commercial, and public sector water demand. Furthermore, this research assumes that water managers have complete control over the water resources that they supply to their customers. However, the complexities inherent in the processes to buy and sell water rights, the intractable legal battles being fought over water resources and the reality that the state owns the water leaves water managers with severely limited options. The deep uncertainty associated with climate change models and the lack of universal methods to quantify the levels of this uncertainty also limits the ability for water managers to incorporate climate change scenarios into water resource planning. 


\section{References}

Abbott, M.B.1993 The electronic encapsulation of knowledge in hydraulics, hydrology, and water resources, Advances in Water Resources 16: 21-39.

Adamowski, J.S. 2008. Peak daily water demand forecast modeling using artificial neural networks. Journal of Water Resources Planning and Management 134: 119128.

Adger, W.N. 2006. Vulnerability. Global Environmental Change 16: 168-281.

Adya, M. and F. Collopy. 1998. How effective are neural networks at forecasting and prediction? A review and evaluation. Journal of Forecasting 17: 481-495.

Al-Qunaibet, M.H. and R.S. Johnston. 1985. Municipal demand for water in Kuwait: methodological issues and empirical results. Water Resources Research 21(4): 433-438.

Anderies, J.M., B.H. Walker, and A.P. Kinzig. 2006. Fifteen weddings and a funeral; case studies and resilience-based management. Ecology and Society 11(1), 21.

Arnfield, A.J. 2003. Two decades of urban climate research: a review of turbulence, exchanges of energy and water, and the urban heat island. International Journal of Climatology 23: 1-26.

Asah, S.T. 2008. Empirical social-ecological system analysis: from theoretical framework to latent variable structural equation model. Environmental Management 42, 1077-1090.

Atwood, C., R. Kreutzwiser, and R. de Loe. 2007. Residents' assessment of an urban outdoor water conservation program in Guelph, Ontario. Journal of the American Water Resources Association 43 (2): 427-439.

Baker, J.P., D.W. Hulse, S.V. Gregory, D. White, J. Van Sickle, P.A. Berger, D. Dole, and N.H. Schumaker. 2004. Alternative futures for the Willamette River Basin, Oregon. Ecological Applications 14: 313-324.

Balling Jr., R.C. and P. Gober. 2006. Climate variability and residential water use in the city of Phoenix, Arizona. Journal of Applied Meteorology and Climatology 46: 
Balling, Jr., R.C., P. Gober, and N. Jones. 2008. Sensitivity of residential water consumption to variations in climate: An intraurban analysis of Phoenix, Arizona. Water Resources Research 44: W10401.

Barnett T.P., D.W. Pierce, H.G. Hidalgo, C. Bonfils, B.D. Santer, T. Das, G. Bala, A.W. Wood, T. Nozawa, A.A. Mirin, D.R. Cayan, M.D. Dettinger. 2008. Humaninduced changes in the hydrology of the western United States, Science 319, 10801083.

Bates, B.C., Z.W. Kundzewicz, S. Wu and J.P. Palutikof, Eds. 2008. Climate change and water. Technical Paper of the Intergovernmental Panel on Climate Change, IPCC Secretariat, Geneva, 210 pp.

Benz, U., P. Hofmann, G. Willhauck, I. Lingenfelder, and M. Hey. 2004. Multiresolution, object-oriented fuzzy analysis of remote sensing data for GIS-ready information. Journal of Photogrammetry and Remote Sensing 58: 239-258.

Berkes, F. and C. Folke. 2001. Back to the future: ecosystem dynamics and local knowledge, in: Panarchy, edited by L.H. Gunderson and C.S. Holling, pp.121-146, Island Press, Washington, DC.

Beven, K. 2009. Environmental Modelling: An Uncertain Future? Routledge, New York.

Birkenholtz, T. 2009. Irrigated landscapes, produced scarcity, and adaptive social institutions in Rajasthan, India. Annals of the Association of American Geographers 99(1): 118-137.

Bloschl, G. and M. Sivapalan.1995. Scale issues in hydrological modeling: A review. Hydrological Processes 9, 251-290.

Borgstrom, S.T., T. Elmqvist, P. Angelstam, and C. Alfsen-Norodom. 2006. Scale mismatches in management of urban landscapes. Ecology and Society 11(2): 16.

Brookshire, D.S., H.S. Burness, J.M. Chermak, K. Krause. 2002 Western urban water demand. Natural Resources Journal 42(4): 873-898.

Brown, Keath, and Wong. 2009. Urban water management in cities: historical, current 
and future regimes. Water Science and Technology 59 (5): 847-855.

Cash, D.W., W.N. Adger, F. Berkes, P. Garden, L. Lebel, P. Olsson, L. Pritchard, and O. Young. 2006. Scale and cross-scale dynamics: governance and information in a multilevel world. Ecology and Society 11(2): 8.

Chang, H., H. Parandvash and V. Shandas. 2010. Spatial variations of single family residential water consumption in Portland, Oregon. Urban Geography, in press.

Chen, Y., E.G. Irwin, and C. Jayaprakash. 2009. Dynamic modeling of environmental amenity-driven migration with ecological feedbacks. Ecological Economics 68: 2498-2510.

Chu, J., C. Wang, J. Chen, H. Wang. 2009. Agent-based residential water use behavior simulation and policy implications: a case study in Beijing City. Water Resoucesr Management 23: 3267-3295. DOI 10.1007/s11269-009-9433-2.

City of Hillsboro. Retrieved on March 10, 2009. http://www.ci.hillsboro.or.us/.

Civerolo, K., C: Hogrefe, B. Lynn, J. Rosenthal, J.-Y. Ku, W. Solecki, J. Cox, C. Small, C. Rosenzweig, R. Goldberg, K. Knowlton, and P. Kinney. 2007.

Estimating the effects of increased urbanization on surface meteorology and ozone concentrations in New York City metropolitan region. Atmospheric Environments 41: 1803-1818.

Clarke, G.P., A. Kashti, A. McDonald, and P. Williamson. 1997. Estimating small area demand for water: a new methodology. Journal of the Institution of Water and Environmental Management. 11(3): 186-192.

Cooley, H. and P. H. Gleick. 2009. Urban water-use efficiencies: Lessons from United States cities. In The World's Water 2008-2009: The Biennial Report on Freshwater Resources, ed. P. H. Gleick. Washington, D. C.: Island Press, 101121.

Corbella, H.M. and D. Sauri Pujol. 2009. What lies behind domestic water use? A review essay on the drivers of domestic water consumption. Boletin de la Asociacion de Geografos Espanoles 50: 297-314.

Coutts, A. M., J. Beringer, and N. J. Tapper. 2007. Impact of increasing urban density on local climate: Spatial and temporal variations in the surface energy balance in 
Melbourne, Australia. American Meteorological Society 46: 477-493.

Cumming, G.S., D.H.M. Cumming, and C.L. Redman. 2006. Scale mismatches in social-ecological systems: causes, consequences, and solutions. Ecology and Society 11(1): 14 .

Dahan, M. and U. Nisan. 2007. Unintended consequences of increasing block tariffs pricing policy in urban water. Water Resources Research 43: W03402.

Dalhuisen, J.M., R.J.G.M. Florax, H.L.F. de Groot, and P. Nijkamp. 2003. Price and income elasticities of residential water demand: a meta-analysis. Land Economics 79(2): 292-308.

de Gispert, C. 2004. The economic analysis of industrial water demand: a review, Environment and Planning C: Government and Policy 22(1): 15-30.

DOGAMI (Oregon Department of Geology and Mineral Industries). 2009. http://www.oregongeology.com/sub/projects/olc/default.htm

Domene, E. and D. Saurí. 2007. Urbanization and water consumption: influencing factors in the metropolitan region of Barcelona. Urban Studies 43 (9): 1605-1623.

Downing, T. E., R. E. Butterfield, B. Edmonds, J. W. Knox, S. Moss, B. S. Piper, and E. K. Weatherhead. 2003. Climate change and the demand for water. Research Report, Stockholm Environment Institute Oxford Office, Oxford.

Endter-Wada, J. and J. Kurtzman, S. P. Keenan, R. K. Kjelgren, and C. M. U. Neale. 2008. Situational waste in landscape watering: Residential and business water use in an urban Utah community. Journal of the American Water Resources Association 44 (4): 902-919.

Environmental Systems Research Institute (ESRI). 2009. ArcGIS 9.3.1. Redlands, California

Fan, H. and D.J. Sailor. 2005. Modeling the impacts of anthropogenic heating on the climate of Philadelphia: a comparison of implementations in two PBL schemes. Atmospheric Environment 39: 73-84.

Firat, M., M.A. Yurdusev, and M.E. Turan. 2009. Evaluation of artificial neural network techniques for municipal water consumption modeling. Water Resour. Manage. 23: 617-632. DOI: 10.1007/s11269-008-9291-3. 
Folke, C., S. Carpenter, T. Elmqvist, L. Gunderson, C.S. Holling, and B. Walker. 2002. Resilience and sustainable development: building adaptive capacity in a world of transformations. Ambio 31(5): 437-440.

Ford, A. 1999. Modeling the environment: an introduction to system dynamics modeling of environmental systems, Island Press, Washington, DC.

Fox, C., B.S. McIntosh, and P. Jeffrey. 2009. Classifying households for water demand forecasting using physical property characteristics. Land Use Policy 26: 558-568.

Franczyk, J. and H. Chang. 2009a. Spatial analysis of water use in Oregon, USA, 1985-2005. Water Resource Management 23: 755-774.

Franczyk, J. and H. Chang. 2009b. The effects of climate change and urbanization on the runoff of the Rock Creek basin in the Portland metropolitan area, Oregon, USA. Hydrological Processes 23: 805-81.

Frederick, K.D. 1997. Adapting to climate impacts on the supply and demand for water. Climatic Change 37: 141-156.

Galán, J.M., A. López-Paredes, and R. del Olmo. 2009. An agent-based model for domestic water management in Valladolid metropolitan area. Water Resources Research, 45, W05401.

Garb, Y., S. Pulver, and S.D. VanDeever. 2008. Scenarios in society, society in scenarios: toward a social scientific analysis of storyline-driven environmental modeling. Environmental Research Letters 3: 045015.

Gato, S., N. Jayasuriya, and P. Roberts. 2007. Temperature and rainfall thresholds for base use urban water demand modeling. Journal of Hydrology 337: 364-376.

Ghiassi, M., D.K. Zimbra, and H. Saidane. 2008. Urban water demand forecasting with a dynamic artificial neural network model. Journal of Water Resources Planning and Management 134(2): 138-146. DOI: 10.1061/(ASCE)07339496(2008)134:2(138).

Ghiassi, M. and S. Nangoy. 2009. A dynamic artificial neural network model for forecasting nonlinear processes. Computers \& Industrial Engineering 57: 287297. 
Gleick, P.H. 2003. Water use. Annual Review of Environmental Resources 28: 275314.

Gleick, P.H. 2009. Urban water-use efficiencies: Lessons from United State cities. In The World's Water 2008-2009 Island Press: New York.

Gober, P., C.W. Kirkwood, R.C. Balling, Jr., A.W. Ellis, and S. Dietrick. 2010a. Water planning under climatic uncertainty in Phoenix: why we need a new paradigm. Annals of the Association of American Geographers 100(2): 356-372.

Gober, P., A. Brazel, R. Quay, S. Myint, S. Grossman-Clarke, A. Miller, and S. Rossi. $2010 \mathrm{~b}$. Using watered landscapes to manipulate urban heat island effects: How much water will it take to cool Phoenix? Journal of the American Planning Association 76(1): 109-121.

Gordon C, Cooper C, Senior CA, Banks H, Gregory JM, Johns TC, Mitchell JFB, Wood RA. 2000. The simulation of SST, sea ice extents and ocean heat transports in a version of the Hadley Centre coupled model without flux adjustments. Climate Dynamics 16: 147-168

Graves, D. and H. Chang. 2007. Hydrologic impacts of climate change in the Upper Clackamas River Basin, Oregon, USA. Climate Research 33: 143-157.

Grimm, N.B., J.M. Grove, S.T.A. Pickett, and C.L. Redman. 2000. Integrated approaches to long-term studies of urban ecological systems. BioScience 50(7): 571-584.

Grimm, NB., D. Foster, P. Groffman, J.M. Grove, C.S. Hopkinson, K.J. Nadelhoffer, D.E. Pataki, and D.P.C. Peters. 2008. The changing landscape: ecosystem responses to urbanization and pollution across climatic and societal gradients. Frontiers in Ecology and Environments 6(5): 264-272.

Grimmond, S. 2007. Urbanization and global environmental change: local effects of urban warming. Cities and Global Environmental Change: 83-88.

Grimmond, C. S. B., and T. R. Oke. 1999. Evapotranspiration rates in urban areas. Impacts of urban growth on surface water and groundwater quality (Proceedings of IUGG 99 Symposium, Birmingham) Publication 259: 235-243.

Grimmond, C. S. B., and T. R. Oke. 2002. Turbulent heat fluxes in urban areas: 
observations and a local-scale urban meteorological parameterization scheme (LUMPS). Journal of Applied Meteorology 41: 792-810.

Guhathakurta, S. and P. Gober. 2007. The impact of the Phoenix urban heat island on residential water use. Journal of the American Planning Association 73 (3): 317 329.

Gunderson, L.H. and C.S. Holling. 2001. Panarchy: understanding transformations in human and natural systems, Island Press, Washington, DC.

Gunderson, L.H., S. R. Carpenter, C. Folke, P. Olssen, and G. Peterson. 2006. Water RATS (resilience, adaptability, and transformability) in lake and wetland socialecological systems. Ecology and Society 11(1): 16.

Gutzler, D. S. and J. S. Nims. 2005. Interannual variability of water demand and summer climate in Albuquerque, New Mexico. Journal of Applied Meteorology 44: $1777-1787$.

Harlan, S.L., S.T. Yabiku, L. Larsen, and A.J. Brazel. 2009. Household water consumption in an arid city: affluence, affordance, and attitudes. Society and Natural Resources 22: 691-709, DOI:10.1080/08941920802064679.

Hart, M.A. and D.J. Sailor. 2009. Quantifying the influence of land-use and surface characteristics on spatial variability in the urban heat island. Theoretical Applied Climatology 95: 397-406.

Head, L. and P. Muir. 2006. Suburban life and the boundaries of nature: resilience and rupture in Australian backyard gardens. Transactions of the Institute of British Geographers 31: 505-524.

Head, L. and P. Muir. 2007. Changing cultures of water in eastern Australian backyard gardens. Social and Cultural Geography 8(6): 889-905.

Hilaire, R.S., M.A. Arnold, D.C. Wilkerson, D.A. Devitt, B.H. Hurd, B.J. Lesikar, V.I. Lohr, C.A. Martin, G.V. McDonald, R.L. Morris, D.R. Pittenger, D.A. Shaw and D.F. Zoldoske. 2008. Efficient Water Use in Residential Urban Landscapes. Hortscience 43: 2081-2092.

Holling, C.S. 2001. Understanding the complexity of economic, ecological, and social systems. Ecosystems 4: 390-405. 
Housè-Peters, L., B. Pratt, and H. Chang. 2010. Effects of urban spatial structure, sociodemographics, and climate on residential water consumption in Hillsboro, Oregon. Journal of the American Water Resources Association (in press).

Hulse, D.W., A. Branscomb, and S.G. Payne. 2004. Envisioning alternatives: using citizen guidance to map future land and water use. Ecological Applications 14(2): 325-341.

Hurlimann, A., S. Dolnicar, P. Meyer. 2009. Understanding behavior to inform water supply management in developed nations: a review of literature, conceptual model and research agenda, Journal of Environmental Management, 91(1), 47-56.

Inman, D. and P. Jeffrey. 2006. A review of residential water conservation tool performance and influences on implementation effectiveness. Urban Water Journal 3(3): 127-143.

Intergovernmental Panel on Climate Change (IPCC). 2007. Summary for Policymakers. In Climate Change 2007: The Physical Science Basis. Contribution of Working Group I to the Fourth Assessment Report of the Intergovernmental Panel on Climate Change. Cambridge University Press: Cambridge, UK and New York, USA.

Irwin, E.G., C. Jayaprakash, and D.K. Munroe. 2009. Towards a comprehensive framework for modeling urban spatial dynamics. Landscape Ecology 24: 12231236.

Janssen, M.A. and E. Ostrom. 2006. Empirically based, agent-based models. Ecology and Society 11(2): 37.

Joint Water Consortium (JWC). 2009. Section 3: Water Conservation. OAR 690-086$0150(1)-(6)$.

Kalra, A., Piechota, T.C. Davies, R., Tootle, G.A. 2008. Changes in U.S. Streamflow and western U.S. snowpack. Journal of Hydrologic Engineering 13(3): 156-163.

Kanda, M. 2007. Progress in urban meteorology: a review. Meteorological Society of Japan 85: 363-383.

Klein,J. and R. Alig. 1999. Does land use planning show the conversion of forest and farm lands? Growth and Change 30: 3-22. 
Kenney, S. D., C. Goemans, R. Klein, J. Lowery, and K. Reidy. 2008. Residential water demand management: lessons from Aurora, Colorado. Journal of the American Water Resources Association 44 (1): 192-207.

Kurtz, T., N. Donaghue, and I. Walker. 2005. Utilizing a social-ecological framework to promote water and energy conservation: A field experiment. Journal of Applied Social Psychology 35 (6): 1281-1300.

Lake, P.S. and N. R. Bond. 2007. Australian futures: Freshwater ecosystems and human water usage. Futures 39: 288-305.

Langridge, R., J. Christian-Smith, and K.A. Lohse. 2006. Access and resilience: analyzing theconstruction of social resilience to the threat of water scarcity. Ecology and Society 11(2): 18.

Lebel, L., J.M. Anderies, B. Campbell, C. Folke, S. Hatfield-Dodds, T.P. Hughes, and J. Wilson. 2006. Governance and the capacity to manage resilience in regional social-ecological systems. Ecology and Society 11(1): 19.

Lee, J. G., and J.P. Heaney. 2003. Estimation of urban imperviousness and its impacts on storm water systems. Journal of Water Resources Planning and Management 129(5): 419-426.

Lee, S.-J. and E.A. Wentz. 2008. Applying Bayesian Maximum Entropy to extrapolating local-scale water consumption in Maricopa County, Arizona. Water Resources Research 44. W01401.

Lee, S.-J., E.A. Wentz, and P. Gober. 2010. Space-time forecasting using soft geostatistics: a case study in forecasting municipal water demand for Phoenix, Arizona. Stochastic Environmental Resource Risk Assessment 24: 283-295.

Liu, J., T. Dietz, S.R. Carpenter, M. Alberti, C. Folke, E. Moran, A.N. Pell, P. Deadman, T. Kratz, J. Lubchenco, E. Ostrom, Z. Ouyang, W. Provencher, C.L. Redman, S.H. Schneider, and W.W. Taylor. 2007. Complexity of coupled human and natural systems. Ambio 317: 1513-1516.

Loridian, T., C.S.B. Grimmond, B.D. Offerle, D.T. Young, T. Smith, and L. Jarvi. 2010. LUMPS-NARP an urban land surface scheme: evaluation and development of a new longwave parameterization. J. Appl. Meteorol. Clim. (in review). 
Lowrey, J.L., A.J. Ray and R.S. Webb. 2009. Factors influencing the use of climate information by Colorado municipal water managers. Climate Research 40: 103119.

Magliocca, N.R. 2008. Induced coupling: an approach to modeling and managing complex human-landscape interactions. Systems Research and Behavioral Science 25: 655-661.

Maidment, D.R. and E. Parzen. 1984. Cascade model of monthly municipal water use. Water Resources Research 20(1): 15-23.

Maidment, D. R., S. Miaou and M. M. Crawford. 1985. Transfer function models of daily urban water use. Water Resources Research 21 (4): 425-432.

Maidment, D.R. and S.P. Miaou. 1986. Daily water use in nine cities. Water Resources Research 22(6): 845-851.

Manson, S.M. and T. Evans. 2007. Agent-based modeling of deforestation in southern Yucatán, Mexico and reforestation in the Midwest United States. Proceedings of the National Academy of Sciences 104(52): 20678-20683.

Marti O, Bracommot P, Bellier J, Benshila R, Bony S, Brockmann P, Cadulle P, Caubel A, Denvil S, Dufresne JL, Fairhead L, Filiberti MA, Hourdin F, Krinner G, Lévy C, Musat I, Talandier C. 2005. The new IPSL climate system model: IPSLCM4. Institut Poerre Simon Laplace des Sciences de l'Environnement Global.

Martin, C.A., P.S. Warren, and A.P. Kinzig. 2004. Neighborhood socioeconomic status is a useful predictor of perennial landscape vegetation in residential neighborhoods and embedded small parks in Phoenix, Arizona. Landscape and Urban Planning 69: 355-368.

Martinez-Espineira, R. 2002. Residential water demand in the Northwest of Spain. Environmental and Resource Economics 21: 161-187.

Masson, V. 2006. Urban surface modeling and the meso-scale impact of cities. Theoretical and Applied Climatology 84: 35-45.

Mauro, S.E.D. 2009. Seeing the local in the global: political ecologies, world systems, and the question of scale. Geoforum 40(1): 116-125.

McPherson, G. 1990. Modeling residential landscape water and energy use to evaluate 
water conservation policies. Landscape Journal 9(2): 122-134.

Metro. 2009. Metroscope Gen 2.3 - Year 2030. http://www.oregonmetro.gov/index.cfm/go/by.web/id=24905 Last accessed on May 6, 2010.

Mestayer, P.G., P. Durand, P. Augustin, S. Bastin, J.M. Bonnefond, B. Benech, B. Campistron, A. Coppalle, H. Delbarre, B. Dousset, P. Drobinski, A. Druilhet, E. Frejafon, C.S.B. Grimmond, D. Groleau, M. Irvine, C. Kergomard, S. Kermadi, J.P. Lagouarde, A. Lemonsu, F. Lohou, N. Long, V. Masson, C. Moppert, J. Noilhan, B. Offerle, T.R. Oke, G. Pigeon, V. Puygrenier, S. Roberts, J.M. Rosant, F. Said, J. Salmond, M. Talbaut, and J. Voogt. 2005. The urban boundary layer field campaign in Marseille (UBL/CLU-ESCOMPTE): Set-up and first results. Boundary Layer Meteorology 114: 315-365.

Miaou, S.P. 1990. A class of time series urban water demand models with nonlinear climatic effects. Water Resources Research 26 (2): 169-178.

Middel, A., B. Hagen, A. Brazel, and S. Myint. 2009. Simulation of possible scenarios for local scale energy balances in residential neighborhoods in Phoenix, AZ, USA. (in review)

Miller, E. and L. Buys. 2008. The impact of social capital on residential wateraffecting behaviors in a drought prone Australian community. Society and Natural Resources 21: 244-257.

Milly, P.C.D., J. Betancourt, M. Falkenmark, R.M. Hirsch, Z.W. Kundzewicz, D.P. Lettenmaier, and R.J. Stouffer. 2008. Stationarity is dead: whither water management? Science 319: 573-574.

Mitchell, V. G., H. A. Cleugh, C. S. B. Grimmond, and J. Xu. 2007. Linking urban water balance and energy balance models to analyze urban design options. Hydrological Processes 22: 2891-2900.

Morehouse B. J., R. H. Carter, and P. Tschakert. 2002. Sensitivity of urban water resources in Phoenix, Tucson, and Sierra Vista, Arizona, to severe drought. Climate Research 21(3): 283-297.

Mote, P. 2003. Trends in snow water equivalent in the Pacific Northwest and their climatic causes. Geophysical Research Letters 30 (12): 1601. 
Myint, S. 2009. Object-based urban classification using a fine resolution imagery. Presented at the 2009 GeoDa center for geospatial analysis and computation, Brown Bag lunch series.

'Newton, T., T.R. Oke, C.S.B. Grimmond, and M. Roth. 2007. The suburban energy balance in Miami, Florida. Geogrfiska Annaler 89A(4): 331-347.

NOAA National Climatic Data Center. 2010. http://www.ncdc.noaa.gov/oa/ncdc.html. (accessed on May 6, 2010)

Offerle, B., C.S.B. Grimmond, and T.R. Oke. 2003. Parameterization of net all-wave radiation for urban areas. Journal of Applied Meteorology 42: 1157-1173.

Offerle, B., P. Jonsson, I. Eliasson, and C. S. B. Grimmond. 2005. Urban modification of the surface energy balance in the West African Sahel: Ouagadougou, Burkina Faso. Journal of Climate 18: 3983-3995.

Ojeda, M. I., A.S. Mayer, and B.S. Solomon. 2008. Economic valuation of environmental services sustained by water flows in the Yaqui River Delta. Ecological Economics 65: 155-166.

Oke, T. R. 1987. Boundary Layer Climates. $2^{\text {nd }}$ ed. London: Methuen.

Oke, T. R., G. Zuener and E. Jauregul.1992. The surface energy balance in Mexico City. Atmospheric Environment, 26B (4): 433-444.

Oleson, K. W., G. B. Bonan, J. Feddema, M. Vertenstein, and C. S. B. Grimmond. 2007. An urban parameterization for a global climate model. Part I: Formulation and evaluation for 2 cities. Journal of Applied Meteorology and Climatology 47: 1038-1060.

Oleson, K. W., G. B. Bonan, J. Feddema, and M. Vertenstein. 2008. An urban parameterization for a global climate model. Part II: Sensitivity to input parameters and the simulated urban heat island in offline simulations. Journal of Applied Meteorology and Climatology 47: 1061-1076.

Oregon Water Resources Department (OWRD). 2010. Oregon Water Supply and Conservation. http://www.oregon.gov/OWRD/LAW/owsci_info.shtml\# Water_Demand_Forecast 
Parker, D.C., S.M. Manson, M.A. Janssen, M.J. Hoffman, and P. Deadman. 2003. Multi-agent systems for the simulation of land-use and land-cover change: a review. Annals of the Association of American Geographers 93(2): 314-337.

Parker, D.C., A. Hessl, and S.C. Davis. 2008. Complexity, land-use modeling, and the human dimension: fundamental challenges for mapping unknown outcome spaces, GeoForum 39: 789-804. DOI:10.1016/j.geoforum.2007.05.005.

Payson, Arizona Water Department. 2007. http://www.ci.payson.az.us/ Last accessed on May 6, 2010.

Pickett, S.T.A., M.L. Cadenasso, J.M. Grove, P.M. Groffman, L.E. Band, C.G. Boone, W.R. Burch Jr., C.S.B. Grimmond, J. Hom, J.C. Jenkins, N.L. Law, C.H. Nilon, R.V. Pouyat, K. Szlavecz, P.S. Watten, and M.A. Wilson. 2008. Beyond urban legends: an emerging framework of urban ecology, as illustrated by the Baltimore Ecosystem Study. BioScience 58(2): 139-150.

Polebitski, A.S. and R.N. Palmer. 2010. Seasonal residential water demand forecasting for census tracts. Journal of Water Resources Planning and Management 136(1): 27-36.

Praskievicz, S. and H. Chang. 2009. Identifying the relationships between urban water consumption and weather variables in Seoul, South Korea. Physical Geography 30(4): 1-14.

Piringer, M., S. Joffe, A. Baklanov, A. Christen, M. Deserti, K. De Ridder, S. Emeis, P. Mestayer, M. Tombrou, D. Middleton, K. Baumann-Stanzer, A. Dandou, A. Karppinen, J. Burzynski.2007. The surface energy balance and the mixing height in urban areas - activities and recommendations of COST-Action 715. Boundary Layer Meteorology 124: 3-24.

Randolph, B. and P. Troy. 2008. Attitudes to conservation and water consumption, Environmental Science and Policy 11: 441-455,DOI:10.1016/j.envsci2008.03.003.

Rey, S.J. and M.V. Janikas. 2006. STARS: Space-time analysis of regional systems, Geographical Analysis 38: 67-86.

Robbins, P., R. Farnsworth, and J.P. Jones. 2008. Insects and institutions: managing emergent hazards in the US Southwest. Journal of Environmental Policy and Planning 10(1): 95-112. 
Rotach, M.W., R. Vogt, C. Bernhofer, E. Batchvarova, A. Christen, A. Clappier, B. Feddersen, S.E. Gryning, G. Martucci, H. Mayer, V. Mitev, T.R. Oke, E. Parlow, H. Richner, M. Roth, Y.A. Roulet, D. Ruffieux, J.A. Salmond, M. Schatzmann, and J.A. Voogt. 2005. BUBBLE - an urban boundary layer meteorology project. Theor. Appl. Climatol. 81: 231-261.

Rufenacht, H.P. and H. Guibentif. 1997. A model for forecasting water consumption in Geneva canton, Switzerland. J Water SRT - Aqua 46(4): 196-201.

Ruth, M., C. Bernier, N. Jollands, and N. Golubiewski. 2007. Adaptation of urban water supply infrastructure to impacts from climate and socioeconomic changes: the case of Hamilton, New Zealand. Water Resour. Manage. 21: 1031-1045. DOI:10.1007/s11269-006-9071-x.

Salathé, Jr., E.P. 2005. Downscaling simulations of future global climate with applications to hydrologic modeling. Int. J. Climatol. 25: 419-436.

Salathé, Jr., E.P., P.W. Mote, and M.W. Wiley. 2007. Review of scenario selection and downscaling methods for the assessment of climate change impacts on hydrology in the United States pacific northwest. Int. J. Climatol. 27: 1611-1621.

Scheffer, M. F. Westly, W.A. Brock, and M. Holmgren. 2001. Dynamic interaction of societies and ecosystems - linking theories from ecology, economy, and sociology, in: Panarchy, edited by L.H. Gunderson and C.S. Holling, pp.195-239, Island Press, Washington, DC.

Schleich, J, and T. Hillenbrand. 2009. Determinants of residential water demand in Germany. Ecological Economics 68: 1756-1769.

DOI:10.1016/j.ecolecon.2008.11.012.

Schluter, M. and C. Pahl-Wostl. 2007. Mechanisms of resilience in common-pool resource management systems: an agent-based model of water use in a river basin. Ecology and Society 12(2): 4.

Shandas, V. and G.H. Parandvash. 2010. Integrating urban form and demographics in water-demand management: an empirical case study of Portland, Oregon. Environment and Planning B: Planning and Design 37: 112-128.

Solar Radiation Monitoring Laboratory. 2010. http://solardat.uoregon.edu/. (Last accessed on May 6, 2010:) 
Souch, C. and S. Grimmond. 2006. Applied climatology: urban climate. Progress in Physical Geography 30: 270-279.

Sovocool, K.A., M. Morgan, and D. Bennett. 2006. An in-depth investigation of xeriscape as a water conservation method. Journal of the American Water Works Association 98(2): 82-93.

Stone, B. and J.M. Norman. 2006. Land use planning and surface heat island formations: a parcel-based radiation flux approach. Atmospheric Environment 40(19): 3561-3573.

Sun, G., S. G. McNulty, J. A. Moore Myers, and E. C. Cohen. 2008. Impacts of multiple stresses on water demand and supply across the southeastern United States. Journal of the American Water Resources Association 44 (6): 1-16.

Syme, G., Q. Shao, M. Po, and E. Campbell. 2004. Predicting and understanding home garden water use. Landscape and Urban Planning 68: 121-128.

Thoning, K.W., D.R. Kitzis, and A. Crotwell. 2007. Atmospheric Carbon Dioxide Dry Air Mole Fractions from quasi-continuous measurements at Barrow, Alaska; Mauna Loa, Hawaii; American Samoa; and South Pole, 1973-2006, Version: 2009-04-10. Path: ftp://ftp.cmdl.noaa.gov/ccg/co2/in-situ/.

Tinker, A., S. Bame, R. Burt, and M. Speed. 2005. Impact of "non-behavioral fixed effects" on water use: weather and economic construction differences on residential water use in Austin, Texas. Electronic Green Journal 1(22): Article 4.

Turner II, B.L., P.A. Matson, J.J. McCarthy, R.W. Correll, L. Christensen, N. Eckley, G.K. Hovelsrud-Broda, J.X. Kasperson, R.E. Kasperson, A. Luers, M.L. Martello, S. Mathlesen, R. Naylor, C. Polsky, A. Pulslpher, A. Schiller, H. Selin, and N. Tyler. 2003. Illustrating the coupled human-environment system for vulnerability analysis: three case studies. Proceedings of the National Academy of Science 100(14): 880-885.

Turner II, B.L., E.F. Lambin, and A. Reenberg. 2007. The emergence of land change science for global environmental change and sustainability. Proceedings of the National Academy of Science 104(52): 20666-20671.

UNPF (United Nations Polulation Fund). 2007. State of the World Population 2007: Unleashing the Potential of Urban Growth. United States, New York. 
US Census Bureau. "State and County Quickfacts." Retrieved on February 10, 2009 http://quickfacts.census.gov/qfd/states/411/4134100.html.

Van de Meene S.J. and R.R. Brown. 2009. Delving into the "Institutional Black Box": Revealing the Attributes of Sustainable Water Resource Management Regimes 1. Journal of the American Water Resources Association 45(6): 1448-1464.

Walker, B.L., C.S. Holling, S.R. Carpenter, and A. Kinzig. 2004. Resilience, adaptability, and transformability in social-ecological systems. Ecology and Society 9(2): 5 .

Walker, B.L., L.H. Gunderson, A. Kinzig, C. Folke, S. Carpenter, and L. Schultz. 2006. A handful of heuristics and some propositions for understanding resilience in social-ecological systems. Ecology and Society 11(1): 13.

Walsh, C., A. Roy, J. Feminella, P. Cottingham, P. Groffman, and R. Morgan II. 2005. The urban stream syndrome: current knowledge and the search for a cure. Journal. of the North American Benthological Society 24(3): 706-723.

Washington W.M., J.W. Weatherly, G.A. Meehl, A.J. Semtner, T.W. Bettge, A.P. Craig,W.G. Strand, J. Arblaster, V.B. Wayland, R. James, Y. Zhang. 2000. Parallel climate model (PCM) control and transient simulations. Climate Dynamics 16: 755-774

Webb, T., S. Burgin, and B. Maheshwari. 2009. Action research for sustainable water futures in Western Sydney: Reaching beyond traditional stakeholder engagement to understand community stakeholder language and its implications for action. Systematic Practical Action Research 22: 1-14.

Wei, S., A. Lei, and S.N. Islam. 2010. Modeling and simulation of industrial water demand of Beijing municipality in China. Front. Environ. Sci. Engin. China 4(1): 91-101. DOI 10.1007/s11783-010-0007-6.

Wentz, E. A. and P. Gober. 2007. Determinants of small-area water consumption for the city of Phoenix, Arizona. Water Resource Management 21:1849-1863.

Werner, B.T., and D.E. McNamara. 2007. Dynamics of coupled human-landscape systems. Geomorphology 91: 393-407.

Widmann, M., Bretherton, C.S., Salathé, E.P. 2003. Statistical precipitation 
downscaling over the northwestern United States using numerically simulated precipitation as a predictor. Journal of Climate 16: 799-816.

Wintz, I., G. Brierley, and S. Trowsdale. 2009. The use of system dynamics simulation in water resources management. Water Resource Management 23: 1301-1323.

Wood, A.W., Maurer, E.P., Kumar, A., Lettenmaier, D.P. 2002. Long-range experimental hydrologic forecasting for the eastern United States. Journal of Geophysical Research-Atmospheres 107: 4429-4443.

Wong, J.S., Q. Zhang, and Y. D. Chen. 2010. Statistical modeling of daily urban water consumption in Hong Kong: trend, changing patterns, and forecast. Water Resources Research 46. doi:10.1029/2009WR008147.

Wong, T.H.F. 2006. Water sensitive urban design - the journey thus far. Australian Journal of Water Resources 10(3): 213-221.

Wong, T.H.F. and R.R. Brown. 2009. The water sensitive city: principles for practice. Water Science and Technology 60(3): 673-682.

Xu, W., M. J. Wooster, and C. S. B. Grimmond. 2008. Modelling of urban sensible heat flux at multiple scales: A demonstration using airborne hyperspectral imagery of Shanghai and a temperature-emissivity separation approach. Remote Sensing of Environment 112: 3493-3510.

Zhang, H. H. and D. F. Brown. 2005. Understanding urban residential water use in Beijing and Tianjin, China. Habitat International 3: 469-491.

Zhou, S. L., T. A. McMahon, A. Walton, and J. Lewis. 2000. Forecasting daily urban water demand: a case study of Melbourne. Journal of Hydrology 236: 153-164. 


\section{Appendix A: Household Water Use Survey}

I. Indoor Water Use (Please darken only one answer per question.)

\begin{tabular}{|c|c|c|c|c|}
\hline $\begin{array}{l}\text { 1. How many full bathrooms } \\
\text { are in your home? } \\
\text { (including sink, toilet, } \\
\text { shower/bath). }\end{array}$ & 01 & 02 & 03 & $04+$ \\
\hline $\begin{array}{l}\text { 2. How many half } \\
\text { bathrooms are in your } \\
\text { home? (including only sink } \\
\text { and toilet) }\end{array}$ & o0 & 01 & 02 & $03+$ \\
\hline $\begin{array}{l}\text { 3. Do you have a } \\
\text { dishwasher? }\end{array}$ & oYes & oNo & & \\
\hline $\begin{array}{l}\text { 4. Is your dishwasher an } \\
\text { Energy Star appliance? }\end{array}$ & oYes & oNo & & \\
\hline $\begin{array}{l}\text { 5. Do you have a washing } \\
\text { machine? }\end{array}$ & oYes & oNo & & \\
\hline $\begin{array}{l}\text { 6. Is your washing machine } \\
\text { an Energy Star appliance? }\end{array}$ & oYes & oNo & & \\
\hline $\begin{array}{l}\text { 7. Do you have any water } \\
\text { conserving "low flow" } \\
\text { faucets? (ex. aerators } \\
\text { installed) }\end{array}$ & oYes & oNo & If yes, how many? & $\begin{array}{l}\text { oNot } \\
\text { sure }\end{array}$ \\
\hline $\begin{array}{l}\text { 8. Do you have any water } \\
\text { conserving "low flow" } \\
\text { shower heads? }\end{array}$ & oYes & oNo & If yes, how many? & $\begin{array}{l}\text { oNot } \\
\text { sure }\end{array}$ \\
\hline $\begin{array}{l}\text { 9. Do you have any low-flow } \\
\text { toilets? (ex. } 1.6 \text { gallon/flush) }\end{array}$ & oYes & oNo & If yes, how many? & $\begin{array}{l}\text { oNot } \\
\text { sure }\end{array}$ \\
\hline $\begin{array}{l}\text { 10. Approximately how } \\
\text { many showers are taken per } \\
\text { day in your home? }\end{array}$ & 00 & 01 & $02-3$ & $04+$ \\
\hline
\end{tabular}




\begin{tabular}{|c|c|c|c|c|}
\hline $\begin{array}{l}\text { 11. Approximately how } \\
\text { many baths are taken per } \\
\text { day in your home? }\end{array}$ & $\mathrm{\circ 0}$ & 01 & $02-3$ & $\begin{array}{r}04+ \\
.\end{array}$ \\
\hline $\begin{array}{l}\text { 12. What is the average } \\
\text { length of time for a shower } \\
\text { in your home? }\end{array}$ & $\begin{array}{l}\text { oLess than } 5 \\
\text { minutes }\end{array}$ & $\begin{array}{l}05-10 \\
\text { minutes }\end{array}$ & $010-15$ minutes & $\begin{array}{l}\text { ols+ } \\
\text { minutes }\end{array}$ \\
\hline $\begin{array}{l}\text { 13. Approximately how } \\
\text { many times per day is the } \\
\text { toilet flushed in your home? }\end{array}$ & $03-5$ & $06-8$ & $09-12$ & $012+$ \\
\hline
\end{tabular}

II. Outdoor Water Use (Please darken only one answer per quest

\begin{tabular}{|c|c|c|c|c|}
\hline 1. Do you have a lawn or & oYes & oNo & \multicolumn{2}{|c|}{${ }^{\star *}$ If NO, skip to question $\# 11$} \\
\hline $\begin{array}{l}\text { 2. What is the composition } \\
\text { of your outdoor space? }\end{array}$ & oMostly lawn & $\begin{array}{l}\text { oMostly } \\
\text { drought } \\
\text { tolerant } \\
\text { plants }\end{array}$ & $\begin{array}{l}\text { oMostly water } \\
\text { needy plants }\end{array}$ & $\begin{array}{l}\text { oA mix of } \\
\text { lawn and } \\
\text { other plants }\end{array}$ \\
\hline $\begin{array}{l}\text { 3. How often in the winter } \\
\text { season do you water your } \\
\text { lawn/garden? }\end{array}$ & oNever & $\begin{array}{l}\text { o1-2 times } \\
\text { per week }\end{array}$ & $\begin{array}{l}\text { o3-5 times per } \\
\text { week }\end{array}$ & oDaily \\
\hline $\begin{array}{l}\text { 4. How often in the } \\
\text { summer season do you } \\
\text { water your lawn/garden? }\end{array}$ & oNever & $\begin{array}{l}\text { ol-2 times } \\
\text { per week }\end{array}$ & $\begin{array}{l}\text { o3-5 times per } \\
\text { week }\end{array}$ & oDaily \\
\hline $\begin{array}{l}\text { 5. Do you have a sprinkler } \\
\text { system? }\end{array}$ & oYes & oNo & & \\
\hline $\begin{array}{l}\text { 6. If you answered yes to } \\
\text { the previous question ( } \# 5 \text { ), } \\
\text { please choose the } \\
\text { description of your system } \\
\text { (check all that apply). }\end{array}$ & $\begin{array}{l}\text { oAutomatic } \\
\text { irrigation system }\end{array}$ & $\begin{array}{l}\text { oManual } \\
\text { irrigation } \\
\text { system }\end{array}$ & $\begin{array}{l}\text { oDrip } \\
\text { irrigation } \\
\text { system }\end{array}$ & $\begin{array}{l}\text { O Traditional } \\
\text { lawn } \\
\text { sprinkler } \\
\text { system }\end{array}$ \\
\hline $\begin{array}{l}\text { 7. How do you normally } \\
\text { water your lawn/garden? }\end{array}$ & $\begin{array}{l}\text { oBy hand using } \\
\text { a watering can }\end{array}$ & $\begin{array}{l}\text { oBy hand } \\
\text { using a hose }\end{array}$ & $\begin{array}{l}\text { ol turn on the } \\
\text { sprinkler } \\
\text { system }\end{array}$ & $\begin{array}{l}\text { OThe } \\
\text { sprinkler } \\
\text { system is } \\
\text { automatic }\end{array}$ \\
\hline
\end{tabular}




\begin{tabular}{|c|c|c|c|c|}
\hline $\begin{array}{l}\text { 8. After how many days } \\
\text { without rain do you } \\
\text { decide to irrigate? }\end{array}$ & ol day & $02-3$ days & $.04-5$ days & $\begin{array}{l}\text { oI water } \\
\text { everyday }\end{array}$ \\
\hline $\begin{array}{l}\text { 9. Which of the following } \\
\text { daytime temperatures } \\
\text { would cause you to water } \\
\text { your lawn/garden? }\end{array}$ & $075^{\circ} \mathrm{F}$ & $080-85^{\circ} \mathrm{F}$ & $090+{ }^{\circ} \mathrm{F}$ & $\begin{array}{l}\text { ol water } \\
\text { everyday } \\
\text { regardless. }\end{array}$ \\
\hline $\begin{array}{l}\text { 10. Approximately how } \\
\text { much time do you spend } \\
\text { watering outside? }\end{array}$ & $\begin{array}{l}\text { oLess than } 5 \\
\text { minutes }\end{array}$ & $\begin{array}{l}05-10 \\
\text { minutes }\end{array}$ & $\begin{array}{l}010-15 \\
\text { minutes }\end{array}$ & $\begin{array}{l}\text { o15t+ } \\
\text { minutes }\end{array}$ \\
\hline $\begin{array}{l}\text { 11. Do you have other } \\
\text { outdoor water features? } \\
\text { (check all that apply) }\end{array}$ & oPool & $\begin{array}{l}\text { oJacuzzi/ } \\
\text { Hot Tub }\end{array}$ & oFountain & oOther: \\
\hline $\begin{array}{l}\text { 12. How many times per } \\
\text { month do you wash your } \\
\text { car at home? }\end{array}$ & o0 & $\begin{array}{r}01 \\
:\end{array}$ & 02 & o3+ \\
\hline $\begin{array}{l}\text { 13. How many cars are } \\
\text { owned by your } \\
\text { household? }\end{array}$ & o0 & 01 & 02 & $03+$ \\
\hline $\begin{array}{l}\text { 14. Where do you usually } \\
\text { wash your car? }\end{array}$ & oOn my láwn & $\begin{array}{l}\text { oOn my } \\
\text { driveway }\end{array}$ & oOn the street & $\begin{array}{l}\text { oAt a } \\
\text { carwash }\end{array}$ \\
\hline $\begin{array}{l}\text { 15. On average, how many } \\
\text { minutes do you spend } \\
\text { washing your car? }\end{array}$ & ol0 minutes & $010-15 \mathrm{~min}$. & $015+$ minutes & $\begin{array}{l}\text { oNot } \\
\text { applicable }\end{array}$ \\
\hline
\end{tabular}

III. Demographic Information (Please darken only one answer per question.)

\begin{tabular}{|l|l|l|l|l|l|}
\hline $\begin{array}{l}\text { 1. In what year was } \\
\text { your house built? (Fill } \\
\text { in year) }\end{array}$ & \multicolumn{4}{|l|}{} \\
\hline 2. Gender & $\circ$ Male & $\circ$ Female & & & \\
\hline 3. Age & $\circ 18-30$ & $\circ 31-45$ & $\circ 46-60$ & $060+$ & \\
\hline
\end{tabular}




\begin{tabular}{|c|c|c|c|c|c|}
\hline $\begin{array}{l}\text { 4. Length of residence } \\
\text { in Hillsboro }\end{array}$ & $00-5$ & $06-10$ years & $010-20$ years & $020+$ years & \\
\hline $\begin{array}{l}\text { 5. Homeownership } \\
\text { status }\end{array}$ & oRent & oOwn & $\cdot$ & & \\
\hline 6. Housing type & $\begin{array}{l}\text { OSingle- } \\
\text { family } \\
\text { residence } \\
\text { (detached) }\end{array}$ & $\begin{array}{l}\text { oSingle- } \\
\text { family } \\
\text { residence } \\
\text { (town- } \\
\text { home) }\end{array}$ & $\begin{array}{l}\text { OMulti- } \\
\text { family } \\
\text { residence } \\
\text { (duplex or } \\
\text { triplex) }\end{array}$ & \multicolumn{2}{|c|}{$\begin{array}{l}\text { Multi-family } \\
\text { residence (apartment } \\
\text { complex) }\end{array}$} \\
\hline $\begin{array}{l}\text { 7. Is your home part of } \\
\text { a Homeowners } \\
\text { Association? }\end{array}$ & oYes & oNo & oDon't know & & \\
\hline $\begin{array}{l}\text { 8. Family Size } \\
\text { (including yourself) }\end{array}$ & ol person & 02 people & o3-4 people & 05-6 people & $\begin{array}{l}\text { 07+ } \\
\text { people }\end{array}$ \\
\hline $\begin{array}{l}\text { 9. Highest level of } \\
\text { education achieved }\end{array}$ & $\begin{array}{l}\text { oNo } \\
\text { diploma }\end{array}$ & $\begin{array}{l}\text { oHigh } \\
\text { School }\end{array}$ & oCollege & oMaster's & oPh.D. \\
\hline 10. Ethnicity & $\begin{array}{l}\text { oCaucasian/ } \\
\text { White }\end{array}$ & oHispanic & $\begin{array}{l}\text { oAfrican } \\
\text { American }\end{array}$ & $\begin{array}{l}\text { OAsian/ } \\
\text { South Asian }\end{array}$ & $\begin{array}{l}\text { oNative } \\
\text { Americ } \\
\text { an }\end{array}$ \\
\hline 11. Household Income & $00-\$ 25,000$ & $\begin{array}{l}\circ \$ 25,000 \text { - } \\
\$ 50,000\end{array}$ & $\begin{array}{l}\$ \$ 50,000- \\
\$ 75,000\end{array}$ & $\begin{array}{l}\$ \$ 75,000 \\
\$ 100,000\end{array}$ & $\begin{array}{l}\text { o\$100,0 } \\
00 \text { and } \\
\text { above }\end{array}$ \\
\hline
\end{tabular}




\section{Appendix B: Human Subjects Review Waiver}

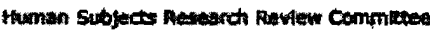

\section{\& 8 Portland State}

post Once Eox 751

Portiand, Orean $97207-0751$

$503-725-4288$

503-775-3415 tor

harreplists.pacedu

Jaly 7, 2009

To: Lily Honse-Peters

Fram: Nuncy Konaloff, HSRRC Chrir

Re: HSRRC writred neview of your xpplication tided, "Mlodeliag Future Fesidential Wates Demand" (ISRRRC Pxoposal \# O91015).

Dexn Lity,

Yous proposal is exempt from frother Hnown Sobjects Research Review Committae review, and yon mory proceed with the stady.

Even with the exemption above, it wens necessacy by University policy for yon to notify this

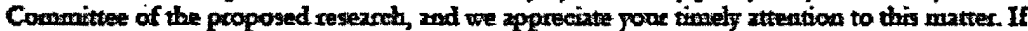

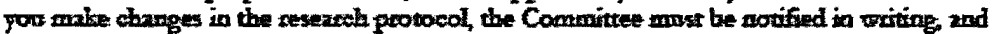
changes mast be appocosed befose being inglemented.

If you brore questions of concerm, please contant the HSIRRC in the Offies of Research and

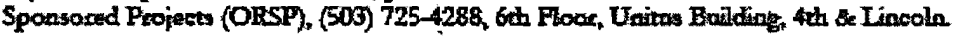

\section{Ce. Heejus Chang}

